\title{
The phylum Cnidaria: A review of phylogenetic patterns and diversity 300 years after Linnaeus*
}

\author{
MARYMEGAN DALY ${ }^{1}$, MERCER R. BRUGLER ${ }^{2}$, PAULYN CARTWRIGHT ${ }^{3}$, ALLEN G. COLLINS ${ }^{4}$, \\ MICHAEL N. DAWSON ${ }^{5}$, DAPHNE G. FAUTIN ${ }^{3}$, SCOTT C. FRANCE ${ }^{2}$, CATHERINE S. MCFADDEN ${ }^{6}$, \\ DENNIS M. OPRESKO ${ }^{7}$, ESTEFANIA RODRIGUEZ ${ }^{1}$, SANDRA L. ROMANO ${ }^{8} \&$ JOEL L. STAKE ${ }^{8}$ \\ ${ }^{1}$ Department of Evolution, Ecology \& Organismal Biology, The Ohio State University, Columbus Ohio USA 43210 \\ daly.66@osu.edu; fani@us.es \\ ${ }^{2}$ Department of Biology, University of Louisiana at Lafayette, Lafayette, LA USA mrbrugler@yahoo.com; france@louisiana.edu \\ ${ }^{3}$ Department of Ecology and Evolutionary Biology, University of Kansas, Lawrence, Kansas 66045, USA University of Kansas, \\ Lawrence KS USA 66045 pcart@ku.edu; fautin@ku.edu \\ ${ }^{4}$ National Systematics Laboratory, NOAA Fisheries Service, Smithsonian Institution, Washington DC USA 20013-7012 \\ collinsa@si.edu \\ ${ }^{5}$ School of Natural Sciences, University of California Merced, Merced CA USA 95344 mdawson@ucmerced.edu \\ ${ }^{6}$ Department of Biology, Harvey Mudd College, Claremont, CA USA $9171191711-5990$ catherine_mcfadden@HMC.edu \\ ${ }^{7}$ Oak Ridge National Laboratory, Oak Ridge, TN, USA \\ ${ }^{8}$ Division of Science and Mathematics, University of the Virgin Islands, St Thomas USVI00802 sromano@uvi.edu; \\ jstake@yahoo.com
}

*In: Zhang, Z.-Q. \& Shear, W.A. (Eds) (2007) Linnaeus Tercentenary: Progress in Invertebrate Taxonomy. Zootaxa, $1668,1-766$.

\section{Table of contents}

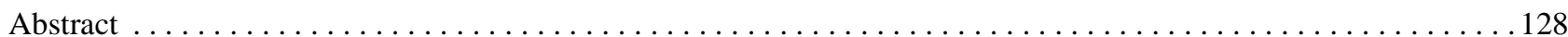

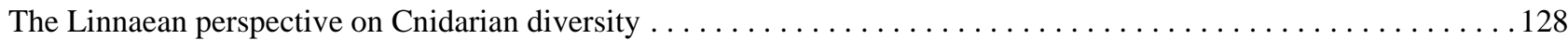

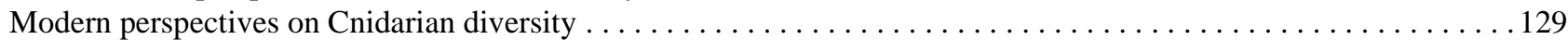

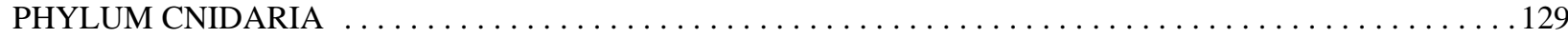

CLASS ANTHOZOA: M. Daly, C. S. McFadden \& D. G. Fautin $\ldots \ldots \ldots \ldots \ldots \ldots \ldots \ldots \ldots \ldots \ldots \ldots$

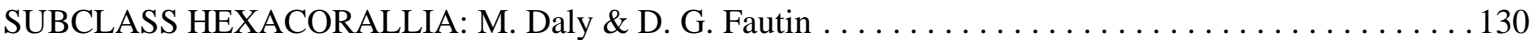

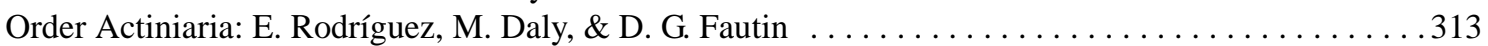

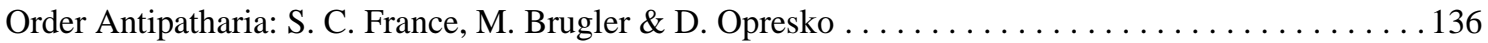

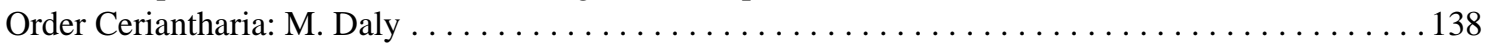

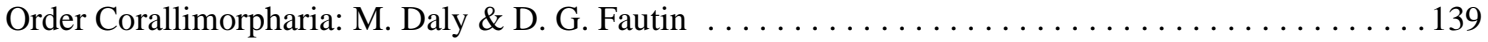

Order Scleractinia: S. L. Romano \& J. L. Stake. . . . . . . . . . . . . . . . . . . . . . . . . . . . . . . . 140

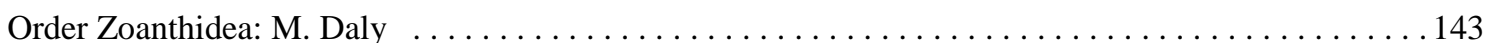

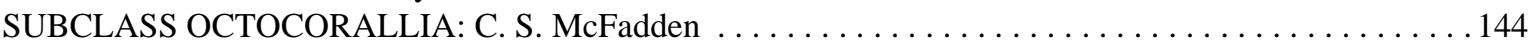

Order Alcyonacea . . . . . . . . . . . . . . . . . . . . . . . . . . . . . . . . . . . . . . . . . . . . . 145

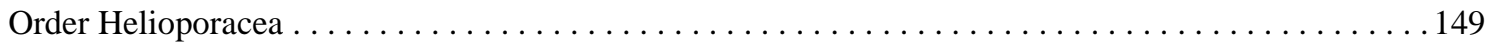

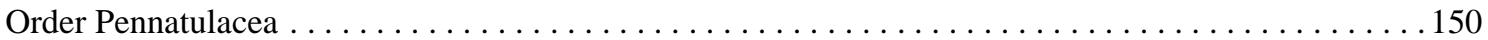

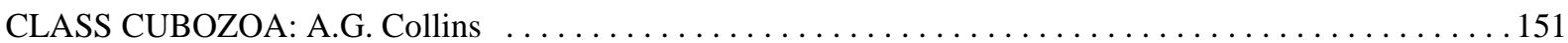

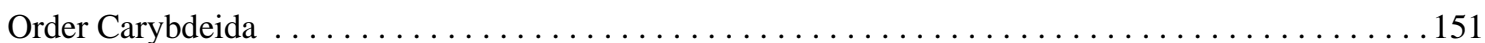

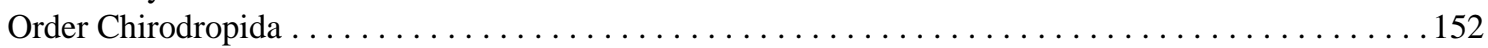

CLASS HYDROZOA: P. Cartwight $\&$ A. G. Collins $\ldots \ldots \ldots \ldots \ldots \ldots \ldots \ldots \ldots \ldots \ldots \ldots \ldots \ldots \ldots \ldots$

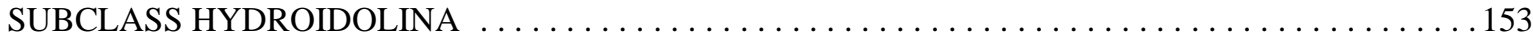

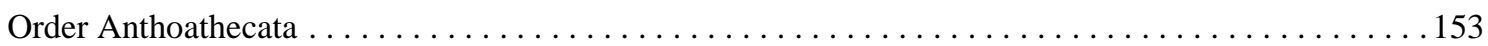

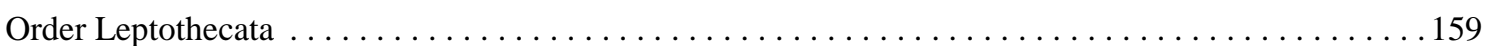




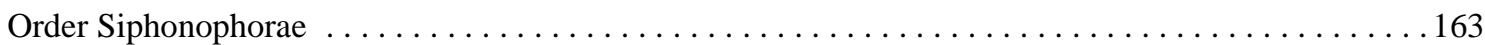

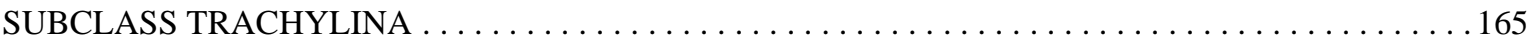

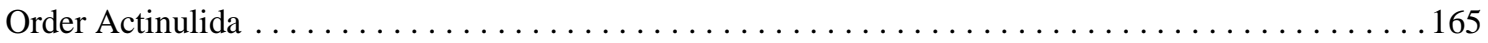

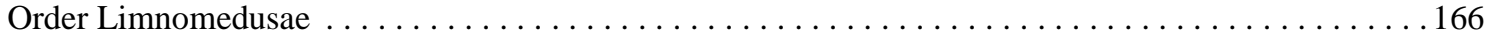

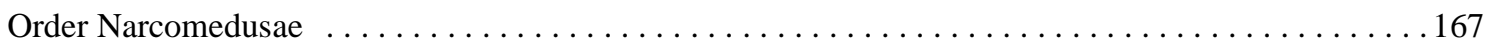

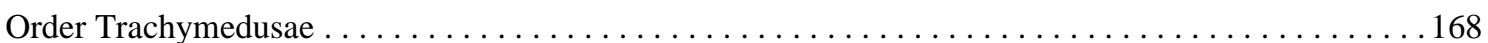

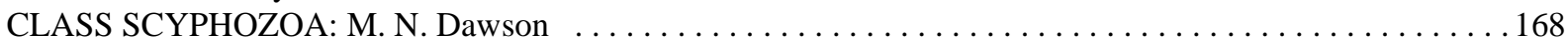

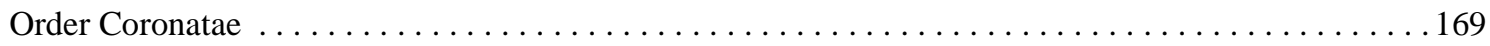

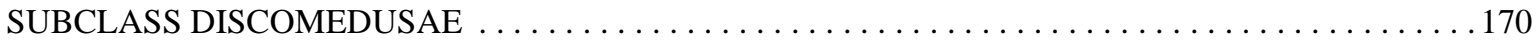

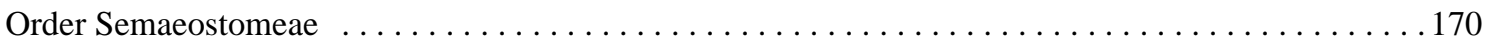

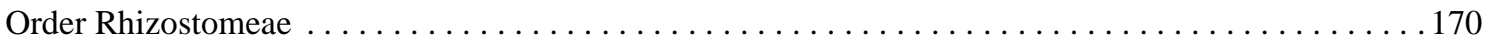

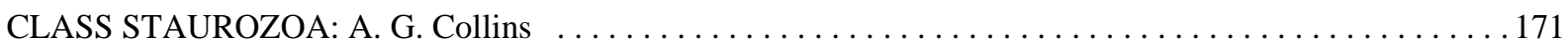

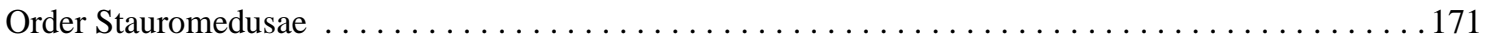

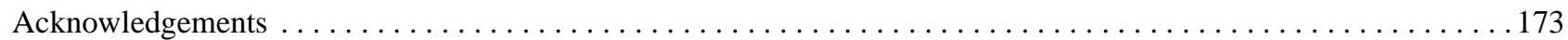

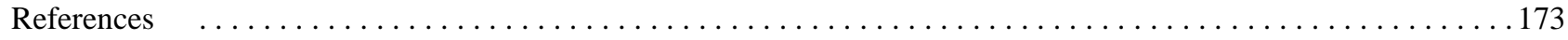

\begin{abstract}
Systema Naturae includes representatives of every major lineage of the animal phylum Cnidaria. However, Linnaeus did not classify the members of the phylum as is now done, and the diversity of the group is not well represented. We contrast the Linnaean perspective on cnidarian diversity with the modern, phylogenetic perspective. For each order, we detail diversity at the family level, providing phylogenetic context where possible.
\end{abstract}

Key words: Systematics, black coral, coral, hydroid, jellyfish, octocoral, sea anemone

\title{
The Linnaean perspective on Cnidarian diversity
}

The phylum Cnidaria is a diverse group of relatively simple animals united by the ability to synthesize a highly complex cellular product, the cnida. Its members, which include corals, hydroids, jellyfishes, sea anemones, and sea fans, are abundant and common in marine environments, and have been known to natural historians for millennia.

Linnaeus (1758) included representatives of all major cnidarian lineages in Systema Naturae in various orders of Vermes Imperfecta. His taxonomic placement of cnidarian species was based largely on whether they were solitary or colonial, and whether they had no skeleton, a stony skeleton, or a proteinaceous skeleton. Linnaeus' Mollusca included three genera with members that are now considered part of Cnidaria: Priapus, Holothuria, and Medusa. Like all members of his Mollusca, these animals have relatively uniform bodies and lack a skeleton. Priapus was defined as having a fixed base and a terminal orifice, characteristics common to many sessile animals; the Linnaean species equinus remains in use as Actinia equina, the type species of the actiniarian sea anemone genus Actinia (see Williams et al. 1982). Linnaeus' Holothuria included free-swimming forms with a humped body and tentacles of unequal length and number; this genus includes the hydrozoan Physalia physalis, described by Linnaeus (1758) as Holothuria physalis. Members of the genus Medusa share a pelagic, gelatinous body with a central mouth on the lower surface. This genus includes all of the Linnaean species now assigned to Scyphozoa and Cubozoa. Common hydrozoans, such as the blue button Porpita porpita and the by the wind sailor Velella velella, were also included in this genus. Not all species of Medusa are cnidarians, however: Medusa beroe is clearly a member of the ctenophore genus Beroe, although identity of the Linnaean species is unclear (Bayha et al. 2004). The genus Priapus was suppressed for Cnidaria in Opinion 1295 of the International Commission on Zoological Nomenclature (Bulletin of Zoological Nomenclature 42:34-36; April 1985): it has been ruled to belong to phylum Priapulida. 
Lithophyta and Zoophyta are distinguished from Mollusca in being colonial. Members of Lithophyta have a hard skeleton; those of Zoophyta have no skeleton, or a flexible one. The lithophytes are a heterogeneous assemblage of hydrozoan corals (e.g., Millepora), octocorals (e.g., Tubipora), scleractinian corals (e.g., Madrepora), and bryozoans. Zoophyta is likewise heterogeneous, including the hydrozoans Hydra and Tubularia, and several groups now classed in Octocorallia, including Isis, Gorgonia, and Pennatula. Although these names remain in use and are valid for particular cnidarian genera, Linnaeus' (1758) concept of each does not correspond to modern use. For example, Gorgonia includes taxa now recognized as belonging to the anthozoan subclass Octocorallia (e.g., the gorgonian Gorgonia flabellum) and to its sister subclass, Hexacorallia (e.g., Gorgonia spiralis, now the black coral Cirripathes spiralis). Hydra includes species belonging to groups other than Cnidaria (e.g., the ciliate Epistylis digitalis, described as Hydra digitalis). Millepora includes at least one scleractinian coral (Millepora damicornis, now Pocillopora damicornis).

Although Linnaeus (1758) recognized the breadth of diversity now encompassed in Cnidaria, none of the higher-level distinctions made in Systema Naturae correspond to modern taxonomic groups. The cnidarians classified together in Mollusca, Lithophyta, or Zoophyta are, by and large, only distantly related. All of the Linnaean categories include representatives of at least two classes, and Mollusca includes three: the anthozoan Actinia equina, the hydrozoan Physalia physalis, and the scyphozoan Aurelia aurita. Nonetheless, the characters Linnaeus used to differentiate taxa are commonly used to recognize groups within lineages, and their importance and applicability remain the focus of taxonomic and phylogenetic discussion (e.g., France $e t$ al. 1996; Berntson et al. 1999; Daly et al. 2003; Marques \& Collins 2004; Dunn et al. 2005; Medina et al 2006; McFadden \& Alderslade 2007).

\section{Modern perspectives on Cnidarian diversity}

\section{Phylum CNidARia}

Cnidaria comprises two reciprocally monophyletic clades. The distinction between Anthozoa and Medusozoa is well-supported by anatomy and life history (Salvini-Plawen 1978; Bridge et al. 1995), genome structure (Bridge et al.1992; but see Brugler 2004 for unusual cerianthid genome), and DNA sequences (e.g., CavalierSmith et al. 1996; Odorico \& Miller 1997; Collins 1998; Berntson et al. 1999; Kim et al. 1999; Medina et al. 2001; Won et al. 2001; Collins 2002). The traditional taxonomic structure of Cnidaria mirrors its phylogenetic structure, although the ranks of many groups are incompatible with their hierarchical phylogenetic position. For instance, the class Anthozoa comprises all members of the clade Anthozoa; its sister taxon, Medusozoa, comprises the remaining classes. Thus, class and other ranks have different phylogenetic implications across the phylum.

Cnidae, organelle-like capsules with eversible tubules (e.g., Weill 1934; Watson 1988), are the diagnostic feature of the phylum. Of the three types of cnidae (nematocysts, ptychocysts, and spirocysts), only nematocysts are found across the clade. All cnidarians possess cnidae; no loss of the feature has been documented. Three other features sometimes considered to be diagnostic of Cnidaria are radial symmetry and planula and polyp stages in development, but all are problematic. Although many cnidarians exhibit radial symmetry, some are directionally asymmetric (Dunn \& Wagner 2006), and many have a biradial or bilateral organization, leading some to conclude that bilateral symmetry is the ancestral condition for the phylum (Salvini-Plawen 1978; Matus et al. 2006). Furthermore, the other two features are difficult to define. For example, the motile stage between embryo and settled juvenile in any given cnidarian's life cycle is typically termed a planula, and, although this stage is usually ciliated, sausage-shaped, and non-feeding, deviations from this pattern e.g., Haliclystus (class Staurozoa), Hydra (class Hydrozoa), Zoanthidea (class Anthozoa)—have been well documented. Polyp forms are even more variable than planulae, being solitary or colonial; if colonial, polyps 
may be monomorphic or polymorphic; they may or may not have a mineralized skeleton; they may be benthic or pelagic; and tentacles, although commonly present, may be absent.

We summarize the current state of knowledge of the membership of classes and orders of cnidarians, with brief notes on families. The most recent coverage of the phylum at these levels was by Dunn (1982).

\section{Class Anthozoa}

M. Daly, C. S. McFadden \& D. G. Fautin

The class Anthozoa comprises two reciprocally monophyletic lineages, Octocorallia and Hexacorallia. All members of Anthozoa are exclusively polypoid, and may be colonial, clonal, or solitary, skeleton-less or with a mineralic and/or proteinaceous skeleton. Anthozoa currently contains approximately 7,500 extant species.

Although an early phylogeny based on fragments of $18 \mathrm{~S}$ rDNA from a relatively small subset of Cnidaria found Anthozoa to be paraphyletic with respect to a monophyletic Medusozoa, this result was interpreted as an artifact of analytical methods and the taxon sample because Anthozoa was recovered as a clade under some analytical parameters and when additional data and taxa were considered (Bridge et al. 1995). Subsequent studies of larger rDNA datasets (France et al. 1996; Odorico \& Miller 1997; Song \& Won 1997; Berntson et al. 1999; Collins 2002) support anthozoan monophyly. Phylogenetic analyses of morphological data (e.g., Won et al. 2001) also have corroborated this hypothesis, and have suggested at least three diagnostic apomorphies for Anthozoa: actinopharynx, siphonoglyph, and mesenteries. The actinopharynx (= stomadeum, gullet) is an ectoderm-lined tube that projects into the gastrovascular cavity (= coelenteron); this structure is found in all Anthozoa, with one known exception, the black coral Sibopathes (Opresko 1993). The siphonoglyph (= sulcus) is a densely ciliated, often more highly glandular region of the actinopharynx; it is single, paired, or, rarely, absent (e.g., in ptyochodactiarian sea anemones; the presence of a siphonoglyph in antipatharians is disputed), and in asexually-derived individuals, there may be more than two. The siphonoglyph reflects the plane of bilateral symmetry for the polyp (Finnerty et al. 2004). Bilateral symmetry is further defined by the mesenteries (the term septa, which has been used for these structures, should be reserved for the calcareous radial partitions secreted by the mesenteries of scleractinians: Bayer et al. 1983), radially-arrayed sheets of tissue that extend all or part of the way from the body wall to the actinopharynx. Unlike the gastric septa of Staurozoa, at least some of the mesenteries extend nearly halfway across the gastrovascular cavity, from the body wall and to the actinopharynx. Mesenteries are arranged in cycles (members of each cycle form more or less simultaneously) and bear the gametogenic tissue and epitheliomuscular cells that are concentrated as retractor muscles. The free edge of a mesentery is typically elaborated into a mesenterial filament with abundant gland cells, nematocysts, and cilia. The exclusively polypoid nature of the anthozoan life cycle is sometimes considered a synapomorphy for the group (e.g., Hyman 1940; Brusca \& Brusca 1990), but this attribute is shared with at least some medusozoans and may be a pleisiomorphy (Collins et al. 2006a).

\section{SUBCLASS HEXACORALLIA}

\section{Daly \& D. G. Fautin}

The anthozoan subclass Hexacorallia comprises all scleractinian and black corals, tube anemones, and sea anemones in the broadest sense (i.e., orders Actiniaria, Antipatharia, Ceriantharia, Corallimorpharia, Scleractinia, and Zoanthidea). Hexacorallia currently contains about 4,300 extant species (Doumenc \& van Praët 1987). As the name suggests, most hexacorallians have hexamerous symmetry, although eight- or ten-part symmetry are not uncommon. All members of Hexacorallia have spirocysts, a type of cnida with a singlewalled capsule and a tubule composed of tiny entangling sub-threads (Mariscal et al. 1977). 
Because the morphology of hexacorallian polyps is more variable than that of octocorallian polyps, monophyly of the group and relationships within it have been difficult to interpret. Based on similarities in morphology between the cerinula larvae of the cerianthid Arachnactis and the antipatharian polyp, Antipatharia and Ceriantharia have been separated from the remaining orders as a distinct subclass, Ceriantipatharia (see van Beneden 1897; Hyman 1940; Wells \& Hill 1956; Berntson et al. 1999). France et al. (1996), Berntson et al. (1999), and Brugler and France (2007) addressed the placement of Ceriantharia and Antipatharia explicitly, and determined that Ceriantharia and Antipatharia are not sister taxa: Ceriantharia is sister to (or the basal member of) Hexacorallia, within which Antipatharia nests. Other studies of hexacorallian relationships corroborate these conclusions (Berntson et al. 2001; Won et al. 2001; Daly et al. 2002, 2003). Two phylogenies based on 18S rDNA (Song et al. 1994; Song \& Won 1997) found support for excluding Ceriantharia from Hexacorallia, but this seems to have been an artifact of their relatively small sample size because subsequent studies of $18 \mathrm{~S}$ that included more taxa concluded that Ceriantharia is the basal-most lineage within Hexacorallia (Berntson et al. 2001; Won et al. 2001; Daly et al. 2002, 2003).

Most molecular phylogenetic analyses support monophyly of each of the extant hexacorallian orders, although the relationship between Scleractinia and Corallimorpharia is controversial. Nuclear data (Won et al. 2001; Daly et al. 2002, 2003) support Corallimorpharia as the sister-group to a monophyletic Scleractinia, but analyses of mitochondrial genes suggest that Corallimorpharia nests within Scleractinia (France et al. 1996; Romano \& Cairns 2000; Medina et al. 2006). This may be the result of relatively limited taxon samples in the analyses of mitochondrial sequences: a study by Brugler and France (2007) that expanded the sample of Medina et al. (2006) to include an antipatharian and a zoanthidean found that Corallimorpharia and Scleractinia are reciprocally monophyletic sister taxa. Chen et al.'s (1995) analysis of a very small fragment of 28S rDNA suggested that Corallimorpharia is more closely related to a subset of Actiniaria, but these authors did not recover this topology in subsequent analysis of a more extensive data set (Veron et al. 1996). The putative order Ptychodactiaria has been subsumed within Actiniaria, based on morphological (Cappola \& Fautin 2000) and molecular (Berntson et al. 1999; Daly et al. 2003) evidence. Questions of monophyly aside, relationships among the orders are unclear. The relationship between Actiniaria and Zoanthidea is poorly resolved in all phylogenetic studies of molecular data (e.g., Daly et al. 2002, 2003; Brugler \& France 2007). However, most analyses agree that Actiniaria, Antipatharia, Corallimorpharia, Scleractinia, and Zoanthidea constitute a clade, with Ceriantharia as its sister group.

\section{Order Actiniaria}

\section{E. Rodríguez, M. Daly, \& D. G. Fautin}

The order Actiniaria Hertwig, 1882 comprises soft-bodied, solitary polyps with tentacles that are not pinnate, and arise at the margin and/or from the disc. These attributes are seen in some members of other hexacorallian orders, raising concern that Actiniaria is not monophyletic (e.g., Stephenson 1921; Schmidt 1972, 1974). Although no published genetic studies have explicitly addressed relationships among actiniarians, all broadscale analyses of hexacorallian or anthozoan phylogeny (e.g., Berntson et al. 1999; Won et al. 2001; Daly et al. 2002, 2003) have included multiple actiniarians, and nearly all have demonstrated monophyly of the order. A notable exception is the analysis by Chen et al. (1995) of 28S rDNA, which found Actiniaria polyphyletic with respect to Corallimorpharia and Scleractinia; this result was based on a very small fragment of DNA, and has not been seen in subsequent analyses.

Currently, Actiniaria comprises approximately 1,200 species in 46 families. Its members are found at all depths, in all oceans, and in many estuaries. The current classification for Actiniaria is based on that of Carlgren (1949), who recognized three suborders: Endocoelantheae, Nynantheae, and Protantheae. Nynantheae is the only suborder to comprise more than two families; it was further divided by Carlgren into three "tribes" 
(actually infraorders) and three "subtribes" (actually superfamilies). This classification was not intended to reflect phylogeny, and does not: at least some of the nyantheae infraorders are paraphyletic (e.g., Berntson $e t$ al. 1999; Daly et al. 2002, 2003).

Actiniarian families are characterized by the types and distribution of nematocysts; they can be distinguished based on polyp structure, including the morphology and development of musculature, number and arrangement of mesenteries, arrangement and morphology of tentacles, and presence of specialized structures such as acontia. Although nematocyst distribution is used to define some actiniarian taxa, the value of these data for differentiating species or higher taxa has been questioned (Fautin 1988). Several classifications of nematocysts have been proposed (e.g., Schmidt 1972; Mariscal 1974; England 1991; Östman 2000), leading to conflicting diagnoses of the cnidom in some taxa. Furthermore, although all systems of classification for cnidae determine type based on the morphology of the tubule of discharged capsules, for most groups, cnidom has been assessed mainly with undischarged capsules from preserved specimens, making assessment of cnida morphology tentative at best (e.g., Fautin submitted). Polyp anatomy is less controversial, but may be no less problematic: features of taxonomic value, including acrorhagi, marginal sphincter musculature, and reproductive morphology have been the subject of re-evaluation or are difficult to distinguish in a few critical instances (e.g., Riemann-Zürneck 1980; Fautin 1984; England 1987; Cappola \& Fautin 2000; Daly \& den Hartog 2004). Few families have been the focus of phylogenetic study, and monophyly is unclear for most groups. Furthermore, lack of type material and inadequate species descriptions mean that many species cannot be reliably identified, necessitating the redescription of species and establishment of neotypes. The chapter in this volume by Fautin et al. (2007) covers the genera of Actiniaria and Corallimorpharia.

\section{Included families}

Aiptasiomorphidae Carlgren, 1949 is a monogeneric family comprising four valid species (Carlgren 1949; Fautin 2007). The family is distinguished by the absence of certain types of nematocysts in the tentacles and relatively weak musculature rather than any uniquely present attribute, so may not be monophyletic.

Acontiophoridae Carlgren, 1938 comprises four genera and fewer than 10 valid species (Fautin 2007). The family is distinguished by the lack of a marginal sphincter rather than any uniquely present attribute, so may not be monophyletic.

Actinernidae Stephenson, 1922 comprises four genera and approximately 10 species (Carlgren 1949; Fautin 2007). Actinernidae belongs to a distinctive suborder of Actiniaria distinguished by an unusual arrangement of mesenteries; it is differentiated from all other members of the Endocoelantheae in lacking microcnemes and in having two siphonoglyphs. The polarities of the diagnostic attributes are unclear, rendering assessment of its probable monophyly difficult.

Actiniidae Rafinesque, $\mathbf{1 8 1 5}$ comprises 44 genera and more than 200 valid species (Carlgren 1949; Fautin 2007). Actiniidae is likely not monophyletic. The diagnosis of the family does not include any attribute not seen in other Actiniaria, and studies of DNA sequences that include exemplars from Actiniidae and those from other families in Endomyaria have failed to recover its members as sister taxa (Daly et al. 2003; contra McCommas et al. 1991).

Actinodendridae Haddon, 1898 comprises three genera and approximately 10 valid species (Ardelean 2003; Fautin 2007). Phylogenetic analysis of morphological attributes indicates that Actinodendridae is monophyletic (Ardelean 2003); its members are united in having the oral disc drawn out into long arm-like lobes bearing dendritic tentacles and in lacking a marginal sphincter.

Aiptasiidae Carlgren, 1924 comprises five genera and approximately 20 valid species (Carlgren 1949; Fautin 2007). Aiptasiidae is distinguished by the types of nematocysts in the acontia and the relatively weak musculature of the sphincter; because these attributes are also present in several other families, Aiptasiidae may not be monophyletic. 
Actinoscyphiidae Stephenson, 1920 comprises eight genera and approximately 10 valid species, most of which live in deep-sea and chemosynthetic habitats (Sanamyan \& Sanamyan, 2007; Rodríguez et al. submitted). Phylogenetic analysis of morphological data (Rodríguez et al. submitted) indicates that Actinoscyphiidae is monophyletic, but its membership is likely to change as its close ally, Actinostolidae, is revised.

Actinostolidae Carlgren, 1893 comprises 19 genera and approximately 70 valid species, most of which are from deep-sea and polar waters (Fautin \& Hessler 1989; Fautin 2007; Rodríguez et al. submitted). The family is distinguished by no acontia and a mesogleal marginal sphincter rather than any unique attribute. A recent phylogenetic analysis of morphological data indicated that this family is not monophyletic (Rodríguez et al. submitted).

Aliciidae Duerden, 1895 comprises five genera and approximately 10 valid species (Fautin 2007). The family is characterized by outgrowths in the column containing macrobasic amastigophores, ectodermal longitudinal muscles in the column, and either no marginal sphincter or a weak one. Schmidt (1974) hypothesized, based on morphology and cnidae, that Aliciidae is closely related to Boloceroididae.

Andresiidae Stephenson, $\mathbf{1 9 2 2}$ is a monospecific family whose sole species is from the sublittoral of the Mediterranean Sea and surrounding waters (Fautin 2007). This family is characterized by a burrowing habit, an endodermal sphincter, 24 pairs of perfect mesenteries, 24 long, sometimes-deciduous tentacles, and no basilar muscles.

Andvakiidae Danielssen, 1890 comprises two genera and fewer than five species (Carlgren 1949; Fautin 2007). Andvakiidae is acontiate, with two kinds of nematocysts in the acontia, and its members have a mesogleal sphincter; it thus resembles families Isophelliidae, Sagartiidae, and Sagartiomorphidae, from which it is distinguished by lacking basilar muscles.

Bathyphelliidae Carlgren, 1932 comprises four genera and eight valid species (Fautin 2007). Riemann-Zürneck (1997a) hypothesized non-monophyly of the family based on attributes of the nematocysts of some members of the family (e.g., Daontesia). Bathyphelliidae is distinguished by acontia containing a single type of nematocysts, and having macro- and micro-cnemes, an elongated body, and few tentacles.

Boloceroididae Carlgren, 1924 comprises three genera and approximately 10 valid species (Fautin 2007). Boloceroididae belongs to infraorder Boloceroidaria, a small group distinguished by longitudinal muscles in the column, a disc-like aboral end, and the absence of basilar muscles. Boloceroididae is distinguished from Nevadneidae, the other family of Boloceroidaria, in having an endodermal sphincter at the base of each tentacle.

Capneidae Gosse, 1860 comprises two genera and five valid species (Carlgren 1949; Dunn 1982). Dunn (1983) reestablished and amended the name and authorship of the family, recognizing Aurelianidae Andres, 1883 as a junior synonym. Capneidae is characterized by short, lobed tentacles that have a relatively unusual arrangement for actiniarians: several tentacles arise from each principal endo- and exo-coel.

Condylanthidae, Stephenson, 1922 comprises five genera and approximately 10 valid species (Fautin 2007). Members of this family have both macro- and micro-cnemes, a rare trait among actiniarians with an endodermal sphincter.

Diadumenidae Stephenson, $\mathbf{1 9 2 0}$ is a monogeneric family comprising approximately 10 valid species (Fautin 2007). Members of Diadumenidae have two types of nematocysts in their acontia and lack a marginal sphincter; both of these attributes are seen in several other families.

Edwardsiidae Andres, 1881 comprises seven genera and more than 100 valid species (Williams 1981; Daly 2002; Fautin 2007). Monophyly of Edwardsiidae has been demonstrated by analyses of molecular (Daly et al. 2002) and morphological (Daly 2002) data, and is evidenced by the shared, derived state of eight macrocnemes. 
Exocoelactiidae Carlgren, 1925 is a monogeneric family comprising two valid species from the deep sea (Arellano \& Fautin 2001; Fautin 2007). Exocoelactiidae is characterized by a weak mesogleal sphincter and the irregular arrangement of the mesenteries in connection with the bilateral development of the younger mesenteries.

Galatheanthemidae Carlgren, 1956 is a monogeneric family comprising two valid species restricted to abyssal-hadal depths (Fautin 2007). Galatheanthemidae is characterized by the formation of a chitinous tube that covers much of the animal's column, a strong mesogleal sphincter, and no basilar muscles.

Gonactiniidae Carlgren, 1893 comprises two monospecific genera. Gonactiniidae belongs to a distinctive suborder of Actiniaria (Protantheae) distinguished by longitudinal muscles in the column, no ciliated tracts on the mesenterial filaments, no marginal sphincter, and no basilar muscles. In lacking all of these features, its members are unique among Actiniaria, and monophyly of the family is expected.

Halcampidae Andres, 1883 comprises six genera and approximately 20 valid species (Fautin 2007). Halcampidae is characterized by an elongated body with cuticle, a marginal sphincter muscle that is either absent or mesogleal, and microcnemes. Because Halcampidae distinguished by absences rather than any uniquely present attributes, this family may not be monophyletic.

Halcampoididae Appellöf, 1896 comprises eight genera and approximately 10 valid species (Dunn 1982; Fautin 2007). Halcampoididae is distinguished by no basilar muscles, a marginal sphincter, a variable number of mesenteries, and relatively longer tentacles in the inner cycle. Because none of these attributes are unique to this group, or even seen uniquely in combination in it, it is probable that Halcampoididae is not monophyletic. Furthermore, boundaries between Halcampoididae and Haloclavidae are not clearly established (Rodríguez \& López-González 2003).

Halcuriidae Carlgren, 1918 comprises two genera and approximately 10 valid species (Fautin 2007). Halcuriidae belongs to suborder Endocoelantheae, which is distinguished by an unusual arrangement of mesenteries; it is differentiated from all other members of the Endocoelantheae in having macro- and micro-cnemes and a unique siphonoglyph. The polarities of these diagnostic attributes are unclear, rendering assessment of its monophyly difficult.

Haliactiidae Carlgren, 1949 comprises six genera and approximately 10 valid species (Fautin 2007). Haliactiidae is distinguished by an elongated body, microcnemes, acontia, and no basilar or marginal sphincter muscles. The absence of musculature that distinguishes Haliactiidae from Acontiophoridae may be a functional rather than a phylogenetic distinction (Hand 1961), and thus Haliactiidae may not be monophyletic.

Haliplanellidae Hand, 1956 comprises two genera and two valid species (Dunn 1982; de Oliveira Pires 1987). Haliplanellidae is distinguished by the relatively small body size of its members, no marginal sphincter, and the types of nematocyst in the acontia. Because these attributes are all seen in other families, the monophyly of Haliplanellidae is unlikely.

Haloclavidae Verrill, 1899 comprises eight genera and approximately 25 valid species (Rodríguez \& LópezGonzález 2003; Fautin 2007). Haloclavidae is distinguished by a single well-developed siphonoglyph and no basilar muscles or marginal sphincter, rather than any unique attribute. The genera of Haloclavidae share relatively longer tentacles in the outer cycle and lack of basilar muscles, but are heterogeneous in terms of the column anatomy and the morphology of the sphincter muscle, which is either absent, weak and endodermal, or relatively strong and endodermal (Stephenson 1935, Carlgren 1949). The distinction between Haloclavidae and Halcampoididae is not clearly established (Rodríguez \& López-González 2003). In phylogenetic analyses of molecular data (Berntson et al. 1999; Daly et al. 2003), the type genus Haloclava clusters with some members of Actiniidae.

Hormathiidae Carlgren, 1932 comprises 15 genera and approximately 110 species, and is especially prominent in the deep sea (Fautin \& Barber 1999; Fautin 2007). Some of its members occur symbiotically 
with crustaceans or molluscs. Hormathiidae is characterized by having acontia containing only one type of nematocyst, a mesogleal marginal sphincter, and column divisible into two regions and usually provided with cuticle and tubercles.

Iosactiidae Riemann-Zürneck, 1997 is a monogeneric family comprising one species from the deep-sea (Riemann-Zürneck 1997b; Fautin 2007). Iosactiidae is characterized by a burrowing habit, no basilar muscles, a small endodermal sphincter, 24 pairs of perfect mesenteries, and 24 deciduous tentacles, each with a sphincter. Its phylogenetic affinity is unclear: in having an endodermal sphincter and deciduous tentacles, it resembles some members of Actiniidae (e.g., Bolocera), but these same features, plus the number of mesenteries and general burrowing structure, relate it to Andresiidae.

Isanthidae Carlgren, 1938 comprises five genera and seven valid species (Fautin 2007). Isanthidae is characterized by an elongated body, mesogleal marginal sphincter, and macro- and micro-cnemes.

Isophelliidae Stephenson, 1935 comprises seven genera and approximately 35 valid species (Fautin 2007). Isophelliidae is distinguished by acontia containing two types of nematocysts and both macro- and micro-cnemes. Isophelliidae is very similar to Andvakiidae, differing only in the former having basilar muscles, although the two have traditionally been placed in separate superfamilies. Microcnemes, which are absent in Sagartiidae, are the sole attribute distinguishing Isophelliidae and Sagartiidae.

Kadosactidae Riemann-Zürneck, 1991 comprises two genera and four valid species from the deep sea (Riemann-Zürneck 1991; Sanamyan \& Sanamyan 2007). Kadosactidae is characterized by a column provided with cuticle and divisible into two regions, a strong mesogleal marginal sphincter, and acontia containing two types of nematocysts. The recent description of Seepactis, a second genus of Kadosactidae, renders the family heterogeneous.

Limnactiniidae Carlgren, 1921 is a monogeneric family comprising two valid species (Fautin 2007). This family is characterized by no tentacles, marginal sphincter, or basilar muscles.

Liponematidae Hertwig, $\mathbf{1 8 8 2}$ is a monogeneric family comprising three valid species from deep-sea and polar waters (Fautin 2007). Liponematidae is characterized by attributes of its tentacles: each of the many tentacles has a sphincter at its base, allowing the tentacle to autotomize, and there is more than one tentacle per exocoel but only one per endocoel. Although its members resemble Bolocera (family Actiniidae) in general anatomy and cnidom, the arrangement of tentacles has been argued as sufficient to warrant family-level distinction (Dunn \& Bakus 1977).

Metridiidae Carlgren, 1893 comprises two genera and approximately five valid species (Fautin 2007). Metridiidae is distinguished in having acontia containing two types of nematocysts, a mesogleal marginal sphincter, and a lobed margin and oral disc with numerous short tentacles arrayed in the lobes. These attributes are not exclusive to members of Metridiidae.

Minyadidae Milne-Edwards, 1857 comprises two genera and approximately five species (Fautin 2007). Its members are unique among Actiniaria in being neritic, using a chitinous float secreted by the pedal disc for buoyancy.

Nemanthidae Carlgren, 1940 is a monogeneric family comprising three valid species (Fautin 2007). Nemanthidae is distinguished by acontia-like structures that are thicker than acontia but with fewer nematocysts that are not necessarily different than those of the filaments, and a mesogleal marginal sphincter.

Nevadneidae Carlgren, 1925 is a monospecific family (Carlgren 1949; Fautin 2007). Nevadneidae belongs to Boloceroidaria, an infraorder of Actiniaria distinguished by the presence of longitudinal muscles in the column, a disc-like aboral end, and no basilar muscles. Nevadneidae it is differentiated from Boloceroididae, the other family of Boloceroidaria, by an unusual arrangement of tentacles and in lacking a sphincter at the base of each tentacle.

Octineonidae Fowler, 1894 is a monogeneric family with three valid species (Carlgren 1949; Fautin 2007). Octineonidae is acontiate, with a single type of nematocyst in the acontia, and thus resembles mem- 
bers of the families Bathyphelliidae and Hormathiidae, from which it is distinguished by lacking basilar muscles.

Oractiidae Riemann-Zürneck, 2000 is a monogeneric family comprising two valid species (Riemann-Zürneck 2000). Oractiidae is distinguished by an endodermal marginal sphincter, 10 pairs of mesenteries but only eight macrocnemes, one siphonoglyph, and no basilar muscles.

Phymanthidae Andres, $\mathbf{1 8 8 3}$ comprises two genera and approximately a dozen valid species (Fautin 2007). Phymanthidae is distinguished by verrucae on the distal column, a weak endodermal marginal sphincter muscle or none at all, and two kinds of tentacles: marginal ones arranged in cycles that may have knoblike or branched protuberances, and discal ones that are typically very short and arranged radially (Carlgren 1949).

Preactiidae England in England \& Robson, 1984 comprises two genera and two valid species (Fautin 2007). Its two species are very similar, sharing a suite of unusual attributes, including mesenteries of each pair fused medially at the animal's proximal end, and tentaculate vesicles on the column. Preactiidae is one of the two families comprising the former order Ptychodactiaria, currently included as a suborder within Actiniaria based on morphological data (Cappola \& Fautin 2000; Fautin 2007). However, molecular evidence supports the inclusion of one of its species, Dactylanthus antarcticus, within the suborder Nynantheae, suggesting a close relationship with endomyarian actiniarians (Berntson et al. 1999; Daly et al. 2003).

Ptychodactiidae Appellöf, 1893 is a monogeneric family comprising one valid species (Fautin 2007). Ptychodactiidae is one of the two families comprising the former order Ptychodactiaria, currently included as suborder Ptychodacteae within Actiniaria based on morphological data (Cappola \& Fautin 2000; Fautin 2007). However, morphological similarities with Preactiidae and the demonstrated close relationship between Preactiidae and members of the suborder Nynantheae suggest that Ptychodactiidae belongs among the endomyarian actiniarians of suborder Nynantheae.

Sagartiidae Gosse, 1858 comprises 14 genera and approximately 85 valid species (Carlgren 1949; Fautin 2007). Sagartiidae is characterized by a mesogleal marginal sphincter and acontia containing two types of nematocysts, attributes also seen in other families. The family is heterogeneous and is probably not monophyletic.

Sagartiomorphidae Carlgren, 1934 is a monospecific family (Fautin 2007). Sagartiomorphidae is characterized by having a strong mesogleal marginal sphincter and acontia containing only one type of nematocyst. It differs from Hormathiidae in having microbasic amastigophores (referred to also as microbasic $p$-mastigophores) rather than basitrichs in the acontia, and from Sagartiidae in lacking basitrichs in the acontia.

Stichodactylidae Andres, $\mathbf{1 8 8 3}$ comprises two genera and approximately 10 valid species (Fautin 2007). Stichodactylidae is distinguished by a column typically bearing distal verrucae, a weak endodermal marginal sphincter, and short tentacles arranged in multiple endocoelic rows or long tentacles arranged in single endocoelic rows. Because of its distinctive arrangement of tentacles, this family has sometimes been accorded rank higher than family (e.g., Stephenson 1921).

Thalassianthidae Milne-Edwards, 1857 comprises four genera and eight valid species (Fautin 2007). Thalassianthidae is distinguished by an oral disc typically lobed with endocoelic dendritic tentacles and nematospheres (globular tentacles with dense cnidae). The highly modified tentacles and their arrangement suggest monophyly of the family.

\section{Order Antipatharia}

S. C. France, M. Brugler \& D. Opresko

The order Antipatharia Milne-Edwards \& Haime, 1857 is composed of noncalcareous, colonial anthozoans characterized by a spiny, proteinaceous skeleton (corallum) that can be unbranched and wire-like or simply to 
complexly dendritic. The skeleton is secreted by the axial epithelial tissue of the polyps in concentric layers around a small central hollow core. The polyps, each of which is often no more than a few millimeters in diameter (maximum size about $1 \mathrm{~cm}$ in diameter), possess six simple (unbranched) tentacles, six primary mesenteries, and zero, four, or six secondary mesenteries. The number of mesenteries and the morphology of the corallum, polyps, and axial spines are the principal taxonomic characters used in classification.

Antipatharians were originally grouped with gorgonians by Linnaeus, where they remained until Dana (1846) transferred them to the suborder Actinoidea. The Antipatharia was not recognized as a distinct order until the treatments of Milne-Edwards \& Haime (1857) and Lacaze-Duthiers (1865). Prior to the $21^{\text {st }}$ century and the work of Opresko (2001, 2002, 2003a, 2004, 2006), the last major taxonomic revision (van Pesch 1914) grouped all species into a single family, Antipathidae ${ }^{1}$. The current classification includes seven families, seven subfamilies, 40 genera, and 235 species; approximately a quarter of these have been described in the past two decades. Opresko (1972) provides an excellent history of the systematics and classification of antipatharians.

Black corals occur in all ocean basins, from 4,000 to 8,600 meters, although most species are found at depths >100 m (Grigg \& Opresko 1977). Due to the relative inaccessibility of the deep-sea habitat, many species have been described from poor and incomplete material, including fragments of colonies, young colonies, or specimens without polyps. Characters used to distinguish antipatharian families include polyp structure (i.e., number of mesenteries, modification of the polyp shape, and possible differences in the absolute and relative size of the tentacles) and general morphology of the spines. Additionally, because the same corallum morphology may occur in different families, there may be uncertainties about family affinities if only the corallum, and not the soft tissue, is available for study. Missing type material and inadequate species descriptions have resulted in many species names that cannot be reliably identified, necessitating the establishment of neotypes. Over the past two decades there has been a spike in the number of new species descriptions (50 since 1990), largely as a result of technological breakthroughs allowing for increased sampling of deep-sea corals (Opresko 2005), and the revisionary works of Opresko (2001, 2002, 2003a, 2004, 2006), which have also erected 20 new genera and three new families since 2001.

Few published genetic studies have assessed phylogenetic relationships within Antipatharia, although several researchers are currently working on the group. Only a single study has examined the evolutionary relationships of select black coral families to one another, although the taxonomic and geographic coverage is very limited (15 species, representing seven genera and three families, all but one from Sulawesi (Indonesia); Lapian et al. 2007). Brugler and France (unpub. data) have analyzed three mitochondrial gene regions (two intergenic spacer regions and coxl) and the nuclear ITS region for species representing all families, and find strong support for monophyly of Cladopathidae, Leiopathidae, Myriopathidae, and Schizopathidae, as well as schizopathid subfamilies Parantipathinae and Schizopathinae. To date, we have sequenced an insufficient number of taxa to assess monophyly of the Stylopathidae, but our analyses suggest both Antipathidae and Aphanipathidae are polyphyletic and require further inspection. A preliminary cladistic analysis of morphological characters, with cerianthids (tube anemones) as the outgroup found the following associations (although many were polyphyletic): Schizopathidae was sister to Cladopathidae, a result strongly supported by DNA sequence analyses (Brugler \& France unpub. data), Myriopathidae was sister to the Aphanipathidae, and Leiopathidae grouped with Antipathidae (Opresko, unpub. data).

\section{Included families}

Antipathidae Ehrenberg, 1834 comprises five genera and approximately 100 species. The Antipathidae, the oldest and most species-rich family, is likely not monophyletic. It has historically been considered a

1. Except for Dendrobrachia fallax Brook, Family Dendrobrachiidae; this was later shown to be a misclassified octocoral (Opresko \& Bayer 1991; Berntson et al. 2001). 
taxonomic dumping ground and is thus, not surprisingly, morphologically heterogeneous, including polyps of variable size, skeletons of varying ramification, and spines of varying shape and size (e.g., Opresko \& Baron-Szabo 2001; Opresko \& Sanchez 2005). Several taxa have recently been transferred to new genera and families in the revisions of Opresko (2001, 2002, 2003a, 2004, 2006), and a revision of the remaining species is pending.

Aphanipathidae Opresko, 2004 comprises nine genera and 22 species. Polyps have six primary and four secondary mesenteries, short, blunt, subequal tentacles, and spines that are tuberculate, but not notched, bifurcated or multiply-lobed at the apex. Two subfamilies (Aphanipathinae, Acanthopathinae) are differentiated by relative development of polypar spines. Phylogenetic analyses of DNA sequence data suggest the family is not monophyletic (Brugler \& France, unpub. data).

Cladopathidae Kinoshita, 1910 comprises six genera and 16 species (Opresko 2003a, 2005). The family is uniquely distinguished by the absence of secondary mesenteries. Polyps are transversely elongated with six primary mesenteries. The genera are further subdivided into three subfamilies: Cladopathinae, Hexapathinae, and Sibopathinae. The last is the only known anthozoan to lack an actinopharynx (and thus has only incomplete mesenteries). Morphological (Opresko, unpub. data) and molecular (Brugler \& France unpub. data) phylogenetic analyses support monophyly of the family.

Leiopathidae Haeckel, 1896 is a monogeneric family comprising six valid species, all of which are fairly distinctive from the remaining Antipatharia. Opresko (1998) suggested that the family may merit higher taxonomic status. Leiopathidae is distinguished by polyps with six primary and six secondary mesenteries, all of which are complete. The corallum is irregularly sympodial, with poorly developed spines and lacking pinnules.

Myriopathidae Opresko, 2001 comprises five genera and 32 species. The family is distinguished by small polyps with short tentacles, six primary and four secondary mesenteries, distinct interpolypar spaces, and tall, conical spines on the corallum. Mitochondrial and nuclear sequences support monophyly of the family (Brugler \& France, unpub. data).

Schizopathidae Brook, 1889 comprises 11 genera and 37 species. Brook (1889) considered Schizopathidae to have 'dimorphic zooids' (two gonozooids flanking one gastrozooid, each bearing one pair of tentacles), but subsequent work has shown there is a single polyp type with lateral chambers specialized for reproduction (Opresko 2005). The family is distinguished by transverse elongation of polyps that have six primary and four secondary mesenteries. Genera are divided into two subfamilies that are differentiated by the transverse diameter of the polyp (Parantipathinae - 2-3 $\mathrm{mm}$; Schizopathinae $>3$ $\mathrm{mm}$ ). Molecular phylogenetic analyses provide good support for monophyly of the family and subfamilies (Brugler \& France unpub. data).

Stylopathidae Opresko, 2006 comprises three genera and nine species. The family is distinguished by the tendency of pinnules to occur in groups of two, three or four, and by parts of the corallum to fuse and anastomose. Spines are smooth, conical, and simple, with an acute or rounded apex. Polyps on the smallest branches are slightly elongated in the axial direction, but always smaller in diameter than those of the Schizopathidae.

\section{Order Ceriantharia}

M. Daly

The order Ceriantharia Perrier, 1883 comprises soft-bodied, solitary, elongate polyps with a ring of short labial tentacles in addition to the marginal tentacles. Ceriantharians have an arrangement of mesenteries unique among hexacorallians: mesenteries are coupled but not paired, with single mesenteries added only in the ventral intermesenterial compartment. Ceriantharians are burrowers, using their muscular column to penetrate sediment and producing a flexible, felt-like tube of discharged cnidae and mucus that sheaths the column. 
Members of this order also possess a unique type of cnida, the ptychocyst, which is used in the construction of the tube (Mariscal et al. 1977). Because Ceriantharians have so many unique attributes, the group is inferred to be monophyletic, but no phylogenetic study has explicitly investigated this question.

Ceriantharia comprises approximately 100 named species, but diversity in this group remains poorly understood. Many species are known only from the long-lived, planktonic larval stage, the cerinula, and synonymies for even relatively common and well-known species are under active investigation (e.g., Molodtsova 2001a, 2001b, 2003; Wirtz et al. 2001). The number of genera is not clear: many monospecific genera have not been used since their creation, but have also not been formally synonymized. Dunn (1982) lists eight valid genera for the order, but Tiffon (1987) cites 18, and Fautin (2007) lists 39. The current higher-level classification was erected by den Hartog (1977), who used attributes of the cnidom to divide Ceriantharia into two suborders, Penicillaria and Spirularia. Penicillaria comprises only the family Arachnanthidae, and is characterized as having pencilli (also called microbasic $p$-mastigophores or microbasic amastigophores) (Schmidt 1972; den Hartog 1977). Spirularia comprises families Botrucnidiferidae and Cerianthidae, and lacks pencilli. The monophyly of each suborder and relationships within them remain unknown.

\section{Included families}

Arachnanthidae McMurrich, 1910 is characterized by nematocyst-dense internal structures called acontioids. The family is composed of two genera known from adults and larvae, and several known from larvae only (Tiffon 1987).

Botrucnidiferidae Carlgren, 1912 is characterized by nematocyst-dense internal structures called botrucnidae. The two most commonly encountered genera, Botruanthus and Botrucnidifer, are each known from a single species (Tiffon 1987).

Cerianthidae Milne-Edwards \& Haime, 1852 is characterized by lacking specialized nematocyst-bearing internal structure. It is composed of three genera known from both adults and larvae, and several genera known from larvae only (Tiffon 1987).

\section{Order Corallimorpharia}

M. Daly \& D. G. Fautin

Members of order Corallimorpharia Carlgren, 1940 have had a complex taxonomic history that mirrors modern confusion about the phylogenetic position of this order within Hexacorallia. Corallimorpharians resemble actiniarians in lacking a skeleton, and in being solitary or clonal rather than colonial. However, the internal morphology and cnidom of a corallimorpharian polyp is more similar to that of a scleractinian coral polyp (e.g., Gosse 1860; Moseley 1877; Schmidt 1972, 1974). In separating Corallimorpharia as a distinct order, Carlgren (1940) recognized that although they clearly have affinities with both actiniarians and scleractinians, corallimorpharians are not easily accommodated in either group. The features used to identify Corallimorpharia are the same as those used for actiniarians.

Molecular phylogenetic analyses have largely focused on the relationship between corallimorpharians and scleractinians. The results of these studies have been mixed: studies emphasizing DNA sequences from the mitochondrion or including a relatively sparse taxon sample (e.g., Fautin \& Lowenstein 1994; Romano \& Cairns 2001; Medina et al. 2006) typically recover Corallimorpharia nested within Scleractinia, whereas those that emphasize nuclear sequences or morphological data, or sample more broadly, find reciprocal monophyly of Scleractinia with respect to Corallimorpharia (e.g., Daly et al. 2003; Brugler \& France 2007; Collins et al. 2006a; but see Chen et al. 1995). In nearly all analyses, Corallimorpharia is monophyletic, regardless of its relationship to Scleractinia. However, no analysis published to date has included multiple representatives of each putative lineage of Corallimorpharia, and thus monophyly is not established for any of its subordinal taxa. The chapter in this volume by Fautin et al. (2007) covers the genera of Actiniaria and Corallimorpharia. 
Corallimorphidae Hertwig, $\mathbf{1 8 8 2}$ comprises three genera and approximately 10 species (den Hartog 1980; Fautin 2007). Its members have retractile tentacles with acrospheres, and lack photosymbionts.

Discosomatidae Duchassaing \& Michelotti, 1864 comprises two genera and approximately 10 species (Dunn \& Hamner 1980; den Hartog 1980; Fautin 2007). Its members have flat, disc-like polyps with discal and marginal tentacles. Discal tentacles are highly variable in morphology and are arranged in radial, endocoelic rows; marginal tentacles are typically small, often with acrospheres (Dunn \& Hamner 1980; den Hartog, 1980). Carlgren (1949) erroneously used the junior synonym Actinodiscus instead of Discosoma in his influential classification and thus named the family Actinodiscidae; Doumenc and van Praët (1987) repeated this name in their treatment of the systematics of Corallimorpharia. Relationships among Discosomatidae have never been examined through phylogenetic analysis.

Ricordeidae Watzl, 1922 is a monogeneric family comprising two valid species (den Hartog 1980; Fautin 2007). Its members have flat, disc-like polyps with short, simple tentacles arranged in radial, endocoelic rows. Neither the tentacles nor the oral disc are retractile. den Hartog (1980) proposed that Ricordeidae was intermediate between Corallimorphidae and Discosomatidae.

Sideractiidae Danielssen, 1890 comprises two monospecific genera (Carlgren 1949; Doumenc \& van Praët 1987; den Hartog et al. 1993). Its members are variable in column morphology, but all have tentacles with well-developed acrospheres that correspond in a one-to-one relationship with both the endocoelic and exocoelic spaces. The relationship between Sideractiidae and the other corallimorpharian families, which have multiple tentacles in each endo- and/or exo-coel, is unclear.

\section{Order Scleractinia}

\section{S. L. Romano \& J. L. Stake}

The Scleractinia Bourne, 1900 are polyp animals found exclusively in marine habitats. Its members are referred to as stony corals because all members of the order bear a solid calcareous skeleton that is external to the soft tissues, secreted by epidermal cells at the base of polyps to form cup-like calyces subdivided by septa and into which the polyp can retract for protection. Within the Anthozoa, such a skeleton is unique to the order. The approximately 1,300 described extant species (Cairns 1999) are divided ecologically into two main groups. One group, the reef builders, comprises 656 species. These are perhaps the best known scleractinian corals and are found mostly in the clear, shallow waters of the tropics. The second group, composed of 669 species, does not build reefs and is found in all regions of the oceans, including temperate and polar regions, and from relatively shallow waters to $6,000 \mathrm{~m}$. The oldest scleractinian coral fossils are from the mid-Triassic (about 240 million years ago) and are similar to the scleractinians of today.

Higher-order relationships between families and suborders of scleractinians are poorly understood. The first comprehensive studies of scleractinian relationships in the mid- $19^{\text {th }}$ century were based on skeletal characters of both fossil and extant taxa (Milne-Edwards \& Haime 1857; Ogilvie 1897). Vaughan and Wells' (1943) more recent treatment of the order revised several families, and is reflected in the current taxonomic organization of the order. The most widely accepted scleractinian phylogeny is that of Wells (1956), whose work is based on co-occurrence of genera in the fossil record and morphological characters of both fossil and extant scleractinians, but this phylogeny is not the product of an explicit phylogenetic analysis.

Scleractinian phylogeny has received renewed attention in recent years, primarily due to the availability of new techniques. Roniewicz and co-workers (Roniewicz \& Morycowa 1993; Stolarski \& Roniewicz 2001) used refined microstructural observations of both fossil and extant taxa to reevaluate scleractinian relationships. Veron (2000) has provided the most recent treatment of the order based on in situ observations and tra- 
ditional morphological characters of extant taxa. However, his descriptions of new species bearing photosymbiotic dinoflagellates (= zooxanthellae) and revisions of families have not followed the International Code of Zoological Nomenclature, calling into question the taxonomic validity of his revisions. Phylogenetic analyses of molecular data have been used to reevaluate the relationships of families and genera within Scleractinia (Chen et al. 1995; Romano \& Palumbi 1996; Veron et al. 1996; Romano \& Cairns 2000; Cuif et al. 2003; Fukami et al. 2004; Le Goff-Vitry et al. 2004). Molecular characters are especially appealing as they are independent of morphological characters and the problems associated with them (determining homologies and high levels of variability). Formal revision of the order has not been proposed based on molecular phylogenetic studies despite development of new hypotheses for groupings within the order. Most recently, Kerr (2005) used a supertree approach based on matrix representation parsimony to provide a comprehensive hypothesis for relationships within the order based on both morphological and molecular data.

Wells (1956) divided the order into five suborders (comprising all fossil and extant taxa) but regarded hypothesized relationships among suborders as tentative, and made few hypotheses about relationships among families. Veron $(1986,1995,2000)$ elevated some families to suborders, resulting in 24 extant families in seven suborders (with another six extinct suborders), but did not include any hypotheses for relationships among suborders due to poor understanding of skeletal homologies. Roniewicz and Morycowa's (1993) hypothesis for evolution within the Scleractinia is based primarily on fossil taxa with consideration of a small number of extant taxa. Their phylogeny is based on microstructural morphological characters and is very different from that of Wells (1956): it suggests that the order is polyphyletic, with the living families divided into two clades. Relationships of families within each of these clades are generally different from those of Wells' (1956) suborders. Phylogenetic analyses based on molecular data generally support traditional groupings of genera into families, but are not congruent with the limited hypotheses proposed for among family relationships. Molecular data suggests a split in the Scleractinia early in the evolutionary history of the group (Chen $e t$ al. 1995; Romano 1996; Veron et al. 1996; Romano \& Cairns 2000; Chen et al. 2002; Cuif et al. 2003; Daly et al. 2003; Fukami et al. 2004; Le Goff-Vitry et al. 2004; Medina et al. 2006). The two clades supported by molecular data do not correspond to the two clades supported by microstructural morphological characters. Several families have member genera spread throughout the phylogenetic tree, with some appearing on opposite sides of the major scleractinian split. Romano and Palumbi's (1996) analysis suggest that this split occurred before the onset of the skeleton in Scleractinia, although further analyses by Medina et al. (2006) do not support this hypothesis. Debate about the origin of the scleractinian skeleton has further confounded the use of morphological characters for evaluating relationships within the order. Kerr's (2005) supertree analysis supports the division of the order into two major clades corresponding to those suggested by molecular data. This is not surprising given the predominance of molecular data in his analysis. The current state of taxonomy in the Scleractinia demonstrates the need for a comprehensive reevaluation of families and their relationships.

The following list of families still follows the nomenclature set forth by Wells (1956) with a few exceptions noted. For traditional family designations that are not supported by recent molecular studies, a brief description of the evidence is provided.

\section{Included families}

Acroporidae Verrill 1902 comprises four genera, all zooxanthellate, and approximately 200 nominal species. A phylogenetic analysis of the family was conducted as part of a monograph on the genus Acropora and found the family to be monophyletic (Wallace 1999). Subsequent analyses based on molecular data have found the family to be paraphyletic because the genus Alveopora (Poritidae) is found within the clade containing all of the acroporids (Fukami et al. 2000; Romano \& Cairns 2000; Le Goff-Vitry et al. 2004; Kerr 2005).

Agariciidae Gray, 1847 comprises six genera, all zooxanthellate, and approximately 45 nominal species. The family is considered to be monophyletic based on limited molecular data (Romano \& Palumbi 1996; 
Romano \& Cairns 2000; Le Goff-Vitry et al. 2004; Kerr 2005). However, there has been no phylogenetic analysis of the entire family.

Anthemiphylliidae Vaughan 1907 comprises a single genus with seven nominal species. All species are azooxanthellate. The family is considered monophyletic based on morphological and limited molecular data, although no phylogenetic analysis has been conducted on the family (Romano \& Cairns 2000; Le Goff-Vitry et al. 2004; Kerr 2005).

Astrocoeniidae Koby, 1890 currently comprises either two or four genera, depending upon the reference used (Wells 1956; Veron 2000). The family is polyphyletic, with one clade equal to Madracis sensu Veron (2000); Veron removed this genus from Pocilloporidae and placed it here. Molecular evidence does not support this move, and without Madracis the family is monophyletic according to limited molecular evidence (Romano \& Cairns 2000; Le Goff-Vitry et al. 2004; Kerr 2005).

Caryophylliidae Gray, 1846 comprises more than 50 genera and approximately 300 nominal species which are neither zooxanthellate or azooxanthellate. The subfamily Euphyllidae was elevated to family status by Veron (2000). Monophyly of the family is not supported by molecular phylogenetic analysis. The family is polyphyletic and molecular data suggests the family needs reevaluation (Romano \& Cairns 2000; Le Goff-Vitry et al. 2004; Kerr 2005).

Dendrophylliidae Gray, 1847 comprises 20 genera and approximately 150 nominal species. The majority of genera are azooxanthellate. A phylogenetic analysis by Cairns (2001) showed that the family is monophyletic. Limited molecular evidence also supports this conclusion (Romano \& Cairns 2000; Cairns 2001; Le Goff-Vitry et al. 2004; Kerr 2005).

Euphyllidae Veron, 2000 comprises five zooxanthellate genera and 14 nominal species. Veron (2000) elevated this subfamily of Caryophylliidae to family status because he found the designation of subfamilies to be artificial. The family has not been subject to phylogenetic analysis. The potential monophyly of the family remains in question and needs further evaluation.

Faviidae Gregory, 1900 comprises 24 genera and over 100 nominal species that are all zooxanthellate. It is thought to be polyphyletic based on evidence in several molecular studies, although a complete phylogenetic analysis has not been conducted for the family (Romano \& Cairns 2000; Cuif et al. 2003; Daly et al. 2003; Fukami et al. 2004; Le Goff-Vitry et al. 2004; Kerr 2005).

Flabellidae Bourne, 1905 comprises 10 genera with approximately 100 nominal species, all of which are azooxanthellate. It is currently monophyletic based on morphological and limited molecular evidence, although no phylogenetic analysis has been conducted for the family (Cairns 1989; Romano \& Cairns 2000; Le Goff-Vitry et al. 2004; Kerr 2005).

Fungiacyathidae Chevalier, 1987 comprises one genus with approximately 20 nominal species, all of which are azooxanthellate. It is monophyletic based on morphological and limited molecular data (Cairns 1989; Romano \& Cairns 2000; Le Goff-Vitry et al. 2004; Kerr 2005).

Fungiidae Dana, 1846 comprises 11 genera with approximately 44 nominal species, all of which are zooxanthellate. It is considered monophyletic based on phylogenetic analysis of morphological data and limited molecular data (Cairns 1984a; Hoeksema 1989; Romano \& Cairns 2000; Kerr 2005). Le GoffVitry et al. (2004) found weak support for paraphyly in the family with limited taxonomic sampling.

Gardineriidae Stolarski, 1996 comprises a single genus made up of five nominal species, all of which are azooxanthellate. It is monophyletic based on morphological data but has not been the subject of a phylogenetic analysis (Stolarski 1996).

Guyniidae Hickson, 1910 comprises seven genera with 10 nominal species. All genera are monospecific except Guynia. The family has been the subject of a phylogenetic analysis using morphological data (Stolarski 2000), but may be polyphyletic based on limited molecular data (Cuif et al. 2003; Le GoffVitry et al. 2004; Kerr 2005). 
Meandrinidae Gray, 1847 comprises seven genera after Veron (2000) placed three species from Caryophylliidae here. All of the genera are zooxanthellate. The genera within this family remain in question. There has not been a phylogenetic analysis conducted for the entire family. Fukami et al. (2004) found the family to be monophyletic with strong support; however, other molecular studies suggest the family is paraphyletic (Romano \& Cairns 2000; Le Goff-Vitry et al. 2004; Kerr 2005).

Merulinidae Verrill, 1866 comprises five genera with approximately 12 nominal species, all of which are zooxanthellate. The family is considered polyphyletic based on molecular evidence (Fukami et al. 2004; Kerr 2005); however, no complete phylogenetic analysis has been conducted for the family.

Micrabaciidae Vaughan, 1905 comprises four genera with 13 nominal species, all of which are azooxanthellate. The family is monophyletic based on morphological data (Cairns 1989).

Mussidae Ortmann, 1890 comprises 13 genera with almost 50 nominal species. All genera are zooxanthellate. The family is polyphyletic based on molecular data although the family has not been analyzed completely (Fukami et al. 2004; Kerr 2005).

Oculinidae Gray, 1847 comprises 11 genera with approximately 30 nominal species. The family is split almost evenly between azooxanthellate and zooxanthellate genera. It is polyphyletic based on molecular evidence although no complete treatment of the family has been conducted (Romano \& Cairns 2000; Le Goff-Vitry et al. 2004; Kerr 2005).

Pectiniidae Vaughan \& Wells, 1943 comprises five genera with almost 20 nominal species, all of which are zooxanthellate. Although the entire family has not been the subject of a phylogenetic analysis, it is considered polyphyletic based on limited molecular data (Fukami et al. 2004; Kerr 2005).

Pocilloporidae Gray, 1842 comprises five genera, of which one is azooxanthellate, with over 30 nominal species. It has not been the subject of a phylogenetic analysis. Based on limited inclusion of some genera in the family, it is paraphyletic if Madracis is included (see Astrocoeniidae). With limited sampling and without Madracis the family forms a monophyletic clade based on molecular data (Romano \& Cairns 2000; Cuif et al. 2003; Le Goff-Vitry et al. 2004; Kerr 2005).

Poritidae Gray, 1842 comprises five genera containing over 70 nominal species, all of which are zooxanthellate. Although it has not been the explicit focus of any phylogenetic analysis, Poritidae is considered polyphyletic based on molecular evidence. The genus Alveopora is consistently found with the acroporids (Romano \& Cairns 2000; Le Goff-Vitry et al. 2004; Kerr 2005).

Rhizangiidae D'Orbigny, 1851 comprises five genera with more than 30 nominal species. All but one genus is azooxanthellate. The family is thought to be monophyletic, but there is little data available to confirm or refute this assertion (Kerr 2005).

Siderastreidae Vaughan \& Wells, 1943 comprises six genera with 27 nominal species, all of which are zooxanthellate. It has not been the subject of a phylogenetic analysis, but is considered polyphyletic based on molecular evidence from several representatives of the family used in larger analyses (Chen et al. 2000; Romano \& Cairns 2000; Daly et al. 2003; Le Goff-Vitry et al. 2004; Kerr 2005).

Trachyphylliidae Verrill, 1901 comprises a single zooxanthellate genus and a single species. The family is by definition monophyletic (Fukami et al. 2004; Kerr 2005).

Turbinoliidae Milne-Edwards \& Haime, 1848 comprises 22 genera and 51 nominal species, all of which are azooxanthellate. It is monophyletic based on morphological data (Cairns 1997; Kerr 2005).

Order Zoanthidea

M. Daly

Members of order Zoanthidea (= Zoantharia, Zoanthinaria) are clonal, soft bodied polyps with two rows of marginal tentacles. Their internal anatomy and mesenterial arrangement is distinctive among hexacorallians, and the group is presumed to be monophyletic, although no published studies have examined this question 
explicitly. Less clear is the relationship between Zoanthidea and other members of Hexacorallia: this group has been interpreted as the sister group to Actiniaria (e.g. Schmidt 1974; Medina et al. 2006; Brugler \& France 2007; Sinniger et al. 2007), as the basal member of a clade that also comprises Antipatharia, Corallimorpharia, and Scleractinia (Daly et al. 2003), and as the sister to Actiniaria, Antipatharia, Corallimorpharia, and Scleractinia (Brugler \& France 2007). None of these analyses have considered many zoanthidean taxa, relative to the sampling for other lineages.

Zoanthideans have traditionally been grouped into two suborders: Macrocnemina and Brachycnemina, which differ in the arrangement of the mesenteries (Haddon \& Shackleton 1891). Many Brachycnemina share a planktonic larval form (Ryland 1997; Ryland et al. 2000). Although these distinctions are well accepted and relatively clear, they seem not to reflect phylogenetic history. In their analysis of relationships among zoanthideans using mitochondrial DNA sequences, Sinniger et al. (2005) found that Macrocnemina is paraphyletic with respect to a monophyletic Brachycnemina. The results of Sinniger et al. (2005) highlight taxonomic difficulties in Zoanthidea, demonstrating para- and poly-phyly of many genera and families. Furthermore, studies of DNA sequences and of allozymes have indicated that there is significant cryptic diversity in Zoanthidea, suggesting that extensive revision of species and genera are necessary (Burnett et al. 1997; Ryland \& Lancaster 2003; Sinniger et al. 2005; Reimer et al. 2006, 2007a, b). Because of this confusion at lower taxonomic levels, estimates of diversity should be considered tentative.

\section{Included families}

Abyssoanthidae Reimer \& Fugiwara, 2007 in Reimer et al. 2007 is a monospecific family. This taxon was erected based on differences in DNA sequence and has not been characterized morphologically. Sequences of 16S rDNA and cytochrome oxidase subunit I from its sole species, Abyssoanthus nankaiensis, were highly divergent compared to other zoanthideans. Phylogenetically, it is the basal-most member of the clade containing Epizoanthidae and Sphenopidae (Reimer et al. 2007a).

Epizoanthidae Delage \& Hirouard, 1910 comprises three genera and approximately five named species. Phylogenetic analysis of multiple representatives of three of its genera failed to recover its members as monophyletic; these taxa formed a paraphyletic grade with respect to Sphenopidae (Sinniger et al. 2005).

Neozoanthidae Herberts, 1972 is a monogeneric family whose sole species has never been included in a phylogenetic analysis. The name has not been used by many other workers, and its species have not been reported since its description.

Sphenopidae Hertwig, 1882 comprises three genera. The number of species in this group is unclear, in part because diversity of its two larger genera, Palythoa and Protopalythoa is poorly known (e.g. Burnett et al 1997; Reimer et al. 2006, 2007b). Nonetheless, phylogenetic analysis of molecular sequence data from two species (in two genera) supported monophyly of the family (Sinniger et al. 2005).

Zoanthidae Gray, 1840 comprises three genera and approximately five named species. Phylogenetic analysis of multiple representatives of three of its genera failed to recover its members as monophyletic; these taxa formed a paraphyletic grade with respect to Sphenopidae (Sinniger et al. 2005).

\section{SUBCLASS OCTOCORALLIA}

\section{S. McFadden}

The anthozoan subclass Octocorallia comprises the soft corals, gorgonians (sea fans, sea whips), sea pens, and blue coral. Octocorallia is currently estimated to include approximately 3,000 extant species. As the name suggests, the diagnostic apomorphies of the subclass are the eight tentacles and eight mesenteries of octocoral polyps, characters that are invariant within the clade. The presence of pinnules (lateral extensions) on the tentacles is also considered diagnostic, although this character is absent in several taxa (Alderslade \& McFadden 
2007). With only the single, well-documented exception of Taiaroa tauhou, all octocorals have colonial polyps. Because of the uniformity of polyp morphology across the group, Octocorallia has long been considered to be monophyletic (e.g., Dana 1846; Haeckel 1866; Kükenthal 1925), a conclusion that has been supported strongly by all molecular phylogenetic analyses of Anthozoa conducted to date (16S rDNA: France et al. 1996; 18S rDNA: Song \& Won 1997; Berntson et al. 1999, 2001; Won et al. 2001; 28S rDNA: Chen et al. 1995).

Interpretations of relationships within Octocorallia vary widely, and at present there is little consensus among octocoral taxonomists about higher order relationships within the clade (Fabricius \& Alderslade 2001; McFadden et al. 2006a). The sea pens (Pennatulacea) and blue corals (Helioporacea) have, however, been assigned to separate orders since the early $20^{\text {th }}$ century (e.g., Hickson 1906; for a notable exception, see Kükenthal 1925). The unique colony form of sea pens, in which an axial polyp differentiates into a proximal peduncle and a distal rachis, represents a morphological synapomorphy that clearly unites order Pennatulacea and distinguishes its members from all other octocorals (Hickson 1930; Bayer 1956, 1981; Williams 1995, 1997). Likewise, Helioporacea, represented only by the monospecific Heliopora and one other enigmatic genus (Bayer 1992), are the only octocorals that produce a skeleton of crystalline aragonite, a convergent feature shared with the hexacorallian order Scleractinia.

Classification of the majority of octocorals - the soft corals and gorgonians-into higher taxonomic levels remains problematic, and in the past they have variously been divided among as few as two (Kükenthal 1925) and as many as six (e.g., Madsen 1944) orders. Historically, the most widely accepted classification, reflected in most mid-late $20^{\text {th }}$ century invertebrate biology texts (e.g. Hyman 1940; Barnes 1980; Brusca \& Brusca 1990), was that of Hickson (1930), who divided the soft corals and gorgonians among four orders (Alcyonacea, Gorgonacea, Stolonifera, Telestacea) distinguished by colony growth form. Recognition that these groups grade into one another without clear morphological distinctions led Bayer (1981) to merge them into a single order, Alcyonacea, a decision that has been embraced by modern taxonomists (e.g., Fabricius \& Alderslade 2001). This large and morphologically diverse order is not, however, defined by any synapomorphies.

For taxonomic convenience, Alcyonacea is often sub-divided into six sub-ordinal groups representing different grades of colony form and skeletal composition, but it is widely acknowledged that these groups do not reflect phylogenetic relationships (Fabricius \& Alderslade 2001). Indeed, molecular phylogenetic analyses using 18S rDNA and mitochondrial protein-coding genes have not recovered any of the sub-ordinal groups of Alcyonacea as monophyletic (Berntson et al. 2001; McFadden et al. 2006a). In addition, the distinctions between orders Alcyonacea, Pennatulacea, and Helioporacea have not been well supported by molecular studies. The $18 \mathrm{~S}$ phylogeny of Berntson et al. (2001) found Pennatulacea to be polyphyletic; in contrast, McFadden et al.'s (2006a) mitochondrial gene phylogeny recovered a monophyletic Pennatulacea, but found it to be nested within a paraphyletic group of alcyonaceans as the sister clade to the gorgonian family Ellisellidae. The phylogenetic position of Heliopora with respect to the other octocorals remains unresolved (Berntson et al. 2001; McFadden et al. 2006a). Even though the traditional ordinal classification has not been well supported, most molecular phylogenetic studies conducted to date have nonetheless divided Octocorallia into two or three genetically distinct clades; morphological synapomorphies distinguishing these clades have, however, yet to be identified (Berntson et al. 2001; Sánchez et al. 2003a; McFadden et al. 2006a).

\section{Order Alcyonacea}

As currently defined, order Alcyonacea Lamouroux, 1816 includes 30 families of soft corals (octocorals without a supporting skeletal axis) and gorgonians (octocorals with a supporting skeletal axis of scleroproteinous gorgonin and/or calcite) (Bayer 1981). Alcyonacean families are distinguished primarily on the basis of overall colony growth form, presence or absence of a supporting skeletal axis, and details of axial composition. The form and distribution of sclerites (microscopic calcite crystals embedded in the coenenchymal tissue and 
polyps) are the most important characters used to distinguish genera and species of octocorals, but are less important for familial distinctions. Alcyonaceans are found worldwide, at all depths and in all oceans.

Within this large order, two groups of gorgonians, Calcaxonia and Holaxonia, are currently recognized as morphologically distinct suborders defined by skeletal apomorphies (Grasshoff 1999). An additional four "subordinal groups" (Alcyoniina, Protoalcyonaria, Scleraxonia, Stolonifera) are distinguished for convenience, but are recognized as grades of colony architecture rather than clades (Fabricius \& Alderslade 2001). Molecular phylogenetic analyses unite the calcaxonian families in a clade with order Pennatulacea, with respect to which they are paraphyletic (McFadden et al. 2006a). The remaining alcyonaceans belong to one or more separate clades within which sub-ordinal and family relationships remain unresolved (Berntson et al. 2001; McFadden et al. 2006a). Many families and genera of Alcyonacea require extensive taxonomic revision, and numerous species remain either undescribed or simply unidentifiable; lost type specimens and the poor quality of most $19^{\text {th }}$ and early $20^{\text {th }}$ century species descriptions preclude species-level identifications in many groups (e.g., McFadden et al. 2006b). Estimates of numbers of species per family are consequently only rough approximations that may not accurately reflect actual numbers of valid species.

[Group Alcyoniina: colonies with polyps united within a fleshy mass of coenenchyme]

\section{Included families}

Alcyoniidae Lamouroux, 1812 comprises 34 genera and approximately 430 species of fleshy or membranous soft corals with polyps not arranged in clusters. The family is defined by the absence of those characters that distinguish the other families belonging to group Alcyoniina, and, not surprisingly, molecular phylogenetic analyses indicate that it is not monophyletic (McFadden et al. 2006a).

Nephtheidae Gray, $\mathbf{1 8 6 2}$ comprises 20 genera and approximately 500 described species of soft corals (250 species in the genus Dendronephthya alone) that form upright, branched colonies with a distinct stalk, and usually have the polyps arranged in clusters along or at the ends of branches. Several genera, however, have digitate or lobate growth forms similar to those found in family Alcyoniidae. The family is not monophyletic (McFadden et al. 2006a).

Nidaliidae Gray, 1869 comprises seven genera and approximately 75 species with an unbranched (digiform or capitate) or arborescent growth form. Colonies are typically stiff and brittle as a result of large, densely packed sclerites that are arranged longitudinally in the tissue surrounding the polyp cavities. The family is probably not monophyletic (McFadden et al. 2006a).

Paralcyoniidae Bayer, 1981 comprises four genera and approximately 10 species of soft corals in which the entire polyparium is retractable into a capsule-like base. The genera Paralcyonium, Studeriotes and Ceeceenus appear to form a monophyletic group (McFadden et al. 2006a; McFadden, unpub. data), but a fourth monospecific genus (Maasella) has never been included in a phylogenetic analysis.

Xeniidae Wright \& Studer, 1889 comprises 14 genera and approximately 130 species of soft corals that lack mesenterial filaments in all but the asulcal pair of mesenteries and have sclerites that are typically in the form of small, smooth-surfaced platelets or corpuscles. The family appears to be monophyletic, with the possible exception of the genus Anthelia, which differs in sclerite ultrastructure (Alderslade 2000) and does not group with other xeniid genera in some molecular analyses (McFadden et al. 2006a).

[Suborder Calcaxonia: gorgonians with an axis of gorgonin containing large amounts of non-scleritic calcite (as internodes or embedded in the gorgonin) and without a hollow, cross-chambered central core]

\section{Included families}

Chrysogorgiidae Verrill, 1883 comprises 12 genera and approximately 90 species of gorgonians characterized by regular, geometric branching patterns and a highly calcified axis that typically exhibits a metallic sheen. The family has not been the subject of a phylogenetic analysis. 
Dendrobrachiidae Brook, 1889 comprises three species in the enigmatic genus Dendrobrachia, gorgonians with an axis that is entirely proteinaceous, has conspicuous ridges and spines, and lacks a hollow core. Based on these skeletal characters, Dendrobrachia was originally assigned to the hexacorallian order Antipatharia (Brook 1889; Thomson 1910). The presence of polyps with eight pinnate tentacles was recently confirmed from newly collected material, however, and the genus has subsequently been transferred to Octocorallia (Opresko \& Bayer 1991). The phylogenetic relationship of Dendrobrachia to other octocoral families remains uncertain (Berntson et al. 2001), although it shares some morphological characters with Chrysogorgiidae (Opresko \& Bayer 1991).

Ellisellidae Gray, 1859 comprises 10 genera and approximately 100 species of gorgonians with a strongly calcified axis and sclerites in the characteristic form of dumbbells, clubs or double-ended spindles ornamented with hemi-spherical tubercles. The 10 genera fall into three groups; within each, generic distinctions are unclear and it has been proposed that most genera should be reduced to subgeneric standing (Bayer \& Grasshoff 1994). Morphological apomorphies and molecular analyses support monophyly of the family (McFadden et al. 2006a).

Ifalukellidae Bayer, 1955 comprises two genera and six species of gorgonians with a highly calcified axis and minute sclerites with coarse surface texture, similar in form to those of Xeniidae. A molecular phylogenetic analysis of the mitochondrial $m s h l$ gene suggests the family is monophyletic (McFadden et al. 2006a).

Isididae Lamouroux, 1812 comprises 38 genera and approximately 135 species of gorgonians divided among four sub-families. The family is distinguished by a segmented axis consisting of nodes of pure gorgonin alternating with solid (or occasionally tubular) non-scleritic calcareous internodes. The family has not been the subject of a phylogenetic analysis, but France and Brugler (unpub. data) have identified a mitochondrial genome arrangement synapomorphy for the subfamily Keratoisidinae.

Primnoidae Gray, 1857 comprises 32 genera and approximately 210 species of gorgonians with a highly calcified axis and non-retractile polyps that are heavily armored with calcareous scales. The family has not been the subject of a phylogenetic analysis.

[Suborder Holaxonia: gorgonians with an axis consisting primarily of gorgonin, often with small amounts of embedded non-scleritic calcite, and with a hollow, cross-chambered central core]

\section{Included families}

Acanthogorgiidae Gray, 1859 comprises six genera and approximately 110 species of gorgonians with conspicuous, non-retractile polyps and an axis of gorgonin surrounding a wide, hollow, cross-chambered central core. The family is not monophyletic, and several genera (Acanthogorgia, Anthogorgia) appear to be paraphyletic with Plexauridae (McFadden et al. 2006a).

Gorgoniidae Lamouroux, 1812 comprises 17 genera and approximately 260 species of gorgonians with retractile polyps and an axis of gorgonin surrounding a narrow, hollow, cross-chambered central core. Several molecular phylogenetic analyses suggest the family is not monophyletic (Sánchez et al. 2003b; Wirshing et al. 2005; McFadden et al. 2006a).

Keroeididae Kinoshita, 1910 comprises five genera and approximately 13 species of gorgonians with an axis of partially fused sclerites surrounding a hollow, cross-chambered central core. The family has not been the subject of a phylogenetic analysis.

Plexauridae Gray, 1859 comprises approximately 38 genera and 365 species of gorgonians divided among two sub-families (Plexaurinae, Stenogorgiinae (=Paramuriceinae)) that have been treated as separate families by some authors (e.g., Bayer 1956). The family is distinguished by an axis with a wide, hollow, cross-chambered central core surrounded by gorgonin with locules (hollow spaces) that often contain embedded non-scleritic calcite; polyps are retractile. Plexauridae is not monophyletic: several 
molecular phylogenetic studies have supported the separation of the two sub-families and identified several other distinct clades that are paraphyletic with respect to Acanthogorgiidae and Gorgoniidae (Sánchez et al. 2003b; Wirshing et al. 2005; McFadden et al. 2006a).

[Group Protoalcyonaria: solitary polyps]

\section{Included families}

Haimeidae Wright, 1865 comprises four monospecific genera of solitary polyps. The validity of these genera and of the family itself is questionable. The family was dropped by Hickson (1930), but re-established by Bayer and Muzik (1976) following the discovery of the solitary polyp Taiaroa. Bayer (1981) did not, however, include Haimeidae in his classification.

Taiaroidae Bayer \& Muzik, 1976 is a monospecific family comprising the species Taiaroa tauhou. This species consists of solitary polyps, a growth form that distinguishes it from all other octocorals. Its phylogenetic position within Octocorallia remains unresolved (Berntson et al. 2001).

[Group Scleraxonia: colonies with an axis or internal axial-like layer composed predominantly of sclerites that may be either unfused or fused with calcite]

\section{Included families}

Anthothelidae Broch, 1916 comprises approximately 13 genera and 55 species, often divided among three subfamilies. This family is distinguished by a medulla (inner tissue layer) that contains unfused sclerites and is separated from the cortex (outer tissue layer that houses the polyps) by longitudinal boundary canals. Inclusion of several anthothelid genera in molecular phylogenetic analyses of Octocorallia suggests the family is not monophyletic (McFadden et al. 2006a).

Briareidae Gray, 1859 comprises two or three genera and approximately 10 species in which the medulla contains unfused sclerites and is not separated from the cortex by a ring of boundary canals. The family has not been the subject of phylogenetic analyses.

Coralliidae Lamouroux, $\mathbf{1 8 1 2}$ comprises three genera, one of them of uncertain status, and approximately 30 species of gorgonians with dimorphic polyps and an axis composed of sclerites fused together solidly with calcite. The family has not been the subject of a phylogenetic analysis.

Melithaeidae Gray, 1870 comprises approximately six genera and 105 species of gorgonians with an axial medulla that consists of flexible nodes (free sclerites embedded in gorgonin) alternating with rigid internodes (sclerites fused with calcite). The five genera in sub-family Melithaeinae grade into one another morphologically and consequently have been collapsed into one to three genera by some authors (Bayer 1981; Grasshoff 1999; Ofwegen 1987; Fabricius \& Alderslade 2001). The family has not been the subject of a phylogenetic analysis.

Paragorgiidae Kükenthal, 1916 comprises two genera and 17 species of gorgonians with dimorphic polyps and an axial medulla formed by unfused sclerites. A recent cladistic analysis suggests the family is monophyletic (Sánchez 2005).

Parisididae Aurivillius, 1931 is a monogeneric family of approximately five species of gorgonians having an axis of flexible nodes (free sclerites embedded in gorgonin) alternating with rigid internodes formed by tuberculate sclerites fused with calcite. The axis construction is similar to that of Melithaeidae, but the form of the sclerites in the nodes and internodes differs. The family has not been the subject of a phylogenetic analysis.

Subergorgiidae Gray, 1859 comprises three genera and approximately six species of gorgonians with an axial medulla of partially fused sclerites that is separated from the cortex by a ring of longitudinal boundary canals. The family has not been the subject of a phylogenetic analysis. 
[Group Stolonifera: colonies with polyps united basally by stolons that may fuse to form ribbons or thin membranes]

\section{Included families}

Acrossotidae Bourne, 1914 is a monogeneric family comprising one or two species in the genus Acrossota. The family is distinguished by the complete absence of pinnules on the tentacles, a trait that may, however, be shared by some species in other families (Alderslade \& McFadden 2007). Acrossota has never been included in a phylogenetic analysis.

Clavulariidae Hickson, 1894 comprises approximately 24 genera and 60 species, often divided among four sub-families. Species in this family are united only by their colony growth form, which consists of polyps that are connected basally by stolons or thin membranes. Although Clavulariidae has not been the subject of a phylogenetic analysis, the inclusion of several genera in broader analyses of sub-class Octocorallia suggests that the family is not monophyletic (McFadden et al. 2006a).

Coelogorgiidae Bourne, $\mathbf{1 9 0 0}$ is a monospecific family comprising the species Coelogorgia palmosa. This species forms colonies in which an elongated axial polyp buds daughter axial polyps that in turn produce short lateral polyps. Several molecular phylogenetic analyses support a sister relationship between this species and family Xeniidae (McFadden et al. 2006a; McFadden et al., unpub. data).

Cornulariidae Dana, 1846 is a monogeneric family comprising approximately four species in the genus Cornularia. The family is distinguished by the presence of a chitinous outer sheath that forms a theca-like cup around the polyp. Cornularia has never been included in a phylogenetic analysis.

Pseudogorgiidae Utinomi \& Harada, 1973 is a monospecific family comprising the species Pseudogorgia godeffroyi. This species, in which a single, very long axial polyp differentiates into a blade-like colony with short lateral polyps embedded in its thick coenenchymal walls, is poorly known and has never been included in a phylogenetic analysis.

Tubiporidae Ehrenberg, 1828 is a monogeneric family in which polyps are housed in vertical, calcareous tubes connected to one another by horizontal, stolonic platforms. Tubipora musica is well known, but the validity of several other nominal species is uncertain. A molecular phylogenetic analysis based on mitochondrial genes suggests a close relationship between Tubipora and some genera of Clavulariidae (McFadden et al. 2006a).

\section{Order Helioporacea}

The order Helioporacea Bock, 1938 comprises just two monogeneric families that are unique among octocorals in producing calcified skeletons of crystalline aragonite. The well-known blue coral, Heliopora coerulea, is distributed widely throughout the Indo-Pacific where it is a common member of shallow coral reef communities. The enigmatic genus Epiphaxum is known from only a few localities at depths of 50-400 m (Bayer 1992). The phylogenetic relationship of these two families to one another and to other Octocorallia remains uncertain.

\section{Included families}

Helioporidae Moseley, $\mathbf{1 8 7 6}$ is a monospecific family comprising the species Heliopora coerulea, the only octocoral known to produce a massive aragonite skeleton similar to that of Scleractinia. Polyps are housed within cylindrical tubes in the skeleton, and are interconnected via solenia; a thin layer of tissue containing solenia also covers the outer surface of the skeleton (Fabricius \& Alderslade 2001).

Lithotelestidae Bayer \& Muzik, 1977 is represented by three extant and one fossil species of the genus Epiphaxum (Bayer 1992). This family has a stoloniferous growth form in which the stolons and the polyp calyces become calcified with non-scleritic aragonite. 


\section{Order Pennatulacea}

The sea pens, order Pennatulacea Verrill, 1865, are arguably the most morphologically distinctive group of octocorals, and achieve the highest level of colony integration among Anthozoa. Colonies develop from an axial polyp (oozooid) that differentiates into a bulbous peduncle used to anchor the colony in soft substrate, and a distal rachis that bears secondary polyps. The colony is usually supported by an internal, rod-like axis of non-scleritic calcite, similar in crystalline structure to that of the ellisellid gorgonians (Bayer 1955). The secondary polyps of sea pens are usually dimorphic, consisting of tentaculate autozooids and siphonozooids that lack or have greatly reduced tentacles (Williams 1995). The 14 families of Pennatulacea currently considered valid (Williams 1995) are distinguished largely by the arrangement of the secondary polyps around the rachis, with some families displaying distinctly bilateral colony symmetry. Sea pens live partially buried in soft sediments; although they reach their highest diversity in the deep-sea some species are found in shallow water, including Indo-Pacific coral reefs (Williams 1993) and estuaries (Imahara \& Ogawa 2006).

Cladistic analyses of Pennatulacea using family-level morphological characters support the monophyly of the order (Williams 1993, 1997), as does a recent molecular phylogeny of Octocorallia based on several mitochondrial genes (McFadden et al. 2006a). No studies to date, however, have examined phylogenetic relationships among or within any families of sea pens. Although representatives of a number of genera have been included in recent molecular phylogenies (Berntson et al. 2001; McFadden et al. 2006a), taxon sampling is still too sparse to draw conclusions regarding monophyly of families. Most families are diagnosed by combinations of character states that are shared with other families, and relatively few families are distinguished by autapomorphies. The most recent taxonomic synopsis of Pennatulacea, summarized below, is that of Williams (1995); he emphasizes that many families are in need of taxonomic revision, and that estimates of numbers of valid species are consequently only approximate.

\section{Included families}

Anthoptilidae Kölliker, $\mathbf{1 8 8 0}$ is a monogeneric family comprising at least two valid species of elongated, whip-like colonies with polyps that are arranged biserially, are non-retractile and lack calyces.

Chunellidae Kükenthal, 1902 comprises three genera and approximately four species that have polyps arranged along the stalk in pairs or groups of three, separated from one another by bare rachis.

Echinoptilidae Hubrecht, 1885 comprises two genera and seven described species of radially symmetrical colonies with non-retractile, bifurcated calyces.

Funiculinidae Gray, $\mathbf{1 8 7 0}$ is a monogeneric family comprising at least three species of whip-like colonies with polyps that are arranged biserially along the rachis and can retract into tubular, eight-toothed calyces.

Halipteridae Williams, 1995 is a monogeneric family comprising at least six valid species of elongated, whip-like colonies with autozooids arranged in oblique rows (often forming raised ridges) along two longitudinal series.

Kophobelemnidae Gray, $\mathbf{1 8 6 0}$ comprises three genera and approximately 18 species of clavate colonies with polyps arranged biserially or along three sides of the rachis.

Pennatulidae Ehrenberg, 1834 comprises six genera and approximately 50 species [sometimes separated into Pennatulidae (two genera) and Pteroeididae Kölliker 1870 (four genera)]. Colonies are bilaterally symmetrical with autozooids disposed along the margins of leaves that are in turn arranged laterally around the rachis.

Protoptilidae Kölliker, 1872 comprises two genera and approximately seven species of bilaterally symmetrical colonies with retractile polyps that are arranged in one to three longitudinal series along the rachis.

Renillidae Gray, $\mathbf{1 8 7 0}$ is a monogeneric family comprising at least four species distinguished from other sea pens by their unique foliate colony growth form. 
Scleroptilidae Jungersen, 1904 is a monogeneric family comprising one valid species and several species of uncertain status. The polyps are arranged along the stalk in pairs or groups of three, separated from one another by bare rachis. This family is distinguished from Chunellidae by the presence of rod- or spindle-shaped sclerites in the rachis.

Stachyptilidae Kölliker, 1880 comprises two genera and four species of somewhat clavate, bilaterally symmetrical colonies with autozooids arranged biserially along the rachis in oblique rows.

Umbellulidae Kölliker, $\mathbf{1 8 8 0}$ is a monogeneric family comprising at least nine valid species of sea pens with a long, slender stalk and a single, terminal cluster of autozooids.

Veretillidae Herklots, $\mathbf{1 8 5 8}$ comprises five genera and approximately 35 species distinguished by radial symmetry of the colony and retractile autozooids without calyces.

Virgulariidae Verrill, 1868 comprises five genera and approximately 40 species. Colonies are bilaterally symmetrical with autozooids disposed along the margins of leaves that are in turn arranged laterally around the rachis.

\section{Class CubozoA}

\section{A.G. Collins}

Cubozoa is the most species-poor class of phylum Cnidaria, presently containing 36 valid species in two orders (Gershwin 2005a, 2005b, 2006a, 2006b). Linnaeus (1758) described the first cubozoan, Carybdea marsupialis (Linnaeus 1758). Given their distinctive features it is not surprising that as additional species were described, they were classified together (e.g., Gegenbaur 1856; Aggasiz 1862; Kramp 1961). Haeckel (1880) was the first to recognize them (in the taxon Cubomedusae) as distinct from other major groups of medusozoans. Werner (1973) elevated the group as class Cubozoa, after he and others recognized that the life cycle and polyps were quite distinct from those of Scyphozoa, in which cubozoan species had been classified.

Few tests of cubozoan monophyly have been conducted, but putative synapomorphies for the group can be found in the cladistic analyses of Schuchert (1993), Bridge et al. (1995), Marques and Collins (2004), and Van Iten et al. (2006). Cubomedusae are distinctive in exhibiting four perradial sensory rhopalia containing strikingly complex eyes with ocelli, vitreous bodies, lenses, and retinas (Pearse \& Pearse 1978), as well as statocysts. A piece of tissue entirely of subumbrellar origin, known as the velarium, narrows the subumbrellar opening of cubozoans. The velarium is infused by canals and supported by perpendicularly arranged structures known as frenulae. The tentacles of cubomedusae are concentrated at the four interradial corners and have thickened muscular bases termed pedalia. Less readily observed diagnostic features of Cubozoa include the organization of the nervous system of the polyps and the process by which the solitary polyp entirely metamorphoses into a single juvenile medusa. Molecular analyses including approximately 10 cubozoan species have found robust support for cubozoan monophyly (Collins 2002; Collins et al. 2006a).

\section{Order Carybdeida}

Four families are presently classified in Carybdeida Gegenbaur 1857 (see Gershwin 2005b, 2006b): Alatinidae, Carybdeidae, Tamoyidae, and Tripedaliidae. Species of Carybdeida can be recognized by their unbranched pedalia located at the four interradial corners of the bell margin. With the exception of one family, Tripedaliidae, pedalia and tentacles number four. Unlike most members of Chirodropida, species of Carybdeida lack gastric saccules. The only explicit tests of monophyly of the group were based on molecular data sampled from nine species representing three of the four families (Collins 2002; Collins et al. 2006a); the results strongly support monophyly of Carybdeida. Alatinidae is the only family not yet sampled, but it seems likely that the group has a single origin within Cubozoa. 


\section{Included families}

Alatinidae Gershwin, 2005b comprises two genera, one monospecific, the other with approximately 10 valid species (Gershwin 2005b). Its members have not been included in any phylogenetic analyses and its monophyly remains untested. Putative synapomorphies and distinguishing characteristics of alatinids are crescentic phacellae and T-shaped rhopaliar niche ostia (Gershwin 2005b). Gershwin (2005b) noted that the cnidoms of Alatinidae and Tripedaliidae are similar.

Carybdeidae Gegenbaur, 1857 is a monogeneric family with six valid species (Gershwin 2005b, 2006b; Gershwin \& Alderslade 2005). Four of these have been sampled for molecular data (Collins 2002; Collins et al. 2006a). One of these species, Carybdea sivickisi, is clearly closely related to a representative of Tripedaliidae, a connection which has also been noted on morphological grounds (Gershwin 2006b). The other species of Carybdeidae can be distinguished by the presence of a heart-shaped opening of the rhopalial niche ostia.

Tamoyidae Haeckel, 1880 comprises four genera and six valid species (Gershwin 2005a; Gershwin \& Alderslade 2005). Two tamoyids representing two genera (one called 'Darwin carybdeid' has since been described as Gerongia rifkinae, Gershwin \& Alderslade 2005) have been sampled for molecular data and were found to form a well supported clade (Collins 2002; Collins et al. 2006a). Character variation across the different tamoyid genera is clearly laid out by Gershwin and Alderslade (2005), and the only character which appears to potentially be an unambiguous synapomorphy for the group should it prove to be monophyletic is the possession of frown-shaped rhopalial niche ostia (Gershwin 2005a).

Tripedaliidae Conant, 1897 is a monogeneric family with two valid species (Moore 1988). Only a single species has been sampled for molecular data, and no explicit tests of the group's monophyly have been conducted. Species are easily distinguished from members of the other families of Carybdeida by the possession of multiple pedalia and tentacles (three for one species, two for the other) at the interradial corners of the bell margin.

\section{Order Chirodropida}

Two families are currently classified in order Chirodropida Haeckel, 1880 (see Gershwin 2006a): Chiropsalmidae and Chirodropidae. Members of Chirodropida are easily distinguished from those of the other cubozoan order Carybdeida by their branched pedalia bearing numerous tentacles. In addition, with the exception of one species, all chirodropids possess gastric saccules (often termed diverticula), a feature absent in Carybdeida. The only explicit tests of the monophyly of the order are weak in terms of taxon sampling, including one species from each order (Collins 2002; Collins et al. 2006a). Nonetheless, these found strong support for a clade of Chirodropida exclusive of Carybdeida.

Included families

Chirodropidae Haeckel, 1880 comprises three genera with four valid species (Gershwin 2006a). Only a single species in this family has been sampled for molecular data (Collins et al. 2006a), and monophyly of the family has not been explicitly tested. It is unclear if any unambiguous putative synapomorphies exist for the group. Three species (in two genera) possess gastric saccules that are branched, but the monospecific genus Chirodectes lacks these structures altogether (Gershwin 2006a).

Chiropsalmidae Thiel, 1936 comprises three genera and seven valid species (Gershwin 2006a). Only a single species in this family has been sampled for molecular data (Collins et al. 2006a), and monophyly of the family has not been explicitly tested. Chiropsalmids are distinguished from other chirodropids by the presence of smooth, unbranched, finger-like gastric saccules that lack any filaments. 


\section{CLASS HYDROZOA}

P. Cartwight \& A.G. Collins

Hydrozoa comprises two reciprocally monophyletic clades, Trachylina and Hydroidolina (Collins 2002; Collins et al. 2006a), which together contain approximately 3,500 valid species (Schuchert 2007a). Molecular and morphological phylogenetic analyses robustly support monophyly of Hydrozoa (Bridge et al. 1992; Collins 2002; Marques \& Collins 2004; Collins et al. 2006a). Despite wide consensus regarding the monophyly and composition of Hydrozoa, it has few unambiguous, diagnostic morphological apomorphies. The cladistic analyses of Schuchert (1993), Bridge et al. (1995), Marques and Collins (2004), and Van Iten et al. (2006) identify sets of putative synapomorphies for Hydrozoa. Gap junctions have only been documented in hydrozoans within Cnidaria. If medusae are present in the life cycle, they usually possess a velum and two nerve rings, and are budded laterally from the polyps rather than arising by strobilation, as in Scyphozoa, or by complete transformation of the polyp, as in Cubozoa. Hydrozoan polyps lack septae. Most hydrozoans have gametogenic tissue of ectodermal origin and location, in contrast with non-hydrozoan cnidarians, which possess gametogenic tissue of endodermal origin and location.

\section{SUBCLASS HYDROIDOLINA}

Hydroidolina Collins, 2000 includes Anthoathecata, Leptothecata, and Siphonophorae (see Marques \& Collins 2004; Collins et al. 2006a). The monophyly of Hydroidolina is well supported by phylogenetic analyses of molecular (Bridge et al. 1995; Collins 2002; Collins et al. 2006a) and morphological (Bouillon \& Boero 2000a; Marques \& Collins 2004) data. The statocysts of Hydroidolina, when present, are ectodermal in origin. Hydroidolina polyps may be solitary or colonial, and the colonies may be polymorphic, a state that is only present in one genus (Monobrachium) of Trachylina. The relationships between major groups of Hydroidolina (Leptothecata, Anthoathecata, Siphonophorae) are uncertain (Collins 2002; Collins et al. 2006a).

\section{Order Anthoathecata}

Anthoathecata Cornelius, 1992 comprises two suborders, Filifera and Capitata, and approximately 1,140 valid species (Bouillon et al. 2006). The polyps do not have a skeletal covering and can be solitary or colonial. The medusae do not have statocysts and the gametogenic tissue is confined to the manubrium. Molecular phylogenetic studies do not support monophyly of Anthoathecata, suggesting instead that Anthoathecata is a paraphyletic assemblage that gave rise to one or more of the other suborders of Hydroidolina (Collins et al. 2006a).

\section{Suborder Filifera}

Filifera comprises 22 families (Schuchert 2007a) and approximately 765 valid species (Bouillon et al. 2006). Although the suborder has the putative morphological synapomorphies of filiferan tentacles on the feeding polyps and desmoneme and eurytele nematocysts, molecular phylogenetic analyses do not support its monophyly (Collins 2002; Collins et al. 2005, 2006a).

\section{Included families}

Australomedusidae Russell 1971 comprises three genera (Schuchert 2007a) and approximately five valid species (Bouillon et al. 2006). No representatives have been included in molecular phylogenetic anal- 
yses and its members have never been the subject of a phylogenetic analysis. This family is distinguished by polyps with large extensible hypostomes and medusae with (usually) four radial canals and four clusters of tentacles at the perradii of the bell margin.

Balellidae Stechow 1922 is a monospecific family (Bouillon et al. 2006) whose sole species has not been included in molecular phylogenetic analyses. This family is distinguished by polyps with two widely separated whorls of filiform tentacles.

Bougainvilliidae Lütken, 1850 comprises 13 genera (Schuchert 2007a) and approximately 100 valid species (Bouillon et al. 2006). Bougainvilliidae includes Rhizorhagium, which is not found within Schuchert's (2007b) classification (2007a). Molecular phylogenetic analyses that include two species from two genera were ambiguous with regard to monophyly (Collins et al. 2006a) and the group awaits a thorough phylogenetic investigation. Bougainvilliidae lacks morphological synapomorphies and shares many features with other families (Calder 1988; Schuchert 2007c). Some genera classified elsewhere by Schuchert (2007a), e.g., Lizzia in Rathkeidae, have been considered part of Bougainvilliidae (Bouillon et al. 2006).

Bythotiaridae Maas, 1905 comprises nine genera (Schuchert 2007a) and approximately 25 valid species (Bouillon et al. 2006). No representatives have been included in molecular phylogenetic analyses and the group has not been the subject of a phylogenetic analysis. Hydroids from this family can be distinguished by their habit of living inside the prebranchial cavity of ascidians. Medusae are recognized by marginal tentacles that have tiny or absent basal bulbs and terminate in a cluster of cnidae, but these features are present in Eucodoniidae.

Clathrozoellidae Peña Cantero, Vervoort \& Watson, 2003 is a monogeneric family (Schuchert 2007a) with four valid species (Bouillon et al. 2006). No representatives have been included in molecular phylogenetic analyses. This family is distinguished by a pseudohydrotheca covering the polyps.

Cytaeididae Agassiz, 1862 comprises three genera (Schuchert 2007a) and approximately 20 valid species (Bouillon et al. 2006). No representatives have been included in molecular phylogenetic analyses and the group has not been the subject of an explicit phylogenetic analysis. There are no known morphological synapomorphies for this group and the validity of one of the genera (Perarella) is questionable (Bouillon et al. 2006; Schuchert 2007c).

Eucodoniidae Schuchert, 1996 is a monospecific family (Schuchert 1996) that has not been included in molecular phylogenetic analyses. This family is distinguished by four clusters of embedded nematocysts around the mouth margin of medusae (Schuchert 1996).

Eudendriidae Agassiz, 1862 comprises two genera (Schuchert 2007a) and approximately 85 valid species (Marques 1996). Only a single representative has been included in molecular phylogenetic analyses (Collins et al. 2006a). Possible synapomorphies for this group include the absence of desmoneme nematocysts, a styloid gonophore, and trumpet-shaped hypostome (Marques 1996).

Hydractiniidae Agassiz, 1862 comprises seven genera (Schuchert 2007a) and approximately 100 valid species (Bouillon et al. 2006). Eleven species representing two genera have been included in molecular phylogenetic analyses, which supported monophyly of the group (Cunningham \& Buss 1993). However, taxon sampling in this analysis was not broad. The hydractiniid genus Clava is sometimes classified together with genera of Oceanidae in the family Clavidae (see Bouillon et al. 2006), suggesting that its phylogenetic status is uncertain. Hydroids of the family are distinguished by stolonal, polymorphic colonies that may bear spines.

Laingiidae Bouillon, 1978 comprises three genera and four valid species (Bouillon 1978; Bouillon et al. 2006). One species has been included in molecular phylogenetic analyses (Collins et al. 2006a). This group was originally classified as its own subclass by Bouillon (1978) but molecular phylogenetic analyses have shown that at least one member of the group, Fabienna sphaerica, is nested within Hydroidolina and closely related to Proboscidactylidae (see Collins et al. 2006a). This hypothesis is 
supported by morphological data, including a solid radial canal and macrobasic euryteles (Schuchert 1996).

Niobiidae Peterson, 1979 is a monospecific family (Bouillon et al. 2006) whose sole species has not been included in molecular phylogenetic analyses. The hydroid stage is unknown and the medusae are distinguished by marginal tentacle bulbs that develop into medusae buds (Petersen 1979).

Oceanidae Eschscholtz, 1829 comprises eight genera (Schuchert 2004) and approximately 25 valid species (Bouillon et al. 2006). Representatives of the family have not been included in any phylogenetic analyses. The family is distinguished by scattered filiform tentacles on the polyps, but this character is not specific to this group (Calder 1988; Schuchert 2004). Several genera of this family are sometimes classified with Clava in the family Clavidae (see Bouillon et al. 2006), suggesting that its phylogenetic status is uncertain.

Pandeidae Haeckel, 1879 comprises 23 genera (Schuchert 2007a) and approximately 75 valid species (Bouillon et al. 2006). One species has been included in molecular phylogenetic analyses (Collins et al. 2006a), but no explicit analyses of its phylogeny have been attempted. There are no known synapomorphies for this group and it is probably not monophyletic, as it encompasses a diverse assemblage of genera (Calder 1988).

Proboscidactylidae Hand \& Hendrickson, 1950 is a monogeneric family (Schuchert 2007a) with six valid species (Bouillon et al. 2006). One species has been included in molecular phylogenetic analyses (Collins et al. 2006a). Hydroids of this family are distinguished by polymorphic stolonal colonies bearing gastrozooid polyps with two filiform tentacles.

Protiaridae Haeckel, 1879 comprises five genera (Schuchert 2007a) and approximately eight valid species (Bouillon et al. 2006). No representatives have been included in molecular phylogenetic analyses. Medusae of this family are distinguished by large, hollow tentacular bulbs and four well-developed tentacles that are often interspersed with short, solid tentacles.

Ptilocodiidae Coward, 1909 comprises six genera (Schuchert 2007a) and eight valid species (Bouillon et al. 2006). The group has not been the subject of a phylogenetic analysis. Hydroids of this family are distinguished by the absence of tentacles on the feeding polyps.

Rathkeidae Russell, 1954 comprises six genera (Schuchert 2007a) and approximately 20 valid species (Bouillon et al. 2006). Three species representing three genera have been included in molecular phylogenetic analyses and in phylogenetic analyses, and these support familial monophyly (Schuchert 2007a). Species of this family are distinguished by primary medusae buds arising from stolons and secondary medusae buds arising interradially from the medusa manubrium.

Rhysiidae Brinckmann, 1965 is a monogeneric family (Schuchert 2007a) with three valid species (Bouillon et al. 2006). No representatives have been included in molecular phylogenetic analyses. This family is distinguished by dactylozooids covered with perisarc to the capitate apical tip and female gonozooids that transform into a sporosac-like structure.

Russelliidae Kramp, 1957 is a monospecific family (Bouillon et al. 2006) whose sole species has not been included in molecular phylogenetic analyses. The hydroid stage is unknown and the medusa possesses marginal tentacles in groups of three: one large and two small hollow tentacles. The large tentacles are sunk into the umbrella margin, forming a furrow.

Stylasteridae Gray, 1847 comprises 26 genera (Schuchert 2007a) and approximately 260 valid species (Bouillon et al. 2006). Cairns (1984b) published a cladistic analysis of the genera of this diverse group, but its monophyly was not tested because only one outgroup was considered. Nevertheless, species of the group are readily distinguished by a massive calcareous exoskeleton, often brightly pigmented, and they very likely form a clade. 
Trichydridae Hincks, $\mathbf{1 8 6 8}$ is a monospecific family (Bouillon et al. 2006) whose sole species has not been included in molecular phylogenetic analyses. No putative synapomorphies are known in the hydroid stage, but medusae are distinguished by the possession of many tiny, anastomosing centripetal canals.

Tubiclavoididae Moura, Cunha \& Schuchert, 2007 is a monospecific family (Moura et al. 2007) whose sole species has been included in molecular phylogenetic analyses (Moura et al. 2007), the results of which have not been published. The species is characterized by elongate polyps with scattered filiform tentacles and hydrocauli covered with striated perisarc.

Suborder Capitata

Capitata comprises 26 families (Schuchert 2007a) and approximately 375 valid species (Bouillon et al. 2006). The putative synapormorphies are stenotele nematocysts and capitate tentacles on the polyps or filiform tentacles in separated whorls (Bouillon \& Boero 2000b). Molecular phylogenetic analyses suggest that Capitata is a paraphyletic assemblage containing two clades, Aplanulata and the other capitates (Collins 2002; Collins et al. 2005, 2006a). The synapomorphy for Aplanulata is the absence of a ciliated planula larva (Petersen 1990). Four families, Tubulariidae, Corymorphidae, Candelabridae, and Hydridae have been sampled in molecular phylogenetic analyses that support monophyly of Aplanulata (Collins et al. 2005; Collins et al. 2006a), but it is likely that other families are part of this group (Petersen 1990; Collins et al. 2006a). Mosaics of features, very few of which appear to be unique to any particular family, distinguish the medusa stages of capitate families.

\section{Included families}

Acaulidae Fraser, 1924 comprises three genera and five valid species (Bouillon et al. 2006). No representatives have been included in molecular phylogenetic analyses and the group has not been the subject of an explicit phylogenetic analysis. Members of this family are distinguished by scattered capitate tentacles on the distal portions of their solitary polyps.

Boeromedusidae Bouillon, 1985 is a monospecific family (Bouillon et al. 2006) whose sole species has not been included in molecular phylogenetic analyses. Hydroids are unknown; medusae have an apical projection, four tentacles terminating in nematocyst clusters, and four perradial pouches bearing gametes hanging from the manubrium.

Boreohydridae Wesblad, 1947 comprises two genera (Bouillon 1985) and two valid species (Bouillon et al. 2006). No representatives have been included in molecular phylogenetic analyses and the group has not been the subject of an explicit phylogenetic analysis. This family is distinguished by small solitary polyps that possess a whorl of three to five diminutive tentacles (Schuchert 2006).

Candelabridae Stechow, 1921 comprises three genera (Schuchert 2006) and approximately 20 valid species (Bouillon et al. 2006). Just a single representative has been included in molecular phylogenetic analyses (Collins et al. 2005) and no explicit tests of the group's monophyly have been conducted. The family is distinguished by its solitary or pseudo-colonial polyps that are relatively large and bear numerous scattered capitate tentacles (Schuchert 2006).

Cladocorynidae Allman, 1872 comprises two genera (Schuchert 2006) and seven valid species (Bouillon et al. 2006). Only a single representative has been included in molecular phylogenetic analyses (Collins et al. 2005) and no explicit tests of the group's monophyly have been conducted. The putative synapomorphy for the family is patches of macrobasic euryteles on the body wall of the polyp (Petersen 1990).

Cladonematidae Gegenbaur, 1856 comprises four genera (Schuchert 2006) and approximately 20 valid species (Bouillon et al. 2006). Phylogenetic analyses including three species representing two genera support monophyly of the group (Collins et al. 2005). The family is distinguished by benthic medusae with branched tentacles and adhesive structures at the tips of the medusae tentacles (Petersen 1990). 
Corymorphidae Allman, 1872 comprises 10 genera (Schuchert 2007a) and approximately 45 valid species (Bouillon et al. 2006). Two species from one genus were included in molecular phylogenetic analyses, the results of which contradicted monophyly (Collins et al. 2005). There are no known synapomorphies for this group (Petersen 1990).

Corynidae Johnston, 1836 comprises seven genera and approximately 90 valid species (Schuchert 2001). A molecular phylogenetic analysis sampling 13 species from four genera strongly contradicted monophyly of the group, with some species being closely allied to members of Polyorchidae (Collins et al. 2005). Not surprisingly, no morphological synapomorphies have been identified for Corynidae (Schuchert 2001).

Halimedusidae Arai \& Brinckmann-Voss, 1980 comprises three genera (Mills 2000; Schuchert 2007a), each with a single valid species (Bouillon et al. 2006). No representatives have been included in molecular phylogenetic analyses and the group has not been the subject of an explicit phylogenetic analysis. Species of this family have small solitary polyps that give rise to medusae with distinct interradial peaks in jelly above the manubrium base, a feature also present in medusae of Boeromedusidae (Mills 2000).

Hydridae Linnaeus, $\mathbf{1 7 5 8}$ is a monogeneric family (Schuchert 2007a) with approximately 30 valid species (Bouillon et al. 2006). A molecular phylogenetic analysis sampling three species representing both the green and brown hydra groups supported monophyly of the family (Collins et al. 2006a). Hemmrich et al. (2007) sampled additional taxa (mainly focused on laboratory strains) and also found the group to be monophyletic, although this study aimed at elucidating relationships within the group. Hydridae is distinguished by the absence of medusae, its freshwater habitat, and lateral budding of polyps.

Hydrocorynidae Rees, 1957 comprises two genera (Schuchert 2007a) and three valid species (Bouillon et al. 2006). No representatives have been included in molecular phylogenetic analyses and the group has not been the subject of an explicit phylogenetic analysis. Hydroids of the group are colonial, with hydranths arising from a chitinized hydrorhizal plate. No putative synapomorphies have been identified for the medusa stage.

Margelopsidae Uchida, 1927 comprises three genera (Schuchert 2006) and six valid species. No representatives have been included in molecular phylogenetic analyses and the group has not been the subject of an explicit phylogenetic analysis. The family is distinguished by its small, pelagic, solitary polyps.

Milleporidae Fleming, $\mathbf{1 8 2 8}$ is a monogeneric family with approximately seven valid species (Razak \& Hoeksema 2003). One species has been sampled for molecular analysis (Collins et al. 2006a). This family is distinguished by colonies that build massive calcareous skeletons, polyps with capitate tentacles, and dimorphism with gastrozooids and dactylozooids.

Moerisiidae Poche, 1914 comprises three genera (Schuchert 2007a) and fewer than 10 valid species (Bouillon et al. 2006). One representative has been included in molecular phylogenetic analyses (Collins $e t$ al. 2005), but the family has never been the subject of an explicit phylogenetic analysis. Polyp stages of this family, where known, are solitary with scattered filiform tentacles. Medusae are recognized by a manubrium with radial lobes that extend toward and connect with the radial canals.

Paracorynidae Picard, 1957 is a monospecific family (Bouillon et al. 2006). No representatives have been included in molecular phylogenetic analyses. This family is distinguished by a flat, highly organized colony, with polymorphic zooids. Bouillon (1974) suggested that Paracoryne could be interpreted as an individual flattened polyp, rather than as a colony.

Pennariidae McCrady, 1859 is a monogeneric family with two valid species (Schuchert 2006). A single, widespread representative has been included in molecular phylogenetic analyses and no explicit tests of the group's monophyly have been conducted. The family is distinguished by a pinnate hydroid colony with polyps that contain an aboral whorl of filiform tentacles and capitate tentacles scattered 
towards the oral end.

Polyorchidae Agassiz, 1862 comprises three genera (Schuchert 2007a) and five valid species (Bouillon et al. 2006). Three species from two genera have been included in molecular phylogenetic analyses, which strongly supported monophyly of the group (Collins et al. 2005). The hydroid is unknown. Its large medusae are distinguished by a conspicuous gastric peduncle, a manubrium with four oral lips studded with nematocysts, numerous tentacles, and abaxial ocelli.

Porpitidae Goldfuss, 1818 comprises two genera and three valid species (Kirkpatrick \& Pugh 1984). One species from each genus was sampled in a molecular phylogenetic analysis, and the family was found to be monophyletic (Collins et al. 2005). This family is distinguished by a highly polymorphic, pelagic colonial stage, although it has been argued that this is not a colony but a modified individual polyp (Petersen 1990).

Protohydridae Allman, 1888 is a monogeneric family with two valid species (Schuchert 2006). No representatives have been included in molecular phylogenetic analyses and the group has not been the subject of an explicit phylogenetic analysis. The family is distinguished by small polyps that lack tentacles and gonophores and a pedal disk that is epidermal in origin (Petersen 1990).

Solanderiidae Marshall, $\mathbf{1 8 7 3}$ is a monogeneric family (Schuchert 1996) with approximately seven valid species (Bouillon et al. 2006). No representatives have been included in molecular phylogenetic analyses and the group has not been the subject of an explicit phylogenetic analysis. Species of the family are easily recognized by their large, branching colonies with chitinous, anastomosing internal skeletons.

Sphaerocorynidae Prévot, 1959 comprises two genera (Petersen 1990) and approximately five valid species (Bouillon et al. 2006). No representatives have been included in molecular phylogenetic analyses and the group has not been the subject of an explicit phylogenetic analysis. Hydroids of the family are long-stemmed and scattered with capitate tentacles at the broadest part of the hydranth. Medusae possess apical projections with an apical chamber and a single abaxial ocellus on each of four tentacles; each tentacle terminates in an elliptical nematocyst pad.

Teissieridae Bouillon, 1974 comprises three genera (Petersen 1990) and approximately 10 valid species (Bouillon et al. 2006). No representatives have been included in molecular phylogenetic analyses and the group has not been the subject of an explicit phylogenetic analysis. Two genera are sometimes classified in a separate family (Bouillon et al. 2006). This family is distinguished by a colony with a unique basal plate of periderm that forms spines.

Tricyclusidae Kramp, 1949 is a monospecific family (Schuchert 2006) whose sole member has not been included in molecular phylogenetic analyses. This family is distinguished by solitary polyps that have a gelatinous perisarc and three whorls of capitate tentacles.

Tubulariidae Fleming, 1828 comprises six genera (Schuchert 2007a) and approximately 60 valid species (Bouillon et al. 2006). Four species from three different genera have been sampled in a molecular phylogenetic analysis and found to be monophyletic (Collins et al. 2005). Although no explicit test of the group's monophyly was conducted, a larger study subjected 32 species to morphological phylogenetic analyses (Marques \& Migotto 2001). This study did support reciprocal monophyly of two subfamilies, Ectopleurinae and Tubulariinae. The family is distinguished by polyps possessing two sets of tentacles, an aboral and oral whorl with gonophores developing between the sets of tentacles. The medusae often have a manubrium surrounded by gametogenic tissue. Based on these features and the molecular data, monophyly of the family is likely.

Zancleidae Russell, 1953 comprises four genera (Schuchert 2007a) and approximately 25 valid species (Bouillon et al. 2006). Two species from one genus have been included in molecular phylogenetic analyses (Collins et al. 2005), but no detailed analyses of the groups' phylogenetic status have been conducted. Phylogenetic analyses contradict monophyly, although the node separating these species 
was poorly supported (Collins et al. 2005). Hydroids of the family possess no obvious putative synapomorphies. Zancleid medusae have four perradial exumbrellar nematocyst pads.

Zancleopsidae Bouillon, 1978 comprises two genera (Petersen 1990) and six valid species (Bouillon et al. 2006). No representatives have been included in molecular phylogenetic analyses and the group has not been the subject of an explicit phylogenetic analysis. The hydroid phase is unknown. Medusae have a conical or dome-shaped umbrella without an apical chamber, and usually have two opposed capitate tentacles that typically have capitate side branches.

\section{Order Leptothecata}

Molecular and morphological phylogenetic analyses support monophyly of Leptothecata Cornelius, 1982 (e.g., Collins et al. 2006a; Leclère et al. 2007). The synapomorphy for Leptothecata is the theca, a skeletal covering on the polyps (hydrotheca) and gonophores (gonotheca). However, some phylogenetic analyses have identified a theca-less taxon as the earliest diverging lineage of Leptothecata, suggesting that the theca may have evolved after the origin of Leptothecata. Leptothecate polyps are always colonial and the tentacles of the polyps are arranged in a single whorl. The medusae usually have shallow bells with gametogenic tissue restricted to the radial canals. The approximately 2,000 valid species are classified into two suborders, Conica and Proboscidoidea (Bouillon et al. 2006). When families of Leptothecata are distinguished based on features of the medusa stage, suites of characters are typically used although very few individual characters are unique to any particular family.

\section{Suborder Conica}

Conica is the more diverse of the two orders of leptothecates, comprising approximately 1,770 valid species (Bouillon et al. 2006) in 29-31 families (Bouillon et al. 2006; Schuchert 2007a). The presumed synapomorphy of the suborder is a conical hypostome on the polyps. Leclère et al. (2007) did not recover a monophyletic Conica; however this work addressed a different question and support in the relevant part of the topologies was weak.

\section{Included families}

Aequoreidae Eschscholtz, 1829 comprises four genera (Schuchert 2007a) with approximately 25 valid species (Bouillon et al. 2006). One species has been included in a molecular phylogenetic analysis (Collins et al. 2006a). No putative synapomorphies are known in the hydroid stage. The family is distinguished by relatively large medusae that possess a large number of (greater than 16) radial canals (Cornelius 1992).

Aglaopheniidae Agassiz, 1862 comprises eight genera (Schuchert 2007a) and approximately 250 valid species (Bouillon et al. 2006). Eleven species, including four genera, have been included in molecular phylogenetic analyses; their monophyly was strongly supported (Leclère et al. 2007). The family is distinguished by one median nematotheca below each hydrotheca and a pair of lateral nematotheca fused with the hydrotheca. Fused lateral nematotheca are thought to be a pleisiomorphy for the family (Leclère et al. 2007).

Barcinidae Bouillon, Gili, Pagès, Palanques \& Puig, 1999 is a monospecific family (Gili et al. 1999) whose sole member has not been included in molecular phylogenetic analyses. Hydroids of the family are unknown; medusae are distinguished by the presence of closed statocysts and adaxial ocelli (Gili et al. 1999).

Blackfordiidae Bouillon, 1984 is a monogeneric family (Schuchert 2007a) with three valid species (Bouillon et al. 2006). A single representative has been included in molecular phylogenetic analyses. No puta- 
tive synapomorphies are known in the hydroid stage; the medusae have four long fluted lips and numerous marginal tentacles with endodermal cores that extend into the mesoglea of the bell.

Campanulinidae Johnston, 1836 comprises 13 genera (Schuchert 2007a) and approximately 40 valid species (Bouillon et al. 2006). None of its species have been included in molecular phylogenetic analyses. No putative synapomorphies are known in the hydroid stage and the group is almost certainly a polyphyletic assemblage of genera that have a tubular hydrotheca with a pointed, segmental or pleated operculum, and that lack a medusa stage (Cornelius 1992; Bouillon et al. 2006).

Cirrholoveniidae Bouillon, 1984 is a monogeneric family (Schuchert 2007a) with two valid species (Bouillon et al. 2006). Neither of its species have been included in molecular phylogenetic analyses, and no putative synapomorphies have been proposed for either the hydroid or medusa stage.

Clathrozoidae Hirohito, 1967 comprises two monospecific genera (Bouillon et al. 2006), neither of which have been included in molecular phylogenetic analyses. Members of this family are distinguished by a hydroid skeleton consisting of anastomosed chitinous stolons.

Dipleurosomatidae Boeck, 1866 comprises four genera and approximately eight valid species (Bouillon et al. 2006). No representatives have been included in molecular phylogenetic analyses and no putative synapomorphies are known in the hydroid stage. Medusae of this family are distinguished by branched or irregularly arranged radial canals and a manubrium with a narrow base.

Eirenidae Haeckel, 1879 comprises nine (Schuchert 2007a) or 10 genera (Bouillon et al. 2006) and approximately 65 valid species (Bouillon et al. 2006). None of its species have been included in molecular phylogenetic analyses. No putative synapomorphies have been proposed for either the medusa or hydroid stages, the latter of which is recognized by elongate polyps and diminutive or absent hydrothecae.

Haleciidae Hincks, 1868 comprises four genera (Schuchert 2007a) and approximately 120 valid species (Bouillon et al. 2006). Two species representing three genera have been included in molecular phylogenetic analyses, which contradict monophyly of this group, albeit with low support for the nodes separating its representatives (Leclère et al. 2007). This family is distinguished by large polyps that are unable to retract into the hydrotheca. The hydrotheca often appears as a collar at the base of the polyp.

Halopterididae Millard, 1962 comprises 12 genera and approximately 85 valid species (Schuchert 1997; Bouillon et al. 2006). Eleven species representing three genera have been included in molecular phylogenetic analyses, which strongly support monophyly of the group (Leclère et al. 2007). This family is distinguished by one median nematotheca and a pair of lateral nematotheca associated with each hydrotheca. The hydrothecae are found on stems and terminal branches. These morphological characters are interpreted as pleisiomorphies for the family (Leclère et al. 2007).

Hebellidae Fraser, 1912 comprises six genera (Schuchert 2007a) and approximately 40 valid species (Bouillon et al. 2006). Two species representing two genera have been included in molecular phylogenetic analyses, which provide low support for monophyly (Leclère et al. 2007). Monophyly of Hebellidae (without the genus Staurodiscus, which is sometimes considered to be a part of Laodiceidae) was also supported in a phylogenetic analysis based on morphology (Marques et al. 2006). None of its diagnostic characters are unique to the group, many of them being present in members of Lafoeidae or putative outgroups (Marques et al. 2006).

Kirchenpaueriidae Stechow, 1921 comprises five genera (Schuchert 2007a) and 40 valid species (Bouillon et al. 2006). Four species from three genera have been sampled for molecular analysis, which strongly support monophyly of the group (Leclère et al. 2007). This family is distinguished by having one median nematotheca below each hydrotheca.

Lafoeidae Agassiz, 1865 comprises nine genera (Marques et al. 2006) and approximately 100 valid species (Bouillon et al. 2006). A tenth genus, Billardia, is sometimes classified in the family (Bouillon et al. 
2006), but its phylogenetic affinity is unclear. Lafoeidae (excluding Billardia) has been shown likely to be monophyletic based on morphology, though putative synapomorphies were dependent on outgroup choice (Marques et al. 2006). Most species in the family have gonothecae closely packed in a coppinia.

Laodiceidae Agassiz, 1862 comprises six genera (Schuchert 2007a) and approximately 25 valid species (Bouillon et al. 2006). The family has not been the subject of phylogenetic analysis, and no putative synapomorphies are known in the hydroid stage. Medusae of Laodiceidae have marginal cordyli and lack statocysts, but cordyli and cordyli-like structures are known in other families of Leptothecata.

Lineolariidae Allman, 1864 comprises three genera and four valid species (Bouillon et al. 2006). The group has never been the subject of a phylogenetic analysis. Species are recognized by having hydrothecae and gonothecae that are adherent to the substrate for most of their lengths.

Lovenellidae Russell, 1953 comprises five genera (Schuchert 2007a) and approximately 30 valid species (Bouillon et al. 2006). Two representatives from two genera, Lovenella and Eucheilota (sometimes considered to be in a separate family, Eucheilotidae), have been sampled for molecular data and found to form a strongly supported monophyletic group (Govindarajan et al. 2006). Further sampling is needed for a more explicit test of monophyly. The family is distinguished only by medusae characters, including lateral cirri, numerous statocysts, and a short manubrium.

Malagazziidae Bouillon, 1984 comprises three genera (Schuchert 2007a) and approximately 20 valid species (Bouillon et al. 2006). No representatives have been included in molecular phylogenetic analyses and the group has not been the subject of any phylogenetic analyses. No putative synapomorphies are known in the hydroid stage. Medusae of this family have gametogenic tissue completely surrounding the radial canals and tentacle bulbs with adaxial excretory papillae, features that are also exhibited by other leptothecate groups.

Melicertidae Agassiz, 1862 comprises four genera (Schuchert 2007a) and as many as six valid species (Bouillon et al. 2006). One species from the family has been included in molecular phylogenetic analyses, and so monophyly of the group remains untested. Phylogenetic analyses suggest that this family may be the sister taxon to the rest of Leptothecata (Collins et al. 2006a). This family is distinguished by the absence of a hydrotheca (though the hydroid is known only for one of the genera), suggesting that the theca may have evolved after the divergence of Melicertidae from the rest of the leptothecates. Medusae are recognized by eight simple or bifurcating radial canals, a manubrium with a broad base, and the absence of cirri, statocysts and cordyli.

Mitrocomidae Haeckel, 1879 comprises 10 genera (Schuchert 2007a) and approximately 30 valid species (Bouillon et al. 2006). The group has never been part of any analysis explicitly assessing its monophyly. Members of the family are distinguished by tubular, sessile hydrothecae in the hydroid stage and by a manubrium attached to the subumbrella along a continuum of the radial canals and open statocysts in the medusa stage. Genera with ocelli associated with open statocysts (Octogonade, Tiaropsidium, and Tiaropsis) are sometimes classified separately in family Triaropsidae (Bouillon et al. 2006).

Octocannoididae Bouillon, Boero \& Seghers, 1991 is a monospecific family (Bouillon et al. 2006). This family is only known from the medusa stage and is distinguished by multiple club shaped tentaculae at the bell margin in addition to eight normal tentacles; all have dark pigment spots. The gametogenic tissue is divided into lateral halves along the radial canals.

Orchistomatidae Bouillon, 1984 is a monogeneric family (Schuchert 2007a) with five valid species (Bouillon et al. 2006). No representatives have been included in molecular phylogenetic analyses and the family's monophyly has not been tested. Hydroid stages are unknown; medusae are distinguished by a short manubrium, a large gastric peduncle, a mouth with many crenulated lips, adaxial ocelli, and laterally compressed tentacles. 
Phialellidae Russell, 1953 comprises two genera (Schuchert 2007a) and approximately 10 valid species (Bouillon et al. 2006). No representatives have been included in molecular phylogenetic analyses. This family is distinguished by the absence of marginal cirri from the medusa and a crease line at the base of the hydrothecal operculum. It is questionable whether these characters are synapomorphies for the group (Cornelius 1982).

Plumulariidae McCrady, 1859 comprises six genera (Schuchert 2007a) with approximately170 valid species (Bouillon et al. 2006). Fourteen species representing five genera have been sampled for molecular phylogenetic analysis, which strongly supports monophyly of the group (Leclère et al. 2007). The family is distinguished by attributes of the paired nematothecae, which are either absent or never fused with hydrothecae.

Sertulariidae Lamouroux, 1812 comprises 26 genera (Schuchert 2007a) and approximately 600 valid species (Bouillon et al. 2006). Five species representing four genera have been included in molecular phylogenetic analyses, which contradicted monophyly of this group, albeit with low support for the nodes separating the different lineages (Leclère et al. 2007). This family is characterized by erect colonies and sessile hydrotheca with a hinged operculum.

Sugiuridae Bouillon, 1984 is a monospecific family (Bouillon et al. 2006) whose sole member has never been included in molecular phylogenetic analyses. No putative synapomorphies are known in the hydroid stage. This family is characterized by medusae with multiple manubria.

Syntheciidae Marktanner-Turneretscher, 1890 comprises three genera (Schuchert 2007a) and approximately 35 valid species (Bouillon et al. 2006). No representatives have been included in molecular phylogenetic analyses and the group's monophyly has not been tested. Species of this family usually have erect colonies that are unbranched or with pinnate stems, with hydrotheca on both sides of the stem.

Teclaiidae Bouillon, Gili, Pagès, Palanques \& Puig, 1999 comprises two genera (Schuchert 2007a), each with a single valid species (Bouillon et al. 2006). No representatives have been included in molecular phylogenetic analyses. The hydroid stage is unknown and the medusae possess marginal tentacles separated by cordiliform structures.

Thyroscyphidae Stechow, 1920 comprises five genera (Schuchert 2007a) and approximately 20 valid species (Bouillon et al. 2006). No representatives have been included in molecular phylogenetic analyses and the group has not been the subject of a phylogenetic analysis. Members of this family possess an ectodermal annular fold on the polyp, but this feature is also present in some species of Aglaopheniidae and Sertulariidae.

Tiarannidae Russell, 1940 comprises six genera (Schuchert 2007a) and approximately 15 valid species (Bouillon et al. 2006). No representatives have been included in molecular phylogenetic analyses. Medusae of this family are distinguished by having the gametogenic tissue folded on the adradial walls of the manubrium and/or on the perradial manubrial pouches.

Suborder Proboscidoidea

Proboscidoidea comprises three families (Schuchert 2007a) and approximately 150 valid species (Bouillon $e t$ al. 2006). The putative synapomorphy for this suborder is a flared hypostome forming a pregastric cavity. The group was not revealed as monophyletic in the analyses of Govindarajan et al. (2006), but this study was not focused on this question and leptothecate taxon sampling was relatively narrow.

\section{Included families}

Bonneviellidae Broch, 1909 is a monogeneric family (Schuchert 2007a) with approximately 10 valid species (Bouillon et al. 2006). Four representatives, only one of which was identified to species, have been 
included in molecular phylogenetic analyses. These analyses supported monophyly of the family (Govindarajan et al. 2006), but more explicit tests await further sampling. This family has a unique hypostome morphology, with the pregastric cavity separated by the base of the tentacles, projecting into the gastric cavity and fusing to form a ring.

Campanulariidae Johnston, 1836 comprises 11 genera (Schuchert 2007a) with approximately 140 valid species (Bouillon et al. 2006). Forty six species representing eight genera have been sampled for molecular phylogenetic analysis. The results fail to support monophyly of the group: members of Bonneviellidae nest inside Campanulariidae (Govindarajan et al. 2006). Members of Campanulariidae are distinguished by the campanulate-shaped skeleton (theca) surrounding the polyp and a peduncled hypostome. Bonneviellidae does not have this feature.

Phialuciidae Bouillon, 1984 is a monospecific family (Bouillon et al. 2006) whose sole species has not been included in molecular phylogenetic analyses. Hydroids are similar to those of campanulariids, but with a rounded hypostome. Medusae possess rudimentary bulbs between hollow marginal tentacles.

\section{Order Siphonophorae}

Siphonophora Eschscholtz, 1829 comprises 16 families (Schuchert 2007a) and approximately 160 valid species (Dunn et al. 2005) divided into three suborders: Calycophorae, Cystonectae, and Physonectae. Molecular phylogenetic analysis strongly support siphonophore monophyly (Collins 2002; Dunn et al. 2005). Siphonophores are characterized by their holopelagic, highly polymorphic colonial organization.

\section{Suborder Calycophorae}

Calycophorae comprises six families and approximately 100 valid species (Pugh 1999). Molecular phylogenetic analyses support monophyly of Calycophorae (Dunn et al. 2005). The putative synapomorphies for the group are the absences of an apical pneumatophore and palpons (Dunn et al. 2005).

\section{Included families}

Abylidae Agassiz, 1862 comprises five genera and approximately 10 valid species (Pugh 1999). Only a single representative has been included in molecular phylogenetic analyses (Dunn et al. 2005), and no explicit tests of the group's monophyly have been conducted. This family is distinguished by having two nectophores, with the posterior one lacking a somatocyst.

Clausophyidae Totton, 1954 comprises four genera and approximately 10 valid species (Pugh 1999). Three species representing two genera have been sampled for molecular analysis, the results of which support monophyly of the group (Dunn et al. 2005). This family is distinguished by the possession of two nectophores, each of which has a somatocyst.

Diphyidae Quoy \& Gaimard, 1827 comprise eight genera and approximately 50 valid species (Pugh 1999). Seven representatives, representing six genera, have been included in molecular phylogenetic analyses, the results of which strongly support monophyly of the group (Dunn et al. 2005). The possession of two dissimilar nectophores appears to be a synapomorphy for the group (Dunn et al. 2005).

Hippopodiidae Kölliker, 1853 comprises two genera and five valid species (Pugh 1999). Four representatives including species from both genera have been included in molecular phylogenetic analyses, the results of which strongly support monophyly of the group (Dunn et al. 2005). This family is distinguished by multiple nectophores of one type and the absence of bracts; both of these features appear to be synapomorphies for this group (Dunn et al. 2005). 
Prayidae Kölliker, 1853 comprises seven genera and 12 valid species (Pugh 1999). Six species from five genera have been included in molecular phylogenetic analyses. The results of these phylogenetic analyses contradict monophyly of the group; Hippopodiidae nests within Prayidae (Dunn et al. 2005). The family is distinguished by two relatively large nectophores.

Sphaeronectidae Huxley, 1859 is a monogeneric family with four valid species (Pugh 1999). A single representative has been included in molecular phylogenetic analyses and no explicit tests of the group's monophyly have been conducted (Dunn et al. 2005). This family is distinguished by a single spherical nectophore.

Suborder Cystonectae

Cystonectae comprises two families and five recognized species (Pugh 1999). Molecular phylogenetic analyses demonstrate that Cystonectae is monophyletic and the sister group to all other siphonophores (Dunn et al. 2005). The putative synapomorphy of Cystonectae is the absence of a nectosome or bracts and a relatively large pneumatophore.

\section{Included families}

Physaliidae Brandt, 1835 is a monospecific family (Pugh 1999). Although its sole species has been included in molecular phylogenetic analyses (Dunn et al. 2005; Collins et al. 2006a), there have been no explicit investigations of cryptic diversity within the group. This family is distinguished by a large, horizontal pneumatophore.

Rhizophysidae Brandt, 1825 comprises two genera and four recognized species (Pugh 1999). Two species have been sampled for molecular analysis, the results of which do not support monophyly: Physaliidae nests within this group (Dunn et al. 2005). Further sampling is needed to test this result. This family is distinguished by an apical and vertical pneumatophore.

Suborder Physonectae

Physonectae comprises seven families and approximately 50 valid species (Pugh 1999). The putative synapomorphies are the relatively small apical pneumatophore and a series of identical nectophores located beneath the pneumatophore. Molecular phylogenetic analyses suggest that the Physonectae is paraphyletic with respect to Calycophorae (Collins 2002; Dunn et al. 2005).

\section{Included families}

Agalmatidae Brandt, 1835 comprises nine genera and approximately 25 valid species (Pugh 1999). Nine species representing three genera have been included in molecular phylogenetic analyses, the results of which contradict monophyly and indicate that Agalmatidae is a polyphyletic assemblage (Dunn et al. 2005). There are no unique morphological features for this family.

Apolemidae Huxley, 1859 comprises three monospecific genera (Pugh 1999). Four representatives from one genus (Apolema) have been included in molecular phylogenetic analyses, although none were identified to species. The results of these phylogenetic analyses strongly support monophyly of the group (Dunn et al. 2005), although further sampling is needed to explicitly test this hypothesis. This family is distinguished by a hollowed nectophore that forms a pair of large axial wings.

Athorybiidae Huxley, 1859 comprises two genera and three known species (Pugh 1999). Two representatives have been included in molecular phylogenetic analyses, but these represent Atlantic and Pacific populations of the same species. Phylogenetic analyses support monophyly (Dunn et al. 2005), but further taxon sampling is needed to test this hypothesis. The family is distinguished by the absence of a nec- 
tophore, a feature which appears to be a synapomorphy for this group (Dunn et al. 2005).

Forskaliidae Haeckel, 1888 is a monogeneric family with six valid species (Pugh 2003). Six representatives of four species have been included in molecular phylogenetic analyses; one of the species (Forskalia edwardsi) was sampled from two locations in the Pacific and one from the Atlantic. Phylogenetic analyses support monophyly (Dunn et al. 2005). The putative synapomorphy for the group is the possession of four types of bracts (Dunn et al. 2005).

Physophoridae Eschscholtz, 1829 is a monospecific family (Pugh 1999) whose sole species has been included in molecular phylogenetic analyses (Dunn et al. 2005). One of the distinguishing features of the species, short stemmed physonects, is a pleisiomorphy (Dunn et al. 2005).

Pyrostephidae Moser, 1925 comprises two genera and four valid species (Kirkpatrick \& Pugh 1984). Two species of Bargmannia have been included in molecular phylogenetic analyses; the results of these analyses support monophyly (Dunn et al. 2005). This family is distinguished by long stems, dioecy, and the absence of palpons. The absence of palpons is likely a synapomorphy that arose convergently in Calycophorae (Dunn et al. 2005); the other traits are pleisiomorphies. Although it has not been tested explicitly, the molecular evidence and the absence of palpons suggest that monophyly of this group is likely.

Rhodaliidae Haeckel, 1888 comprises seven genera and 10 valid species (Pugh 1983). Only a single representative has been included in molecular phylogenetic analyses (Dunn et al. 2005) and no explicit tests of the group's monophyly have been conducted. The distinguishing features of the family are short stemmed physonects and a benthic life style.

\section{SUBCLASS TRACHYLINA}

The hydrozoan subclass Trachylina comprises all species classified in Actinulida, Limnomedusae, Narcomedusae, and Trachymedusae (Schuchert 2007). These four orders presently contain about 150 valid extant species (Bouillon et al. 2006).

The phylogenetic hypotheses of Bouillon and Boero (2000) and Marques and Collins (2004) recognize a close relationship between Actinulida, Narcomedusae, and Trachymedusae, all of which are direct developing and have ecto-endodermal statocysts. However, the position of Limnomedusae has been somewhat controversial. Bouillon and Boero (2000) maintain that the presence of a polyp stage in Limnomedusae indicates that it shares a common ancestry with Anthoathecata, Leptothecata, and Siphonophora, but its position was equivocal in cladistic analyses of morphological and life history characteristics (Marques \& Collins 2004). Molecular phylogenetic analyses including samples from Limnomedusae, Narcomedusae, and Trachymedusae have provided strong evidence for their close relationship (Collins 2002; Collins et al. 2006a). Actinulida has yet to be sampled for molecular data. The clearest diagnostic apomorphy for Trachylina is statocysts of ecto-endodermal origin (Haeckel 1879).

\section{$\underline{\text { Order Actinulida }}$}

Actinulida Swedmark \& Teissier, 1959 was created for Halammohydridae and Otohydridae, two groups of interstitial species. Integral to their decision was the documentation that species of both groups have direct development via an actinula-like stage. Swedmark and Teissier (1966) regarded this life cycle as ancestral for Hydrozoa, and therefore rejected earlier ideas that Halammohydridae was a derived group of Narcomedusae (Remane 1927). However, subsequent authors have suggested that these animals are most likely descendants of trachyline species with free-swimming medusa stages (e.g., Werner 1965; Salvini-Plawen 1987; Bouillon \& Boero 2000; Marques \& Collins, 2004). Trachymedusae and Narcomedusae are also direct developers with 
ontogenetically similar (ecto-endodermal) statocysts. However, characters affiliating the two actinulid families to any particular group within Trachylina, or even to each other, are lacking.

\section{Included families}

Halammohydridae Remane, 1927 is a monogeneric family with ten valid species (Bouillon et al., 2006), all of which live interstitially. No species of this family have ever been included in a phylogenetic analysis. Members of Halammohydridae possess a distinctive aboral adhesive organ, a nerve ring, and two amphicoronate whorls of aboral tentacles; these unique features suggest that the group is monophyletic.

Otohydridae Swedmark \& Teissier, 1958 is a monogeneric family with two valid species (Bouillon et al. 2006). Its members have not been included in any phylogenetic analyses. The species of Otohydridae are readily distinguished from those of Halammohydridae because they lack a nerve ring and have one whorl of dimorphic oral tentacles.

\section{$\underline{\text { Order Limnomedusae }}$}

Limnomedusae Kramp, 1938 has a complicated taxonomic history. Kramp (1938; Browne \& Kramp 1939) erected the taxon for the hydrozoan families Moerisiidae, Olindiasidae (= Olindiidae), and Proboscidactylidae to accommodate species with a biphasic life-cycle that did not readily fit in the Anthoathecata (=Anthomedusae or Athecata) because their medusae had either ecto-endodermal statocysts or gametogenic tissue along their radial canals, and also failed to fall in Leptothecata (=Leptomedusae or Thecata) because their polyps were not covered by a theca. Naumov (1960) added Monobrachiidae, whose species meet the criteria above. Two other families, Armorhydridae and Microhydrulidae, have also been classified within Limnomedusae, for lack of better alternatives (Bouillon 1985).

Broader considerations of more characteristics, including the cnidom, have indicated that Moerisiidae has a closer relationship to members of the anthoathecate group Capitata (Rees 1958; Petersen 1990). Likewise, the absence of statocysts and the presence of desmonemes strongly suggest that Proboscidactylidae shares a recent common ancestor with anthoathecate species classified in Filifera (Edwards 1973; Schuchert 1996). Molecular data have confirmed that Moerisiidae and Proboscidactylidae are more closely related to anthoathecate species than they are to those of Limnomedusae (Collins 2002; Collins et al. 2006a). Thus, Limnomedusae is presently limited to Armorhydridae, Microhydrulidae, Monobrachiidae, and Olindiasidae.

The molecular phylogenetic analyses of Collins et al. (2006a) included representatives of Monobrachiidae and Olindiasidae. These analyses did not support monophyly of the order, instead favoring (but with modest support values) the hypothesis that the group is a paraphyletic grade at the base of Trachylina. Additionally, these data provided relatively strong support for the hypothesis that the trachymedusan family Geryoniidae is derived within Limnomedusae. It is unclear precisely why Armorhydridae is included in Limnomedusae, as it appears to not share any putative synapomorphies with other limnomedusans. Their medusae, which inhabit the interstices of coarse sediments, differ from those of other limnomedusans by the presence of hollow tentacles and the absence of radial canals (gametes borne on the manubrium), statocysts, or other sense organs. The position of Microhydrulidae in Limnomedusae is also somewhat tentative. Adult stages of species of Microhydrulidae are unknown. Their polyps are solitary, minute, without tentacles, and armed with just a general nematocyst type, microbasic euryteles.

\section{Included families}

Armorhydridae Swedmark \& Teissier, 1958 is a monospecific family whose single valid species, Armorhydra janowiczi, lives interstitially in coarse sediments. This species has never been included in a population-level analysis, which could presumably reveal cryptic diversity. 
Microhydrulidae Bouillon \& Deroux, 1967 comprises two genera and three described species, all considered valid (Bouillon et al. 2006). Its members have not been included in any phylogenetic analyses. The species are only known from the minute polyp stage $(<500 \mu \mathrm{m})$, which are distinguished from those of other Limnomedusae by their lack of tentacles and mouths. There is no evidence of monophyly.

Monobrachiidae Naumov, 1960 is a monogeneric family containing three valid species (Bouillon et al. 2006). Only a single species has been sampled for molecular data, and the species have never been the subject of a phylogenetic analysis. The family can be differentiated from other limnomedusans by its polymorphic hydroid colonies, which live on bivalve molluscs. Monophyly of the family is likely.

Olindiasidae Haeckel, 1879 comprises 16 genera (Schuchert 2007) and approximately 40 valid species (Bouillon et al., 2006). Six species and genera were included in the analyses of Collins et al. (2006a); results of these analyses indicate that the family is paraphyletic, having given rise to the trachymedusan family Geryoniidae. Olindiasidae differs from Geryoniidae only in the presence of a polyp stage, so non-monophyly of the group is not surprising.

\section{Order Narcomedusae}

Narcomedusae Haeckel, 1879 currently contains four families (Schuchert 2007): Aeginidae, Cuninidae, Solmarisidae, and Tetraplatiidae. Investigations of narcomedusan relationships are still in their infancy. The most detailed published analysis is that of Collins et al. (2006b), which included representatives of Aeginidae, Cuninidae, and Tetraplatiidae and corroborated the narcomedusan affinities suggested by Hand (1955) for the worm-shaped Tetraplatia. Molecular data consistently support the monophyly of Narcomedusae (Collins 2002; Collins et al. 2006a, b). Even as taxon sampling increases in such studies, monophyly of Narcomedusae is likely to be upheld because its members share a number of distinctive features that are likely to be synapomorphies. For instance, the oral-aboral axes in adult medusae are derived from the transverse axes of their respective planulae (Bouillon 1987) and the tentacles arise from the exumbrella rather than at the margin.

\section{Included families}

Aeginidae Gegenbaur, 1857 comprises six genera (Schuchert 2007) with fewer than ten accepted species (Bouillon et al. 2006). Only two species have been sampled for molecular data, and these do not form a clade (Collins et al. 2006b) because Tetraplatia is derived within them. The paraphyly of Aeginidae is not surprising, as it is differentiated from Cuninidae and Solmarisidae by the presence of interradial manubrial pouches that are very similar to pouches that run up into the interradially located flying buttresses of Tetraplatia. This character may be a synapomorphy of Aeginidae plus Tetraplatiidae.

Cuninidae Bigelow, 1913 comprises four genera (Schuchert 2007) and approximately 20 valid species (Bouillon et al. 2006). A single species has been sampled for molecular data (Collins et al. 2006b); no test of the monophyly of the group has been conducted. Cuninidae is distinguished from other narcomedusans by manubrial pouches located in the perradii.

Solmarisidae Haeckel, 1879 comprises two genera (Schuchert 2007) and approximately 10 valid species (Bouillon et al., 2006). No representatives have been sampled for molecular data and monophyly of the group has not been assessed. Solmarisidae is separated from other narcomedusans because its species lack manubrial pouches.

Tetraplatiidae Schuchert, 2007 is a monogeneric family containing two valid species (Rees \& White 1957), one of which has been sampled for molecular data (Collins et al. 2006b). While monophyly of the group has not been tested, the distinctive morphology of its members (Hand 1955; Rees \& White 1957) would suggest that the species of Tetraplatia have a single evolutionary origin. 
As presently constituted, Trachymedusae Haeckel, 1866 contains five families (Schuchert 2007): Geryoniidae, Halicreatidae, Petasidae, Ptychogastriidea, and Rhopalonematidae. No detailed analyses of their relationships have been conducted. Only four species, representing Geryoniidae, Halicreatidae, and Rhopalonematidae, have been sampled for molecular data (Collins et al. 2006a). These data indicate that the group may be diphyletic; a representative of Geryoniidae was found to have a close relationship to some members of Limnomedusae. As a practical matter, the two groups are difficult to distinguish. Members of Geryoniidae, like other trachymedusans and unlike limnomedusans, lack polyp stages. However, geryonids share several characters (e.g., centripetal canals, hollow marginal tentacles, and four or six radial canals) with members of Limnomedusae. Disentangling the relationships among limnomedusans and trachymedusans is clearly a priority for future studies in trachyline systematics.

\section{Included families}

Geryoniidae Péron \& Lesueur, 1810 comprises two monospecific genera (Bouillon et al. 2006). Each of the geryonid species has a cosmopolitan distribution and neither has been the subject of population-level genetic studies, which could detect cryptic diversity. The two genera are distinctive, differing mainly in symmetry: one is four-parted and the other six-parted. Monophyly is likely.

Halicreatidae Fewkes, 1886 comprises five genera (Schuchert 2007) and approximately 10 valid species (Bouillon et al. 2006). A single representative has been sampled for molecular data (Collins et al. 2006a). Halicreatidae is distinguished from other trachymedusans by a wide circular manubrium that lacks lips, and tentacles that are stiff distally.

Petasidae Haeckel, 1879 comprises two monospecific genera (Bouillon et al. 2006; Schuchert 2007). No representatives have been sampled for molecular data and monophyly of the group has not been assessed. Petasidae is distinguished from other trachymedusans in having tentacles that terminate in a clubshaped knob of cnidae and four radial canals (shared with Liriope of Geryoniidae and Varitentaculata of Halicreatidae).

Ptychogastriidae Mayer, 1910 comprises two genera (Schuchert 2007) and three valid species (Bouillon et al. 2006). No representatives have been sampled for molecular data and monophyly of the group has not been assessed. Members of Ptychogastriidae are benthopelagic and distinguished from other trachymedusan families by having adhesive discs on some tentacles.

Rhopalonematidae Russell, 1953 comprises 16 genera (Schuchert 2007) and approximately 35 valid species (Bouillon et al. 2006). Two species have been sampled for molecular data (Collins et al. 2006a), and although they did not form a clade, no convincing test of the group's monophyly has been conducted. The family is distinguished from other trachymedusans by the possession of eight (usually) narrow radial canals and a narrow manubrium that terminates in a mouth with distinct lips.

\section{CLASS SCYPHOZOA}

M.N. Dawson

Class Scyphozoa presently contains approximately 200 extant morphospecies (Mianzan \& Cornelius 1999), but the true diversity of the group is likely to be at least two times greater (Dawson 2004). Thus, current estimates of species richness in any higher taxon are best viewed as an estimate. Scyphozoa has historically included five morphogroups, ascribed ordinal status but known colloquially as coronates, cubomedusae, rhizostomes, semaeostomes, and stauromedusae (e.g., Mayer 1910; Kramp 1961). However, many investigators using morphological data (e.g., Thiel 1966; Russell 1970; Werner 1973; Marques \& Collins 2004; see 
also Arai 1997) determined that Class Scyphozoa is composed of only coronates, rhizostomes, and semaeostomes. This interpretation has been corroborated by the consensus of recent molecular analyses (Collins 2002; Collins et al. 2006a), Cubozoa and Staurozoa are now recognized as distinct classes. Moreover, molecular analyses also have indicated that Scyphozoa comprises only two monophyletic groups: Order Coronatae and Order Discomedusae. Discomedusae comprises the semaeostomes, which are paraphyletic with respect to a monophyletic Rhizostomeae (Collins 2002; Dawson 2004; Collins et al. 2006a).

The life-history of almost all Scyphozoa includes a sexually reproducing planktonic medusoid phase (absent in Cassiopeidae) alternating with an asexually reproducing benthic polypoid phase (absent in a handful of polyp-less deep-water medusae). Scyphozoa are distinguished from other Medusozoa by the presence of polydisc strobilation in metamorphosing polyps (a pattern of strobilation that is further modified in some rhizostomes), rhopalia (as opposed to rhopaloids or complex eyes), and ephyrae (Marques \& Collins 2004; Collins et al. 2006a).

The current operational classification for Scyphozoa is therefore a somewhat cumbersome mix of ordinal and higher taxonomic groupings based on a molecular and morphological consensus (e.g., Thiel 1966; Russell 1970; Werner 1973; Arai 1997; Collins 2002; Dawson 2004; Marques \& Collins 2004; Collins et al. 2006a) coupled with the sub-ordinal and family-level treatment of Kramp (1961) used by Russell (1970) and Mianzan and Cornelius (1999). The contribution of analyses of the polyps to systematic classification within Scyphozoa remains practically negligible, with some notable exceptions (e.g., Jarms et al. 2002).

\section{$\underline{\text { Order Coronatae }}$}

Coronatae Vanhöffen, 1892 comprises many deepwater (three families exclusively) and some shallow-water species (all or a fraction of species in the three remaining families; Jarms et al. 2002). Coronates possess three synapomorphies that distinguish them from other scyphozoans: a coronal furrow, a coronate pedalium, and oocytes that develop without accessory pigments (Marques \& Collins 2004). Molecular analyses including representatives of as many as four coronate families support monophyly of Coronatae (e.g. Collins 2002; Dawson 2004; Collins et al. 2006a). However, little is known about many of the medusae that inhabit deepwater and the morphological characters listed by Kramp (1961) distinguish some families poorly.

\section{Included families}

Atollidae Bigelow, 1913 is a monogeneric family composed of six valid species that inhabit the mesopelagic zone. Medusae have more than eight rhopalia alternating with an equal number of tentacles; the marginal lappets are twice as numerous as the tentacles (Kramp 1961).

Atorellidae Vanhöffen, 1902 is a monogeneric family composed of five valid species. Medusae have six rhopalia.

Linuchidae Haeckel, 1879 is composed of two genera with four valid species, all of which are found in tropical shallow waters. Kramp (1961) considered the monospecific genus Linantha doubtful.

Nausithoidae Bigelow, 1913 comprises three genera with 22 valid species. Medusae have eight rhopalia, eight tentacles, 16 marginal lappets, and 16 radiating stomach pouches (Kramp, 1961). Preliminary molecular analyses suggest that Nausithoidae may be polyphyletic (Dawson 2004).

Paraphyllinidae Maas, 1903 is a monogeneric family comprising three valid species. Medusae in this family have four interradial rhopalia with four or more tentacles (Kramp 1961). All exclusively inhabit deepwater.

Periphyllidae Haeckel, 1880 comprises four genera and seven valid species. Medusae in this family have four interradial rhopalia with four to 28 tentacles (Kramp 1961). All exclusively inhabit deepwater. 


\section{SUBCLASS DISCOMEDUSAE}

Discomedusae are distinguished from coronates in having heterotrichous anisorhiza nematocysts, podocysts, complex radial canals, and a partially present circular canal (Marques \& Collins, 2004), although the complex radial canal is a homoplasy (also being present in some hydromedusae) and medial circular canals are prominent in some rhizostomes.

\section{Order Semaeostomeae}

Within Discomedusae, three genera constitute a group, traditionally known as order Semaeostomeae Agassiz, 1862 , which is probably paraphyletic with respect to Order Rhizostomeae. The semaeostomes are distinguished from rhizostomes by two homoplasies (loss of desmocytes, shared with Staurozoa; presence of glandular cells, shared with Anthozoa and Hydrozoa) and a synapomorphy (presence of nerve cells in the planulae: Marques \& Collins 2004).

\section{Included families}

Cyaneidae Agassiz, 1862 comprises three genera, one distributed globally in shallow-water, another in the Southern Ocean (Larson 1986), and the third in low-to-mid latitude Atlantic and adjacent basins, with approximately 20 recognized morphospecies. The cyaneid medusae are the only Discomedusae having tentacles originating on the subumbrellar surface of the bell at some distance inside of the bell margin.

Pelagiidae Gegenbaur, 1856 comprises three genera (Kramp 1961) and 15-20 recognized morphospecies. Cladistic analyses of morphological variation indicate that traditionally recognized genera are likely polyphyletic (Gershwin \& Collins 2002). Pelagiidae are discomedusae with completely separated but unbranched gastric pouches and long, pointed, folded oral arms (Kramp 1961).

Ulmaridae Haeckel, 1879 comprises 14 genera and approximately 40 valid species. Slightly more than onethird are in the genus Aurelia and are currently identifiable only using molecular comparisons (e.g., Dawson 2003, Dawson et al. 2005), although many may represent previously described morphospecies (e.g., Mayer 1910). Many of the remaining species are in monospecific genera of deepwater medusae. Ulmarid medusae have simple or branched radial canals and a ring canal, which distinguish them from all other semaeostomes (but not from all rhizostome medusae).

\section{Order Rhizostomeae}

The most diverse order of Scyphozoa, Rhizostomeae Cuvier, 1799 is a monophyletic clade according to phylogenetic analyses of DNA sequence data (Dawson 2004) and is often distinguished from other Discomedusae by monodisc strobilation (although this is not diagnostic of all species in the clade), having oral arms that bear suctorial mouths and are fused proximally, and the absence of tentacles on the bell margin (a feature shared with some deepwater semaeostomes). Kramp (1961), following Stiasny (1921) separated Rhizostomes into suborders and superfamilies in addition to the more standard Linnaean ranks. The phylogeny implied by Stiasny's (1921) taxonomy is largely supported by patterns of development (Holst et al. 2007) and phylogenetic analyses of DNA sequence from five families representing all superfamilies and suborders (Daryanabard \& Dawson, in press). Stiasny's (1921) taxonomy therefore remains the most current (Mianzan \& Cornelius 1999) and so is presented below without further embellishment (see Kramp 1961 for more details). 
Cassiopeidae Agassiz, $\mathbf{1 8 6 2}$ is a monogeneric family comprising 10 species.

Cepheidae Agassiz, $\mathbf{1 8 6 2}$ comprises four genera and 16 species.

Mastigiidae Stiasny, 1921 comprises three genera and 14 species.

Thysanostomatidae Gegenbaur, $\mathbf{1 8 5 7}$ is a monogeneric family with three species.

Versurigidae Gegenbaur, 1857 is a monospecific family.

Suborder Daktyliophorae

Lychnorhizidae Haeckel, 1880 comprises three genera and six species.

Catostylidae Gegenbaur, 1857 comprises six genera and 24 species.

Lobonematidae Stiasny, 1921 comprises two genera and five species.

Rhizostomatidae Cuvier, 1799 comprises four genera and 11 species.

Stomolophidae Haeckel, $\mathbf{1 8 8 0}$ is a monogeneric family with two species.

\section{ClaSs STAUROZOA}

A.G. Collins

Staurozoa is the most recently designated class of phylum Cnidaria (Marques \& Collins 2004). The primary justification for its creation was that order Stauromedusae failed to form a clade with the other scyphozoan taxa in cladistic analyses of morphology and life history characteristics (Marques \& Collins 2004), or in molecular phylogenetic analyses (Collins 2002). The cladistic analysis of Marques and Collins (2004) included a problematic extinct group, Conulata, which had a sister group relationship to Stauromedusae in their analyses. The class Staurozoa was erected to contain both of these groups. Subsequent work refining the character scoring for Conulata suggested that these enigmatic fossils are more likely to share a common ancestry with Scyphozoa than with Stauromedusae (Van Iten et al. 2006), contradicting the original concept of Staurozoa. Nevertheless, the cladistic analysis of Van Iten et al. (2006) and further phylogenetic research based on molecular sequence data (Collins \& Daly 2005; Collins et al. 2006a) have suggested that Stauromedusae may be the sister group to all other medusozoans. In terms of extant diversity, Staurozoa is equivalent to the order Stauromedusae.

\section{Order Stauromedusae}

The approximately 50 valid species of Stauromedusae Haeckel, 1879 are currently classified in two suborders, Cleistocarpida and Eleutherocarpida (Mills 2007). Only preliminary results from ongoing studies of the systematics of Stauromedusae have been published (Collins \& Daly 2005; Collins et al. 2006). Thus far, six species of Stauromedusae, representing both suborders and three of the six families, have been sampled for molecular data. These data strongly support monophyly of the sampled species (Collins \& Daly 2005; Collins et al. 2006a).

As benthic medusozoans, staurozoans are quite distinctive. Several likely synapomorphies of the clade are listed by Collins and Daly (2005), including eight adradial clusters of capitate tentacles and non-ciliated creeping planulae. Families and genera of Stauromedusae are recognized by a combination of characters (Uchida 1929; Kramp 1961; Larson \& Fautin 1989; Kikinger \& Salvini-Plawen 1995), e.g., with or without a claustrum, peduncle having one or four chambers, peduncle having four intramesogleal muscles or not, coro- 
nal muscle being discontinuous in each adradius or unbroken, possession of eight perradial and interradial marginal anchors, primary tentacles, or none. While genera appear to be well defined, the families and suborders seem to be confused.

\section{Suborder Cleistocarpida}

Cleistocarpida comprises two families, Craterolophidae and Depastridae. The presumed synapomorphy of the suborder is the claustrum, tissue that transversely divides the four gastric pockets. The only explicit tests of the group's monophyly were based on molecular data from two cleistocarpid representatives, each representing one of the families (Collins \& Daly 2005; Collins et al. 2006a). Monophyly of Cleistocarpida is contradicted by these data. The claustrum, a relatively complex feature (Berrill 1963), appears to be derived independently in different groups of Stauromedusae.

\section{Included families}

Craterolophidae Uchida, 1929 is a monogeneric family with two valid species (Mills 2007). One species of Craterolophidae has been sampled for molecular data and no explicit test of the group's monophyly has been conducted. Members of this family are distinguished from other cleistocarpids by the lack of primary tentacles in the perradii and interradii and the absence of longitudinal muscles in the peduncle.

Depastridae Haeckel, 1879 comprises four genera and approximately 10 valid species (Mills 2007). Only one species has been sampled for molecular data, and species of the family have never been the subject of a phylogenetic analysis. The family can be differentiated from other cleistocarpids by the presence of four longitudinal muscles running the length of the peduncle and primary perradial and interradial tentacles (Larson \& Fautin 1989).

\section{Suborder Eleutherocarpida}

Eleutherocarpida is distinguished from Cleistocarpida by the lack of a claustrum (Mills 2007). Phylogenetic assessments of Eleutherocarpida are still in their infancy: only members of Lucernariidae have been sampled for molecular data. Analyses of these data suggest that the suborder does not form a clade, and therefore the lack of a claustrum is not a synapomorphy of the group (Collins \& Daly 2005; Collins et al. 2006a).

\section{Included families}

Kishinouyeidae Uchida, 1929 comprises three genera and approximately 10 species (Mills 2007). No representative from this family has been included in a phylogenetic analysis and its monophyly is untested. The one potential synapomorphy of the group is the lack of muscles in the peduncle.

Kyopodiidae Larson, $\mathbf{1 9 8 8}$ is a monospecific family. Its sole species has never been included in a population-level analysis, which could presumably reveal cryptic diversity. Its morphology is highly unusual within Stauromedusae: the calyx is tiny in comparison with the peduncle, and the gametes and gastric cavity reside at the base of the peduncle (Larson 1988). Even if further diversity is revealed in the family, Kyopodiidae is likely to be monophyletic.

Lipkeidae Vogt, 1887 is a monogeneric family with three species. No representative from this family has been included in a phylogenetic analysis and its monophyly is untested. Its species are distinguished from other Eleutherocarpida by their lack of anchors or papillae and their possession of eight adradial arms bearing either rudimentary or no secondary tentacles (Kramp 1961). The peduncle is single chambered, with muscles, and the coronal muscle is unbroken. 
Lucernariidae Johnston, $\mathbf{1 8 4 7}$ is the most diverse family of Stauromedusae, comprising four genera and approximately 20 valid species (Mills 2007). Four species (one only identified to genus) representing two genera have been sampled for molecular data (Collins \& Daly 2005; Collins et al. 2006a); the results of these analyses strongly contradict monophyly of the group. Of the characters typically used in classifying Eleutherocarpida, the only one shared by members of Lucernariidae is the possession of muscles throughout the length of the peduncle.

\section{Acknowledgements}

This work is part of the Assembling the Cnidarian Tree of Life project, and was supported by NSF EF0531779 (to P.C., A.G.C. \& D.G.F.), 0531763 (to M.D.), 0531570 (to C.S.M.), and 0531735 (to S.L.R.). J.L.S. is supported through NSF-0346483 (VI-EPSCoR program) and M.N.D. is supported through NSF DEB0717078. Leen van Ofwegen provided helpful comments on octocoral taxonomy. Max Castorani helped organize and proofread literature. We gratefully acknowledge comments from Dale Calder and an anonymous reviewer.

\section{References}

Agassiz, L. (1862) Contributions to the Natural History of the United States of America. vol. IV. pt. III. Discophorae. pt. IV. Hydroidae. pt. V. Homologies of the Radiata. Little, Brown, Trubner, Boston, London, 380 pp.

Alderslade, P. (2000) Four new genera of soft corals (Coelenterata: Octocorallia), with notes on the classification of some established taxa. Zoologische Mededelingen Leiden, 74, 237-249.

Alderslade, P. \& McFadden, C.S. (2007) Pinnule-less polyps: a new genus and species of Indo-Pacific Clavulariidae and validation of the soft coral genus Acrossota and the family Acrossotidae (Coelenterata: Octocorallia). Zootaxa, 1400, 27-44.

Arai, M.N. (1997) A Functional Biology of Scyphozoa. Chapman \& Hall, London, 316 pp.

Ardelean, A. (2003) Revision of the family Actinodendriidae (Cnidaria: Actiniaria). Ph.D. Thesis, University of Kansas, 273 pp.

Arellano, S.M. \& Fautin, D.G. (2001) Redescription and range extension of the sea anemone Exocoelactis actinostoloides (Wassilieff, 1908), with revision of genus Exocoelactis (Cnidaria, Anthozoa, Actiniaria). Zoosystema, 23(4), 645-657.

Barnes, R.D. (1980) Invertebrate Zoology, $4^{\text {th }}$ ed. Saunders College, Philadelphia, 1089 pp.

Bayer, F.M. (1955) Contributions to the nomenclature, systematics, and morphology of the Octocorallia. Proceedings of the United States National Museum, 105, 207-220, plates 1-8.

Bayer, F.M. (1956) Octocorallia. In: Moore, R.C. (Ed), Treatise on Invertebrate Paleontology. Part F. Coelenterata. University of Kansas Press, Lawrence, pp. 166-231.

Bayer, F.M. (1981) Key to the genera of Octocorallia exclusive of Pennatulacea (Coelenterata: Anthozoa) with diagnoses of new taxa. Proceedings of the Biological Society of Washington, 94, 902-947.

Bayer, F.M. (1992) The helioporan octocoral Epiphaxum, recent and fossil: a monographic iconography. Studies in Tropical Oceanography, 15, 1-76.

Bayer, F.M. \& Grasshoff, M. (1994) The genus group taxa of the family Ellisellidae, with clarification of the genera established by J.E. Gray (Cnidaria; Octocorallia). Senckenbergiana biologica, 74, 21-45.

Bayer F.M., Grasshoff, M. \& Verseveldt, J. (1983) Illustrated Trilingual Glossary of Morphological and Anatomical Terms Applied to Octocorallia. E.J. Brill/Dr. W. Backhuys, Leiden, 75 pp.

Bayer, F.M. \& Muzik, K.M. (1976) A new solitary octocoral, Taiaroa tauhou gen. et sp. nov. (Coelenterata: Protoalcyonaria) from New Zealand. Journal of the Royal Society of New Zealand, 6, 499-515.

Bayha, K.M., Harbison, G.R., McDonald, J.H. \& Gaffney, P.M. (2004) Preliminary investigation on the molecular systematics of the invasive ctenophore Beroe ovata. In: Dumont, H., Shiganova, T.A. \& Niermann, U. (Eds), Aquatic Invasions in the Black, Caspian, and Mediterranean Seas. Springer, Netherlands, pp 167-175.

Berntson, E.A., France, S.C. \& Mullineaux, L.S. (1999) Phylogenetic relationships within the Class Anthozoa (Phylum Cnidaria) based on nuclear 18S rDNA sequences. Molecular Phylogenetics and Evolution, 13, 417-433. 
Berntson, E.A., Bayer, F.M., McArthur, A.G. \& France, S.C. (2001) Phylogenetic relationships within the Octocorallia (Cnidaria: Anthozoa) based on nuclear 18S rRNA sequences. Marine Biology, 138, 235-246.

Berrill, M. (1963) Comparative functional morphology of the Stauromedusae. Canadian Journal of Zoology, 41, 741752.

Bouillon, J. (1974) Sur la structure de Paracoryne huvei Picard, 1957 (Coelenterata, Hydrozoa, Athecata). Mémoires Académie Royale de Belgique, Classes des Sciences, 18(3), 5-45.

Bouillon, J. (1978) Hydroméduses de la mer de Bismarck (Papouasie, Nouvelle-Guinée). II. Limnomedusa, Narcomedusa, Trachymedusa et Laingiomedusa (sous-classe nov.). Cahiers de Biologie Marine, 19, 473-483.

Bouillon, J. (1985) Essai de classification des hydropolypes-hydroméduses (Hydrozoa-Cnidaria). Indo-Malayan Zoology, 2, 29-243.

Bouillon, J. (1987) Considérations sur le dévéloppement des narcoméduses et sur leur position phylogénétique. IndoMalayan Zoology, 4, 189-278.

Bouillon, J. \& Boero, F. (2000a) The Hydrozoa: a new classification in the light of old knowledge. Thalassia Salentina, $24,1-45$.

Bouillon, J. \& Boero, F. (2000b) Synopsis of the families and genera of the hydromedusae of the world, with a list of worldwide species. Thalassia Salentina, 24, 47-296.

Bouillon, J. \& Deroux, G. (1967) Remarques sur des Cnidaires du type de Microhydrula pontica Valkanov 1965, trouvés a Roscoff. Cahiers de Biologie Marine, 8, 253-272.

Bouillon, J., Gravili, C., Pagès, F., Gili, J.M. \& Boero, F. (2006) An introduction to Hydrozoa. Paris: Publications Scientifiques du Muséum, Paris, $591 \mathrm{pp}$.

Bridge, D., Cunningham, C.W., DeSalle, R. \& Buss, L.W. (1995) Class-level relationships in the phylum Cnidaria: Molecular and morphological evidence. Molecular Biology and Evolution, 12(4), 679-689.

Bridge, D., Cunningham, C.W., Schierwater, B., DeSalle, R. \& Buss, L.W. (1992) Class-level relationships in the phylum Cnidaria: evidence from mitochondrial genome structure. Proceedings of the National Academy of Sciences of the United States of America, 89(18), 8750-8753.

Brook, G. (1889) The Voyage of H.M.S. Challenger. Zoology. Report on the Antipatharia collected by H.M.S. Challenger during the years 1873-1876. The Voyage of H.M.S. Challenger, LXXX, 1-222.

Browne, E.T. \& Kramp, P.L. (1939) Hydromedusae from the Falkland Islands. Discovery Reports, XVIII, $265-322$.

Brugler, M (2004) The complete mitochondrial DNA sequence of the black coral Chrysopathes formosa (Antipatharia) and six non-contiguous mitochondrial genes of the tube anemone Ceriantheopsis americanus (Ceriantharia): implications for cnidarian phylogeny. M.Sc. thesis, University of Charleston, South Carolina. 103 pp.

Brugler, M.R. \& France, S.C. (2007) The complete mitochondrial genome of the black coral Chrysopathes formosa (Cnidaria: Anthozoa: Antipatharia) supports classification of antipatharians within the subclass Hexacorallia. Molecular Phylogenetics and Evolution, 42, 776-788.

Brusca, R.C. \& Brusca, G.J. (1990) The Invertebrates. Sinauer Associates, Sunderland, MA (USA), 922 pp.

Burnett, W.J., Benzie, J.A., Beardmore, J.A. \& Ryland, J.S. (1997) Zoanthids (Anthozoa, Hexacorallia) from the Great Barrier Reef and Torres Strait, Australia: systematics, evolution, and a key to species. Coral Reefs, 16, 55-68.

Cairns, S.D. (1984a) An application of phylogenetic analysis to the Scleractinia: Family Fungiidae. Palaeontographica Americana, 54, 49-57.

Cairns, S.D. (1984b) A generic revision of the Stylasteridae (Coelenterata: Hydrozoa), Part 2: Phylogenetic analysis. Bulletin of Marine Science, 35, 38-53.

Cairns, S.D. (1989) A revision of the ahermatypic Scleractinia of the Philippine Islands and adjacent Waters, Part 1: Fungiacyathidae, Micrabaciidae, Turbinoliinae, Guyniidae, and Flabellidae. Smithsonian Contributions to Zoology 486, 1-136.

Cairns, S.D. (1997) A generic revision and phylogenetic analysis of the Turbinoliidae (Cnidaria: Scleractinia). Smithsonian Contributions to Zoology, 591, 1-55.

Cairns, S.D. (1999) Species richness of recent Scleractinia. Atoll Research Bulletin 459, 1-46

Cairns, S.D. (2001) A generic revision and phylogenetic analysis of the Dendrophylliidae (Cnidaria: Scleractinia). Smithsonian Contributions to Zoology, 615, 1-75.

Calder, D.R. (1988) Shallow-water hydroids of Bermuda: The Athecatae. Royal Ontario Museum Life Sciences Contributions, 148, 1-107.

Cappola, V.A. \& Fautin D.G. (2000) All three species of Ptychodactiaria belong to order Actiniaria (Cnidaria: Anthozoa). Journal of the Marine Biological Association of the United Kingdom, 80, 995-1005.

Carlgren, O. (1949). A survey of the Ptychodactiaria, Corallimorpharia and Actiniaria. Kunglia Svenska VetenskapsAkadamiens Handlingar 1, 1-121.

Cavalier-Smith, T., Allsopp, M.T.E.P., Chao, E.E., Boury-Esnault, N. \& Vacelet, J. (1996) Sponge phylogeny, animal monophyly, and the origin of the nervous system: 18S rRNA evidence. Canadian Journal of Zoology, 74, 20312045.

Chen, C.A, Odorico, D.M., ten Lohuis, M.R., Veron, J.E.N. \& Miller, D.J. (1995) Systematic relationships within the 
Anthozoa (Cnidaria: Anthozoa) using the 5'-end of the 28S rDNA. Molecular Phylogenetics and Evolution, 4, 175183.

Chen, C., Wallace, C.C., Yu J. \& Wei, N. (2000) Strategies for amplification by polymerase chain reaction of the complete sequence of the gene encoding nuclear large subunit ribosomal RNA in corals. Marine Biotechnology, 2, 558570.

Chen, C.A., Wallace, C.C. \& Wolstenholme, J.K. (2002) Analysis of the mitochondrial 12S rRNA gene supports a twoclade hypothesis of the evolutionary history of scleractinian corals. Molecular Phylogenetics and Evolution, 23, 137-149.

Clubb, J.A. (1908) Coelentera. National Antarctic Expedition 1901-1904 Natural History, IV Actiniae, 1-12.

Collins, A.G. (1998) Evaluating multiple alternative hypotheses for the origin of Bilateria: An analysis of 18S rRNA molecular evidence. Proceedings of the National Academy of Sciences of the United States of America, 95, 1545815463.

Collins, A.G. (2002) Phylogeny of Medusozoa and the evolution of cnidarian life cycles. Journal of Evolutionary Biology, 15(3), 418-432.

Collins, A.G., Winkelmann, S., Hadrys, H. \& Schierwater, B. (2005) Phylogeny of Capitata and Corynidae (Cnidaria, Hydrozoa) in light of mitochondrial 16s rDNA data. Zoologica Scripta, 34(1), 91-99.

Collins, A.G., Schuchert, P., Marques, A.C., Jankowski, T., Medina, M. \& Schierwater, B. (2006a) Medusozoan phylogeny and character evolution clarified by new large and small subunit rDNA data and an assessment of the utility of phylogenetic mixture models. Systematic Biology, 55(1), 97-115.

Collins, A.G., Bentlage, B., Matsumoto, G.I., Haddock, S.H.D., Osborn, K. \& Schierwater, B. (2006b) Solution to the phylogenetic enigma of Tetraplatia, a worm-shaped cnidarian. Biology Letters, 2, 120-124.

Cornelius, P.F.S. (1982) Hydroids and medusae of the family Campanulariidae recorded from the eastern North Atlantic, with a world synopsis of the genera. Bulletin of the British Museum (Natural History). Zoology, 42(2), 37-148.

Cuif, J.-P., Lecointre, G., Perrin, C., Tillier, A. \& Tillier, S. (2003) Patterns of septal biomineralization in Scleractinia compared with their 28S rRNA phylogeny: a dual approach for a new taxonomic framework. Zoologica Scripta, 32, 459-473.

Cunningham, C.W. \& Buss, L.W. (1993) Molecular evidence for multiple episodes of paedomorphosis in the family Hydractiniidae. Biochemical Systematics and Ecology, 21(1), 57-69.

Daly, M. (2002) A systematic revision of Edwardsiidae (Cnidaria: Anthozoa). Invertebrate Biology, 121, $212-225$.

Daly, M., Fautin, D.G. \& Cappola, V.A. (2003) Systematics of the Hexacorallia (Cnidaria: Anthozoa). Zoological Journal of the Linnean Society, 139, 419-437.

Daly, M., Lipscomb, D.L. \& Allard, M.W. (2002) A simple test: evaluating explanations for the relative simplicity of the Edwardsiidae. Evolution, 56, 502-510.

Daly, M. \& den Hartog J.C. (2004) Taxonomy, circumscription, and usage in Anthopleura (Cnidaria: Anthozoa: Actiniaria) from the Gulf of Mexico and Caribbean. Bulletin of Marine Science, 74, 401-421.

Dana, J.D. (1846) Zoophytes. Volumen VII of the United States Exploring Expedition during the years 1838, 1839, 1840 , 1841, 1842, under the command of Charles Wilkes, U.S.N. Lea \& Blanchard, Philadelphia, 740 pp.

Daryanabard, R. \& Dawson, M.N. Jellyfish blooms: Crambionella orsini (Scyphozoa, Rhizostomeae) in the Gulf of Oman, Iran, 2002-2003. Journal of the Marine Biological Association of the United Kingdom, in press.

Dawson, M.N. (2003) Macro-morphological variation among cryptic species of the moon jellyfish, Aurelia (Cnidaria: Scyphozoa). Marine Biology 143, 369-379. Erratum: Marine Biology, 144, 203.

Dawson, M.N. (2004) Some implications of molecular phylogenetics for understanding biodiversity in jellyfishes, with emphasis on Scyphozoa. Hydrobiologia, 530/531, 249-260.

Dawson, M.N., Gupta, A.S. \& England, M.H. (2005) Coupled biophysical global ocean model and molecular genetic analyses identify multiple introductions of cryptogenic species. Proceedings of the National Academy of Sciences of the USA, 102, 11968-11973.

Doumenc, D.A. \& Van Praët, M. (1987) ORDRE des Actiniaires, ordre des Ptyochodactiares, ORDRE des Corallimorphares. In: Grassé, P.P. (Ed), Traite de Zoologie, Tome III, Fasicule 3, Cnidaries Anthozoaires. Masson, Paris, pp. 257-401.

Dunn, C.W., Pugh, P.R. \& Haddock, S.H.D. (2005) Molecular phylogenetics of Siphonophora (Cnidaria), with implications for the evolution of functional specialization. Systematic Biology, 54(6), 916-935.

Dunn, C.W. \& Wagner, G.P. (2006) The evolution of colony-level development in the Siphonophora (Cnidaria: Hydrozoa). Development, Genes, and Evolution, 216, 743-754.

Dunn, D.F. (1982) Cnidaria. In: Parker, S.P. (Ed), Synopsis and classification of living things. McGraw-Hill, New York, pp. 669-706.

Dunn, D.F. (1983) Some Antarctic and sub-Antarctic sea anemones (Coelenterata: Ptychodactiaria and Actiniaria). Antarctic Research Series, 39, 1-67.

Dunn, D.F. \& Bakus, G.J. (1977) Redescription and ecology of Liponema brevicornis (McMurrich, 1893), with definition of the family Liponematidae (Coelenterata, Actiniaria). Astarte, 10, 77-85. 
Dunn, D.G. \& Hamner, W.M. (1980) Amplexidiscus fenestrafer n. gen., n. sp. (Coelenterata: Anthozoa), a tropical IndoPacific Corallimorpharian. Micronesica, 16, 29-36.

Edwards, C. (1973) Contributory thoughts on form, function, habitat and classification of hydroids and hydromedusae. Publications of the Seto Marine Biological Laboratory, 20, 11-22.

Ehrenberg, C.G. 1834. Die Corallienthiere des rothen Meeres. Abhandlungen der Königlichen Akademie der Wissenschaften zu Berlin, 156 pp.

England, K.W. (1987) Certain Actiniaria (Cnidaria, Anthozoa) from the Red Sea and tropical Indo-Pacific Ocean. Bulletin of the British Museum (Natural History), 53(4), 205-292.

England, K.W. (1991) Nematocysts of sea anemones (Actiniaria, Ceriantharia, and Corallimorpharia: Cnidaria): nomenclature. Hydrobiologia, 216/217, 691-697.

Fabricius, K. \& Alderslade, P. (2001) Soft Corals and Sea Fans: a Comprehensive Guide to the Tropical Shallow-water Genera of the Central-West Pacific, the Indian Ocean and the Red Sea. Australian Institute of Marine Science, Townsville, $264 \mathrm{pp}$.

Fautin, D.G. (1984) More Antarctic and Subantarctic sea anemones (Coelenterata: Corallimorpharia and Actiniaria). Antarctic Research Series, 41, 1-42.

Fautin, D.G. (1988) The importance of nematocysts to actinian taxonomy. In: Hessinger, D.A. \& Lenhoff, H.M. (Eds), The Biology of Nematocysts. Academic Press, London, pp. 487-500.

Fautin, D.G. (2007) Hexacorallians of the World. Available from: http://geoportal.kgs.ku.edu/hexacoral/anemone2/ index.cfm (accessed November 1, 2007).Fautin, D.G. Nematocyst structural diversity, systematics, and evolution. Toxicon, submitted.

Fautin, D.G. \& Barber, B.R. (1999) Maractis rimicarivora, a new genus and species of sea anemone (Cnidaria: Anthozoa: Actiniaria: Actinostolidae) from an Atlantic hydrothermal vent. Proceedings of the Biological Society of Washington, 112, 624-31.

Fautin, D.G., Zelenchuk, T. \& Raveendran, D. (2007) Genera of orders Actiniaria and Corallimorpharia (Cnidaria, Anthozoa, Hexacorallia), and their type species. Zootaxa, 1668, 183-244.

Finnerty, J.R., Pang, K., Burton, P., Paulson, D. \& Martindale, M.Q. (2004) Origins of Bilateral Symmetry: Hox and Dpp Expression in a Sea Anemone. Science, 304, 1335-1337.

France, S.C., Rosel, P.E., Agenbroad, J.E., Mullineaux L.S. \& Kocher, T.D. (1996) DNA sequence variation of mitochondrial large-subunit rRNA provides support for a two-sublass organization of the Anthozoa (Cnidaria). Molecular Marine Biology and Biotechnology, 5, 15-28.

Fukami, H., Omori, M. \& Hatta, M. (2000) Phylogenetic relationships in the coral family Acroporidae, reassessed by inference from mitochondrial genes. Zoological Sciences, 17, 689-696.

Fukami, H., Budd, A.F., Paulay, G., Sole-Cava, A.M., Chen, C.A., Iwao, K. \& Knowlton, N. (2004) Conventional taxonomy obscures deep divergence between Pacific and Atlantic corals. Nature, 427, 832-835.

Gegenbaur, C. (1856) Versuch eines Systemes der Medusen, mit Beschreibung neuer oder wenig gekannter Formen; zugleich ein Beitrag zur Kenntnis der Fauna des Mittelmeeres. Zeitschrift für Wissenschaftliche Zoologie, Leipzig, 8, 202-273.

Gershwin, L. (2005a) Two new species of jellyfishes (Cnidaria: Cubozoa: Carybdeida) from tropical Western Australia, presumed to cause Irukandji Syndrome. Zootaxa, 1084, 1-30.

Gershwin, L. (2005b) Carybdea alata auct. and Manokia stiasnyi, reclassification to a new family with description of a new genus and two new species. Memoirs of the Queensland Museum, 51, 501-523.

Gershwin, L. (2006a) Comments on Chiropsalmus (Cnidaria: Cubozoa: Chirodropida): a preliminary revision of the Chiropsalmidae, with descriptions of two new genera and two new species. Zootaxa, 1231, 1-42.

Gershwin, L. (2006b) Nematocysts of the Cubozoa. Zootaxa, 1232, 1-57.

Gershwin, L. \& Alderslade, P. (2005) A new genus and species of box jellyfish (Cubozoa: Carybdeida) from tropical Australian waters. The Beagle, 21, 27-36.

Gershwin, L. \& Collins, A.G. (2002) A preliminary phylogeny of Pelagiidae (Cnidaria, Scyphozoa), with new observations of Chrysaora colorata comb. nov. Journal of Natural History, 36, 127-148.

Gili, J.M., Bouillon, J., Pagès, F., Palanques, A. \& Puig, P. (1999) Submarine canyons as habitats of prolific plankton populations: three new deep-sea Hydroidomedusae in western Mediterranean. Zoological Journal of the Linnean Society, 125, 313-329.

Govindarajan, A.F., Boero, F., Halanych, K.M. (2006) Phylogenetic analysis with multiple markers indicates repeated loss of the adult medusa stage in Campanulariidae (Hydrozoa, Cnidaria). Molecular Phylogenetics and Evolution, 38(3), 820-834.

Gosse, P.H. (1860) A History of the British Sea-Anemones and Corals. Van Voorst, Paternoster Row, London, 362 pp.

Grasshoff, M. (1999) The shallow-water gorgonians of New Caledonia and adjacent islands (Coelenterata, Octocorallia). Senckenbergiana biologica, 78, 1-121.

Grigg, R.W. \& Opresko, D. (1977) Order Antipatharia. In: Devaney, D.M. \& Eldredge, L.G. (Eds), Reef and Shore Fauna of Hawaii. Bishop Museum Press, Honolulu, pp. 242-261. 
Haeckel, E. (1866) Generelle morphologie der Organismen, vol. 2. Verlag von Georg Reimer, Berlin.

Haeckel, E. (1879) Das System der Medusen. Erster Theil einer Monographie der Medusen. Gustav Fischer, Jena, 81 pp. Haeckel, E. (1880) System der Acraspeden. Zweite Halfte des System der Medusen. Gustav Fischer, Jena, 361-672.

Hand, C. (1955) A study of the structure, affinities, and distribution of Tetraplatia volitans Busch (Coelenterata: Hydrozoa: Pteromedusae). Pacific Science, 9, 332-348.

den Hartog, J.C. (1977) Descriptions of two new Ceriantharia from the Caribbean region, Pachycerianthus curacaoensis n. sp. and Arachnanthus nocturnus n. sp., with a discussion of the cnidom and of the classification of the Ceriantharia. Zoologische Mededelingen, 51, 211-242.

den Hartog, J.C. (1980) Caribbean shallow water Corallimorpharia. Zoologische Verhandelingen, 176, 3-83.

den Hartog, J.C., Ocaña, O. \& Brito, A. (1993) Corallimorpharia collected during the CANCAP expeditions (1976-1986) in the south-eastern part of the North Atlantic. Zoologische Verhandelingen, 282, 3-76.

Hemmrich, G., Anokhin, B., Zacharias, H. \& Bosch, T.C.G. (2007) Molecular phylogenetics in Hydra, a classical model in evolutionary developmental biology. Molecular Phylogenetics and Evolution, 44, 281-290.

Hickson, S.J. (1906) Coelenterata: Anthozoa = Actinozoa - general characters - Alcyonaria. In: Harmer, S.F. \& Shipley, A.E. (Eds), The Cambridge Natural History, vol. 1, pp. 326-364.

Hickson, S.J. (1930) On the classification of the Alcyonaria. Proceedings of the Zoological Society of London, 1930, 229-252.

Hoeksema, B. (1989) Taxonomy, phylogeny and biogeography of mushroom corals (Scleractinia: Fungiidae). Zoologische Verhandelingen, 254, 1-295.

Holst, S., Sötje, I., Tiemann, H. \& Jarms, G. (2007) Life cycle of the rhizostome jellyfish Rhizostoma octopus (L.) (Scyphozoa, Rhizostomeae), with studies on cnidocysts and statoliths. Marine Biology, 151, 1695-1710.

Hyman, L.H. (1940) The Invertebrates: Protozoa through Ctenophora. McGraw-Hill Book Company, New York, 726 pp.

Imahara, Y. \& Ogawa, K. (2006) Rediscovery of Virgularia juncea (Octocorallia, Pennatulacea) from a tidal marsh in Okinawa, with a short note on its peculiar behavior. Proceedings of the $10^{\text {th }}$ International Coral Reef Symposium, 913.

Jarms, G., Morandini, A.C. \& da Silveira, F.L. (2002) Cultivation of polyps and medusae of Coronatae (Cnidaria, Scyphozoa) with a brief review of important characters. Helgoland Marine Research, 56, 203-210.

Kerr, A.M. (2005) Molecular and morphological supertree of stony corals (Anthozoa: Scleractinia) using matrix representation parsimony. Biological Reviews, 80, 1-16.

Kikinger, R. \& Salvini-Plawen, L.V. (1995) Development from polyp to stauromedusa in Stylocoronella (Cnidaria: Scyphozoa). Journal of the Marine Biological Association of the United Kingdom, 75, 899-912.

Kim, J.H., Kim, W. \& Cunningham, C.W. (1999) A new perspective on lower metazoan relationships from 18S rDNA sequences. Molecular Biology \& Evolution, 16, $423-427$.

Kirkpatrick, P.A. \& Pugh, P.R. (1984) Siphonophores and Velellids: Keys and notes for the identification of the species. In: Kermack, D.M., Barnes, R.S.K. (Eds), Synopses of the British Fauna: New Series. E.J. Brill, London, pp. 1-154.

Kramp, P.L. (1938) Die meduse von Ostroumovia inkermanica (Pal.-Ostr.) und die systematische Stellung der olindiiden. Zoologischer Anzeiger, 122, 103-108.

Kramp, P.L. (1961) Synopsis of the medusae of the world. Journal of the Marine Biological Association of the United Kingdom, 40, 1-469.

Kükenthal, W. (1925) Octocorallia. In: Krumbach, T. (Ed), Handbuch der Zoologie, pp. 690-769.

Lacaze-Duthiers, F.J.H.D. (1865) Deuxieme memoire sur les Antipathaires (Antipathes vrais). Annales des Sciences Naturelles, 4, 5-62.

Lapian, H.F.N., Barucca, M., Bavestrello, G., Biscotti, M.A., Bo, M., Canapa, A., Tazioli, S. \& Olmo, E. (2007) A systematic study of some black corals species (Antipatharia, Hexacorallia) based on rDNA internal transcribed spacers sequences. Marine Biology, 151, 785-792.

Larson, R.J. (1986) Pelagic Scyphomedusae (Scyphozoa: Coronatae and Semaeostomeae) of the Southern Ocean. Antarctic Research Series, 41, 59-165.

Larson, R.J. (1988) Kyopoda lamberti gen. nov., sp. nov., an atypical stauromedusa (Scyphozoa, Cnidaria) from the eastern Pacific, representing a new family. Canadian Journal of Zoology, 66, 2301-2303.

Larson, R.J. \& Fautin, D.G. (1989) Stauromedusae of the genus Manania (= Thaumatoscyphus) (Cnidaria, Scyphozoa) in the northeast Pacific, including descriptions of new species Manania gwilliami and Manania handi. Canadian Journal of Zoology, 67, 1543-1549.

Leclère, L., Schuchert, P. \& Manuel, M. (2007) Phylogeny of the Plumularioidea (Hydrozoa, Leptothecata): evolution of colonial organization and life cycle. Zoologica Scripta, 36(4), 371-394.

Le Goff-Vitry, M.C., Rogers, A.D. \& Baglow, D (2004) A deep-sea slant on the molecular phylogeny of the Scleractinia. Molecular Phylogenetics and Evolution, 30, 167-177.

Linnaeus, C. (1758) Systema naturae per regna tria naturae, secundum classes, ordines, genera, species, cum characteribus, differentiis, synonymis, locis. Tomus I. Editio decima, reformata. Holmiae, Laurentii Salvii, $824 \mathrm{pp}$. 
Madsen, F.J. (1944) Octocorallia (Stolonifera - Telestacea - Xeniidea - Alcyonacea - Gorgonacea). Danish IngolfExpedition, 13, 1-65.

Mariscal, R.N. (1974). Nematocysts. In: Muscatine, L. \& Lenhoff H.M. (Eds), Coelenterate biology: reviews and new perspectives. Academic Press, New York, pp. 129-178.

Mariscal R.N., Conklin, E.J.\& Bigger, C.H. (1977) The ptychocyst, a major new category of cnida used in tube construction by a cerianthid anemone. Biological Bulletin, 152, 392-405.

Marques, A.C. (1996) A critical analysis of a cladistic study of the genus Eudendrium (Cnidaria: Hydrozoa), with some comments on the family Eudendriidae. Journal of Computational Biology, 1, 153-162.

Marques, A.C. \& Migotto, A.E. (2001) Cladistic analysis and new classification of the family Tubulariidae (Hydrozoa, Anthomedusae). Papéis Avulsos de Zoologia, 41, 465-488.

Marques, A.C. \& Collins, A.G. (2004) Cladistic analysis of Medusozoa and cnidarian evolution. Invertebrate Biology, 123(1), 23-42.

Marques, A.C., Peña Cantero, A.L. \& Migotto, A.E. (2006) An overview of the phylogeny of the families Lafoeidae and Hebellidae (Hydrozoa: Leptothecata): their composition and classification. Invertebrate Systematics, 20, 43-58.

Matus, D.Q., Pang, K., Marlow, H., Dunn, C.W., Thomsen, G.H. \& Martindale, M.Q. (2006) Molecular evidence for deep evolutionary roots of bilaterality in animal development. Proceedings of the National Academy of Sciences of the United States of America, 103, 11195-11200.

Mayer, A.G. (1910) Medusae of the World, Hydromedusae, vols. I \& II. Scyphomedusae, vol. III. Carnegie Institution, Washington DC, 735 pp.

McFadden, C.S., France, S.C., Sánchez, J.A. \& Alderslade, P. (2006a) A molecular phylogenetic analysis of the Octocorallia (Cnidaria: Anthozoa) based on mitochondrial protein-coding sequences. Molecular Phylogenetics and Evolution, 41, 513-527.

McFadden, C.S., Alderslade, P., van Ofwegen, L.P., Johnsen, H. \& Rusmevichientong, A. (2006b) Phylogenetic relationships within the tropical soft coral genera Sarcophyton and Lobophytum (Anthozoa, Octocorallia). Invertebrate Biology, 125, 288-305.

Medina, M., Collins, A.G., Silberman, J.D. \& Sogin, M.L. (2001) Evaluating hypotheses of basal animal phylogeny using complete sequences of large and small subunit rRNA. Proceedings of the National Academy of Sciences of the United States of America, 98, 9707-9712.

Medina, M., Collins, A.G., Takaoka, T.L., Kuehl, J.V. \& Boore, J.L. (2006) Naked corals: skeleton loss in Scleractinia. Proceedings of the National Academy of Sciences of the United States of America, 103, 9096-9100.

Mianzan, H.W. \& Cornelius, P.F.S. (1999) Cubomedusae and Scyphomedusae. In: Boltovskoy, D. (Ed), South Atlantic Zooplankton. 1. Backhuys Press, Leiden, pp. 513-559.

Mills, C.E. (2000) The life cycle of Halimedusa typus, with discussion of other species closely related to the family Halimedusidae (Hydrozoa, Capitata, Anthomedusae). Scientia Marina, 64, 97-106.

Mills, C.E. (2007) Stauromedusae: list of all valid species names, last updated 30 October 2006. Available from: http:// faculty.washington.edu/cemills/Staurolist.html (October 1, 2007).

Milne Edwards, H. \& Haime, J. (1857) Histoire Naturelle des Coralliaires ou Polypes Proprement Dits, volumen 1. Librairie Encyclopédique de Roret, Paris, 326 pp.

Molodtstova, T.N. (2001a) Cerianthids (Anthozoa, Cnidaria) from Bengual upwelling region. 2. Cerianthus malakhovi and composition of the genus Cerianthus. Zoologicheskii Zhurnal, 80, 909-920.

Molodtsova, T.N. (2001b) On the taxonomic status of Cerianthus septentrionalis van Beneden, 1923 (Cnidaria: Anthozoa: Ceriantharia). Zoosystematica Rossica, 10, 9-10.

Molodtsova, T.N. (2003) On Isarachnanthus from central Atlantic and Caribbean region with notes on Isarachnactis lobiancoi (Carlgren, 1912). Zoologische Verhandelingen, 345, 249-255.

Montgomery, A.D. (2002) The feasibility of transplanting black coral (Order Antipatharia). Hydrobiologia, 471, 157164.

Moore, S.J. (1988) A new species of cubomedusan (Cubozoa: Cnidaria) from northern Australia. The Beagle, Records of the Northern Territory Museum of Arts and Sciences, 5, 1-4.

Moura, C.J., Cunha, M.R. \& Schuchert, P.S. (2007) Tubiclavoides striatum gen. nov. et sp. nov. (Cnidaria: Hydrozoa) a new bathyal hydroid from the Gulf of Cadiz, north-east Atlantic Ocean. Journal of the Marine Biological Association of the United Kingdom, 87, 421-428.

Naumov, D.V. (1960) Hydroids and Hydromedusae of the USSR (translated from Russian 1969). Israel Program for Scientific Translations, Jerusalem, $660 \mathrm{pp}$.

Odorico, D.M. \& Miller, D.J. (1997) Internal and external relationships of the Cnidaria: implications of primary and predicted secondary structure of the 5'-end of the 23S-like rDNA. Proceedings of the Royal Society of London, series B, 264, 77-82.

Ofwegen, L.P. van (1987) Melithaeidae (Coelenterata: Anthozoa) from the Indian Ocean and Malay Archipelago. Zoologische Verhandelingen, 239, 1-57.

de Oliveira Pires, D. (1987) Tricnidactis errans, n. gen., n. sp., (Cnidaria, Actiniaria, Haliplanellidae) from Guanabara 
Bay, Rio de Janeiro, Brazil. Anais da Academia Brasileira de Ciências (Rio de Janeiro), 59(3), 275.

Ogilvie, M.M. (1897) Korallen der Stramberger Schichten. Palaeontographica, (Supplement), 2, 73-282.

Opresko, D.M. (1972) Redescriptions and reevaluations of antipatharians described by L.D. de Pourtales. Bulletin of Marine Science, 22, 950-1017.

Opresko, D.M. (1998) Three new species of Leiopathes (Cnidaria: Anthozoa: Antipatharia) from Southern Australia. Records of the South Australian Museum, 31, 99-111.

Opresko, D.M. (2001) Revision of the Antipatharia (Cnidaria: Anthozoa). Part I. Establishment of a new family, Myriopathidae. Zoologische Mededelingen Leiden, 75, 343-370.

Opresko, D.M. (2002) Revision of the Antipatharia (Cnidaria: Anthozoa). Part II. Schizopathidae. Zoologische Mededelingen Leiden, 76, 411-442.

Opresko, D.M. (2003a) Revision of the Antipatharia (Cnidaria: Anthozoa). Part III. Cladopathidae. Zoologische Mededelingen Leiden, 77, 495-536.

Opresko, D.M. (2003b) A new species of Allopathes (Cnidaria: Antipatharia) from the eastern Atlantic. Zoologische Verhandelingen Leiden, 345, 275-280.

Opresko, D.M. (2004) Revision of the Antipatharia (Cnidaria: Anthozoa). Part IV. Establishment of a new family, Aphanipathidae. Zoologische Mededelingen Leiden, 78, 209-240.

Opresko, D.M. (2005) New genera and species of antipatharian corals (Cnidaria: Anthozoa) from the North Pacific. Zoologische Mededelingen Leiden, 79, 129-165.

Opresko, D.M. (2006) Revision of the Antipatharia (Cnidaria: Anthozoa). Part V. Establishment of a new family, Stylopathidae. Zoologische Mededelingen Leiden, 80/4, 109-138.

Opresko, D.M. \& Baron-Szabo, R.C. (2001) Re-descriptions of the antipatharian coral described by E.J.C. Esper with select English translations of the original German text. Senckenbergiana biologica, 81, 1-21.

Opresko, D.M. \& Bayer, F.M. (1991) Rediscovery of the enigmatic coelenterate Dendrobrachia, (Octocorallia: Gorgonacea) with descriptions of two new species. Transactions of the Royal Society of South Australia, 115, 1-19.

Opresko, D.M. \& Sanchez, J.A. (2005) Caribbean shallow-water black corals (Cnidaria: Anthozoa: Antipatharia). Caribbean Journal of Science, 41, 492-507.

Östman, C. (2000). A guideline to nematocyst nomenclature and classification, and some note on the systematic value of nematocysts. Scientia Marina, 64(1), 31-46.

Pearse, J.S. \& Pearse, V.B. (1978) Vision in cubomedusan jellyfishes. Science, 199, 458.

Petersen, K.W. (1979) Development of coloniality in Hydrozoa. In: Larwood, G. \& Rosen, B.R. (Eds), Biology and Systematics of Colonial Organisms. Academic Press, London, pp. 105-139.

Petersen, K.W. (1990) Evolution and taxonomy in capitate hydroids and medusae (Cnidaria: Hydrozoa). Zoological Journal of the Linnean Society, 100, 101-231.

Pugh, P.R. (1983) Benthic Siphonophores: A Review of the Family Rhodaliidae (Siphonophora, Physonectae). Philosophical Transactions of the Royal Society, Biological Sciences, 301(1105), 165-300.

Pugh, P.R. (1999) Siphonophorae. In: Boltovskoy, D. (Ed), South Atlantic Zooplankton. Backhuys Publishers, Leiden, pp. 467-511.

Pugh, P.R. (2003) A revision of the family Forskaliidae (Siphonophora, Physonectae). Journal of Natural History, $37(11), 1281-1327$.

Razak, T.B. \& Hoeksema, B.W. (2003) The hydrocoral genus Millepora (Hydrozoa: Capitata: Milleporidae) in Indonesia. Zoologische Verhandelingen Leiden, 345, 313-336.

Rees, W.J. (1958) The relationships of Moerisia lyonsi Boulenger and the family Moerisiidae, with capitate hydroids. Proceedings of the Zoological Society of London, 130, 537-545.

Rees, W.J. \& White, E. (1957) Two new records of Tetraplatia chuni Carlgren from the South Atlantic. Journal of the Faculty of Science, Hokkaido University, Series 6, Zoology, 13, 101-104.

Remane, A. (1927) Halamohydra, ein eigenartiges Hydrozoon der Nord- und Ostsee. Zeitschrft für Morphologie und Ökologie der Tiere, 7, 643-677.

Riemann-Zürneck, K. (1980) Actiniaria des Südwestatlantik. V. Bolocera, Isotealia, Isosicyonis (Actiniidae). Mitteilungen aus dem Hamburgischen Zoologischen Museum und Institut, 77, 19-33.

Riemann-Zürneck, K. (1991) The abyssal Sea Anemone Kadosactis sulcata Carlgren 1934, (Cnidaria: Actiniaria: Kadosactidae nov. fam.). Mitteilungen aus dem Hamburgischen Zoologischen Museum und Institut, 21(5/6), 191204.

Riemann-Zürneck, K. (1997a) A hemisessile anemone from the Porcupine Abyssal Plain, North Atlantic Ocean: Iosactis vagabunda gen. nov., sp. nov. Journal of the Marine Biological Association of the United Kingdom, 77, 1011-1025.

Riemann-Zürneck, K. (1997b) The deep-sea anemones Bathyphellia margaritacea and Daontesia porcupina sp. nov. with comments on the family Bathyphelliidae. Journal of the Marine Biological Association of the United Kingdom, 77, 361-374.

Riemann-Zürneck, K. (2000) Oractis bursifera sp. nov., an Arctic deep-sea anemone with peculiar invaginations of its oral disc (Cnidaria: Actiniaria). Polar Biology, 23, 604-608. 
Reimer, J.D., Ono, S., Takishita, K., Tsukahara, J. \& Maruyama, T. (2006) Molecular evidence suggesting species in the zoanthid genera Palythoa and Protopalythoa (Anthozoa: Hexacorallia) are congeneric. Zoological Science, 23, 8794.

Reimer, J.D., Hirano, S., Fujiwara, Y., Sinniger, F. \& Maruyama, T. (2007a) Morphological and molecular characterization of Abyssoanthus nankaiensis, a new family, new genus and new species of deep-sea zoanthid (Anthozoa: Hexacorallia: Zoantharia) from a northwest Pacific methane cold seep. Invertebrate Systematics, 21, 255-262.

Reimer, J.D., Takishita, K., Ono, S. \& Maruyama, T. (2007b) Diversity and evolution in the zoanthid genus Palythoa (Cnidaria: Hexacorallia) based on nuclear ITS-rDNA. Coral Reefs, 26, 399-410.

Rodríguez, E. \& López-González, P.J. (2003) Stephanthus antarcticus a new genus and species of sea anemone (Actiniaria, Haloclavidae) from the South Shetland Islands, Antarctica. Helgoland Marine Research, 57, 54-62.

Rodríguez, E, Castorani, C.N. \& Daly, M. Morphological phylogeny of family Actinostolidae (Anthozoa: Actiniaria) with a description of a new genus and species of hydrothermal vent sea anemone. Invertebrate Systematics, submitted.

Romano S.L. (1996) A molecular perspective on the evolution of scleractinian corals. In: Stanley GD, Jr. (Ed) Paleobiology and Biology of Corals. The Paleontological Society, Columbus, pp 39-57.

Romano, S.L. \& Cairns, S.D. (2000) Molecular phylogenetic hypotheses for the evolution of scleractinian corals. Bulletin of Marine Science, 67(3), 1043-1068.

Roniewicz, E. \& Morycowa, E. (1993) Evolution of the Scleractinia in the light of microstructural data. Courier Forschungsinstitut Senckenberg, 164, 233-240.

Russell, F.S. (1970) The Medusae of the British Isles. II, Pelagic Scyphozoa with a Supplement to the First Volume on Hydromedusae. Cambridge University Press, Cambridge.

Ryland, J.S. (1997) Reproduction in Zoanthidea. Invertebrate Reproduction and Development, 31, 177-188.

Ryland, J.S., de Putron, S., Scheltema, R. S., Chimonides, P. J. \& Zhadan, D.G. (2000) Semper's (zoanthid) larvae: pelagic life, parentage and other problems. Hydrobiologia 440, 191-198.

Ryland, J.S. \& Lancaster J.E. (2003) Revision of methods for separating species of Protopalythoa (Hexacorallia: Zoanthidea) in the tropical west Pacific. Invertebrate Systematics, 17, 407-428.

Salvini-Plawen L.v. (1978) On the origin and evolution of the lower Metazoa. Zeitschrift fur zoologische Cnidaria und evolutionsforschung, 16, 40-88.

Salvini-Plawen, L.v. (1987) Mesopsammic Cnidaria from Plymouth (with systematic notes). Journal of the Marine Biological Association of the United Kingdom, 67, 623-637.

Sanamyan, N.P. \& Sanamyan, K.E. (2007) Deep-water Actiniaria from East Pacific hydrothermal vents and cold seeps. Invertebrate Zoology, 4(1), 83-102.

Sánchez, J.A. (2005) Systematics of the bubblegum corals (Cnidaria: Octocorallia: Paragorgiidae) with description of new species from New Zealand and the Eastern Pacific. Zootaxa, 1014, 1-72.

Sánchez, J.A., Lasker, H.R. \& Taylor, D.J. (2003a) Phylogenetic analyses among octocorals (Cnidaria): mitochondrial and nuclear DNA sequences (lsu-rRNA, 16S and ssu-rRNA, 18S) support two convergent clades of branching gorgonians. Molecular Phylogenetics and Evolution, 29, 31-42.

Sánchez, J.A., McFadden, C.S., France, S.C. \& Lasker, H.R. (2003b) Molecular phylogenetic analyses of shallow-water Caribbean octocorals. Marine Biology, 142, 975-987.

Schmidt, H. (1972) Die Nesselkapseln der Anthozoen und ihre Bedeutung fur die phylogenetische Systematik. Helgoländer Wissenschaftliche Meeresuntersuchungen 23, 422-458.

Schmidt, H. (1974) On evolution in the Anthozoa. Proceedings of the Second International Coral Reef Symposium 1 , 533-560.

Schuchert, P. (1993) Phylogenetic analysis of the Cnidaria. Zeitschrift fuer Zoologische Systematik und Evolutionsforschung, 31, 161-173.

Schuchert, P. (1996) The Marine Fauna of New Zealand: Athecate Hydroids and their Medusae (Cnidaria: Hydrozoa). New Zealand Oceanographic Institute Memoir, 106, 5-159.

Schuchert, P. (1997) Review of the family Halopterididae (Hydrozoa, Cnidaria). Nationaal Natuurhistorisch Museum, Leiden, $162 \mathrm{pp}$.

Schuchert, P. (2001) Survey of the family Corynidae (Cnidaria, Hydrozoa). Revue Suisse de Zoologie, 108(4), 739-878.

Schuchert, P. (2004) Revision of the European athecate hydroids and their medusae (Hydrozoa, Cnidaria): Families of Oceanidae and Pachycordylidae. Revue Suisse de Zoologie, 111(2), 315- 369.

Schuchert, P. (2006) The European athecate hydroids and their medusae (Hydrozoa, Cnidaria): Capitata Part 1. Revue Suisse de Zoologie, 113(2), 325-410.

Schuchert, P. (2007a) The Hydrozoa Directory, Version 15. Available from: http://www.ville-ge.ch/musinfo/mhng/hydrozoa/hydrozoa-directory.htm. (accessed November 1, 2007).

Schuchert, P. (2007b) The European athecate hydroids and their medusae (Hydrozoa, Cnidaria): Filifera Part 2. Revue Suisse de Zoologie, 114(2), 195-396.

Sinniger, F., Montoya-Burgess, J.I., Chevaldonné, P. \& Pawlowski J. (2005) Phylogeny of the order Zoantharia (Antho- 
zoa, Hexacorallia) based on mitochondrial ribosomal genes. Marine Biology 147, 1121-1128.

Sinniger, F., P. Chevaldonné, P.\& Pawlowski, J. (2007). Mitochondrial genome of Savalia savaglia (Cnidaria, Hexacorallia) and early metazoan phylogeny.Journal of Molecular Evolution 64, 196-203.

Song, J.-I., Kim, W., Kim, E.K. \& Kim, J. (1994) Molecular Phylogeny of Anthozoans (Phylum Cnidaria) based on the Nucleotide sequences of 18S rRNA gene. Korean Journal of Zoology, 37, 343-351.

Song, J.-I. \& Won, J.H. (1997) Systematic relationships of the Anthozoan orders based on the partial nuclear 18S rDNA sequences. Korean Journal of Biological Science, 1, 43-52.

Stephenson, T.A. (1921) On the classification of Actiniaria. Part II. Consideration of the whole group and its relationships, with special reference to forms not treated in Part I. Quarterly Journal of Microscopical Science 65, 493-576.

Stephenson, T.A. (1922) On the classification of Actiniaria. Part III. Definitions connected with the forms dealt with in Part II. Quarterly Journal of Microscopical Science, 66, 247-319.

Stephenson, T.A. (1935) The British sea anemones. II. The Ray Society, London.

Stiasny, G. (1921) Studien über rhizostomeen. In: van Oort, E.D. (Ed), Capita Zoologica. Martinus Njhoff, Gravenhage.

Stolarski, J. (1996) Gardineria - a scleractinian living fossil. Acta Palaeontologica Polonica, 41, 339-367.

Stolarski, J. (2000) Origin and phylogeny of Guyniidae (Scleractinia) in the light of microstructural data. Lethia, 33, 1338.

Stolarski, J. \& Roniewicz, E. (2001) Towards a new synthesis of evolutionary relationships and classification of Scleractinia. Journal of Paleontology, 75, 1090-1108.

Swedmark, B. \& Teissier, G. (1958) Otohydra vagans n. g., n. sp., hydrozoaire des sables, apparanté aux Halammohydridées. Comptes rendus hebdomadaires des séances de l'Académie des sciences de Paris, 247, 238-240.

Swedmark, B. \& Teissier, G. (1959) Halammohydra et Otohydra, Hydrozoaires de la microfaune des sable et l'ordre des Actinulides. Proceedings of the XVth International Congress of Zoology, London 1958, 4(15), 330-332.

Swedmark, B. \& Teissier, G. (1966) The Actinulida and their evolutionary significance in the Cnidaria. In: Rees, W.J. (Ed), The Cnidaria and their Evolution. Academic Press, London, pp. 119-133.

Thiel, H. (1966) The evolution of the Scyphozoa, a review. In: Rees, W.J. (Ed), Cnidaria and their Evolution. Academic Press, London, pp. 77-117.

Thomson, J.A. (1910) Note on Dendrobrachia fallax, a rare and remarkable antipatharian. Journal of the Royal Microscopical Society, 1910, 142-143.

Tiffon, Y. (1987) Ordres des Cerianthaires. In: Grassé, P.-P. (Ed), Traite de Zoologie, Tome III, Fasicule 3. Cnidaries Anthozoaires. Masson, Paris, pp. 211-256.

Uchida, T. (1929) Studies on the Stauromedusae and Cubomedusae, with special reference to their metamorphosis. Japanese Journal of Zoology, 2, 103-193.

Van Beneden, E. (1897) Les Anthozoaires de la Plankton-Expedition. Ergebnisse der Plankton-Expedition der Humboldt-Stiftung, 2, 1-222.

Van Iten, H., De Moraes Leme, J., Simões, M.G., Marques, A.C. \& Collins, A.G. (2006) Reassessment of the phylogenetic position of conulariids (?Ediacaran-Triassic) within the subphylum Medusozoa (phylum Cnidaria). Journal of Systematic Paleontology, 4, 109-118.

Van Pesch, A.J. (1914) The Antipatharia of the Siboga Expedition. Siboga-Expeditie, 17, 1-258.

Vaughan, T.W. \& Wells, J.W. (1943) Revision of the suborders, families, and genera of the Scleractinia. Geological Society of America Special Papers, 44, 1-363.

Veron, J.E.N. (1986) Corals of Australia and the Indo-Pacific. Australian Institute of Marine Science and the University of Hawaii Press, Honolulu, 644 pp.

Veron, J.E.N. (1995) Corals in Space and Time: The Biogeography and Evolution of the Scleractinia. University of New South Wales Press, Sydney, $321 \mathrm{pp}$.

Veron, J.E.N. (2000) Corals of the World. Volumes 1-3. Australian Institute of Marine Science, Townsville.

Veron, J.E.N., Odorico, D.M., Chen, C.A. \& Miller, D.J. (1996) Reassessing relationships of scleractinian corals. Coral Reefs, 15, 1-9.

Wallace, C.C. (1999) Staghorn Corals of the World: A Revision of the Genus Acropora. CSIRO Publishing, Melbourne, Australia. $421 \mathrm{pp}$.

Watson, G.M. (1988) Ultrastructure and cytochemistry of developing nematocysts. In: Hessinger, D.A. \& Lenhoff, H.M. (Eds), The Biology of Nematocysts. Academic Press, San Diego, pp. 143-164.

Weill, R. (1934) Contribution à l'étude des cnidaires et de leurs nématocystes. 1. Recherches sur les nématocystes (Morphologie, Physiologie, Développement). 2. Valeur taxonomique du cnidome. Travaux de Station Zoologique Wimereux, 11, 1-701.

Wells, J.W. (1956) Scleractinia. In: Moore, R.C. (Ed) Treatise on Invertebrate Paleontology: Coelenterata. Geological Society of America and University of Kansas Press, Lawrence, pp. F328-F443.

Wells, J.W. \& Hill, D. (1956) Anthozoa-general features. In: Moore, R.C. (Ed), Treatise on Invertebrate Paleontology Part F: Coelenterata. Geological Society of America and University of Kansas Press, Lawrence, pp. F161-F166.

Werner, B. (1965) Halammohydra Remane, Medusennatur und Stellung im System. Zoologischer Anzeiger, suppl. 28, 
$163-177$.

Werner, B. (1973) New investigations on systematics and evolution of the class Scyphozoa and the phylum Cnidaria. Publications of the Seto Marine Biological Laboratory, 20, 35-61.

Williams, G.C. (1993) Biotic diversity, biogeography, and phylogeny of pennatulacean octocorals associated with coral reefs in the Indo-Pacific. Proceedings of the Seventh International Coral Reef Symposium, Guam, 1992, 2, $729-736$.

Williams, G.C. (1995) Living genera of sea pens (Coelenterata: Octocorallia: Pennatulacea): illustrated key and synopsis. Zoological Journal of the Linnean Society, 113, 93-140.

Williams, G.C. (1997) Preliminary assessment of the phylogeny of Pennatulacea (Anthozoa: Octocorallia), with a reevaluation of Ediacaran frond-like fossils, and a synopsis of the history of evolutionary thought regarding the sea pens. Proceedings of the Sixth International Conference on Coelenterate Biology, 1995, 495-509.

Williams, R.B. (1981) A sea anemone, Edwardsia meridionalis sp. nov., from Antarctica and a preliminary revision of the genus Edwardsia De Quatrefages, 1841 (Coelenterata: Actiniaria). Records of the Australian Museum (Sydney), 33(6), 325-360.

Williams, R.B., Cornelius, P.F.S. \& Clark, A. M. (1982) Proposed conservation of Actinia Linnaeus, 1767 and Actiniidae Goldfuss, 1820 (Coelenterata, Actiniaria) and Pentacta Goldfuss, 1820 (Echinodermata, Holothurioidea) Z.N. (S.) 825. Bulletin of Zoological Nomenclature, 39(4), 288-292.

Wirshing, H.H., Messing, C.G., Douady, C.J., Reed, J., Stanhope, M.J. \& Shivji, M.S. (2005) Molecular evidence for multiple lineages in the gorgonian family Plexauridae (Anthozoa: Octocorallia). Marine Biology, 147: 497-508.

Wirtz, P., Ocaña, O. \& Molodtsova, T.N. (2003) Actiniaria and Ceriantharia of the Azores (Cnidaria Anthozoa). Helgoland Marine Research, 57, 114-117.

Won, J., Rho, B. \& Song, J. (2001) A phylogenetic study of the Anthozoa (phylum Cnidaria) based on morphological and molecular characters. Coral Reefs, 20, 39-50. 